Pontifícia Universidade C $_{\text {atólica }}$

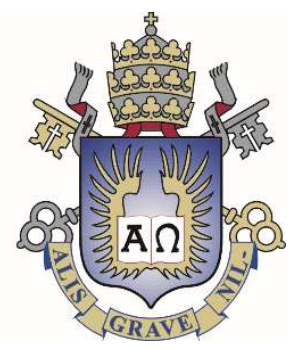

Camila Gomes Peçanha de Souza

\title{
Otimização da caracterização tridimensional de pelotas de minério de ferro
}

Dissertação de Mestrado

Dissertação apresentada como requisito parcial para obtenção do grau de Mestre pelo Programa de PósGraduação em Engenharia de Materiais e de Processos Químicos e Metalúrgicos da PUC- Rio.

Orientador: Prof. Sidnei Paciornik Coorientadora: Dra. Karen Soares Augusto 


\section{Pontifícia U Universidade Católica $_{\text {a }}$ DO RIO DE JANEIRO}

\section{Camila Gomes Peçanha de Souza}

\section{Otimização da caracterização tridimensional}

de pelotas de minério de ferro

Dissertação apresentada como requisito parcial para obtenção do grau de Mestre pelo Programa de Pósgraduação em Engenharia de Materiais e de Processos Químicos e Metalúrgicos da PUC-Rio. Aprovada pela Comissão Examinadora abaixo assinada.

Prof. Sidnei Paciornik Orientador

Departamento de Engenharia Química e de Materiais - PUC-Rio

Dra. Karen Soares Augusto Coorientador Departamento de Engenharia Química e de Materiais - PUC-Rio

Dr. Otávio da Fonseca Martins Gomes Centro de Tecnologia Mineral - CETEM

Dr. Marcos Henrique de Pinho Maurício Departamento de Engenharia Química e de Materiais - PUC-Rio

Prof. Marcio da Silveira Carvalho Coordenador Setorial de Pós-Graduação do Centro Técnico Científico PUC-Rio 
Todos os direitos reservados. É proibida a reprodução total ou parcial do trabalho sem autorização da universidade, do autor e do orientador.

\section{Camila Gomes Peçanha de Souza}

Formada em Engenharia Química pela Universidade Federal Rural do Rio de Janeiro em 2016. As áreas de atual interesse são Ciência dos Materiais, Microtomografia Computadorizada de Raios X, Processamento e Análise de Imagens.

Ficha Catalográfica

Souza, Camila Gomes Peçanha de.

Otimização da caracterização tridimensional de pelotas de minério de ferro / Camila Gomes Peçanha de Souza; orientador: Sidnei Paciornik; coorientadora: Karen Soares Augusto - 2018. v., 93 f: il. color. ; $30 \mathrm{~cm}$

Dissertação (mestrado) - Pontifícia Universidade Católica do Rio de Janeiro, Rio de Janeiro, Departamento de Engenharia Química e de Materiais, 2018. Inclui bibliografia

1. Engenharia de materiais - Teses. 2. Pelotização. 3. Caracterização Tridimensional. 4. Microtomografia computadorizada de raios X. 5. Análise de Imagens. I. Paciornik, Sidnei. II. Augusto, Karen Soares. III. Pontifícia Universidade Católica do Rio de Janeiro. Departamento de Engenharia Química e de Materiais. IV. Título. 


\section{Agradecimentos}

Primeiramente quero agradecer a Deus por simplesmente permitir que eu concluísse o mestrado e por me dar forças para superar todas as dificuldades que encontrei na vida.

Aos meus pais, Denise e Nilton, e meu irmão Nilton Jr. por sempre acreditarem no meu potencial, por darem todo o suporte necessário e por estarem a todo instante me incentivando a ser uma pessoa cada dia melhor.

Ao meu namorado Nícolas Magioli por todo apoio e incentivo, por estar ao meu lado em todos os momentos, inclusive os mais difíceis, me oferecendo muito carinho e amor.

Ao restante da família, que mesmo não estando presente fisicamente, esteve sempre me desejando o melhor e me transmitindo muita energia positiva.

À PUC-Rio, universidade a qual me acolheu neste desafio de me tornar mestre em Engenharia de Materiais e Processos Químicos, inclusive com isenção de mensalidades da Pós-Graduação.

Ao meu orientador Prof. Dr. Sidnei Paciornik por todo suporte na solução dos problemas encontrados ao longo do desenvolvimento deste trabalho, pelo apoio incondicional em todos os momentos e pela preocupação com todos os seus alunos de maneira totalmente carinhosa e prestativa.

À minha coorientadora Dr ${ }^{\mathrm{a}}$ Karen Soares Augusto, que me acolheu desde o primeiro instante e não me deixou desistir, mesmo nos dias mais desesperadores me guiou com muita maestria.

Ao Grupo de Pesquisa em Microscopia Digital e Análise de Imagens, sendo literalmente uma família.

Ao Marcos Henrique de Pinho Mauricio, que esteve sempre solícito quanto aos processos tomográficos, me auxiliando de maneira brilhante. 
Aos amigos que fiz na PUC-Rio. Aos amigos de longa data, em especial: Bruna Bronsato, Gabriela Paiva, Caio César, Rafael Alves, Mariana Trindade e Adonis Batista.

À Vale pela disponibilização de amostras para a realização das análises necessárias, pelo interesse na pesquisa e apoio financeiro.

O presente trabalho foi realizado com apoio da Coordenação de Aperfeiçoamento de Pessoal de Nível Superior - Brasil (CAPES) - Código de Financiamento 001. 


\section{Resumo}

Souza, Camila Gomes Peçanha de; Paciornik, Sidnei; Augusto, Karen Soares. Otimização da caracterização tridimensional de pelotas de minério de ferro. Rio de Janeiro, 2018. 93p. Dissertação de Mestrado - Departamento de Engenharia Química e de Materiais, Pontifícia Universidade Católica do Rio de Janeiro.

A porosidade e o arranjo espacial dos poros são essenciais para a transferência de calor e para o processo de redução das pelotas de minério de ferro em fornos siderúrgicos. Portanto, a caracterização microestrutural das pelotas torna-se importante para o controle de qualidade do produto final, o aço, auxiliando no entendimento de seu comportamento nos altos-fornos. Atualmente, as técnicas mais utilizadas para a caracterização são a microscopia ótica, que oferece resultados somente bidimensionais e com isso não representa exatamente a realidade; e a Porosimetria por intrusão de mercúrio, na qual utiliza-se mercúrio, que é altamente nocivo à saúde humana, e avalia apenas poros conectados com a superfície. Além disso, são técnicas consideradas destrutivas, ou seja, não é possível fazer outras análises porque há a perda do material. Este trabalho propõe otimizar uma metodologia de caracterização tridimensional de porosidade em pelotas a partir da técnica de Microtomografia Computadorizada de Raios X (microCT) - que é uma técnica não destrutiva e fornece informações tridimensionais, porém apresenta limitações relacionadas ao tempo de análise e resolução - e análise e processamento das imagens geradas. Foi possível caracterizar em 3D a porosidade de amostras cedidas pela empresa Vale, a partir da distribuição espacial e obtenção do volume dos poros, além da discriminação de poros abertos e fechados por uma nova metodologia desenvolvida. Assim, a metodologia de aquisição foi otimizada, alcançando-se uma redução de tempo para todas as análises - foram necessárias 3 horas para a análise de uma pelota inteira. Confirmou-se que a resolução de fato causa grande impacto na caracterização de porosidade em pelotas de minério de ferro, evidenciado na grande diferença entre os percentuais de porosidades medidos nas diferentes resoluções alcançadas: $14,83 \%$ para $7,6 \mu \mathrm{m}, 23,69 \%$ para $4 \mu \mathrm{m}$ e $26,75 \%$ para $2 \mu \mathrm{m}$.

\section{Palavras-chave}

Processamento Digital de Imagens; Pelotas de minério de ferro; Caracterização tridimensional; Microtomografia de Raios X. 


\section{Abstract}

Souza, Camila Gomes Peçanha de; Paciornik, Sidnei (Advisor); Augusto, Karen Soares (Co-advisor). Optimization of the three-dimensional characterization of iron ore pellets. Rio de Janeiro, 2018. 93p. Dissertação de Mestrado - Departamento de Engenharia Química e de Materiais, Pontifícia Universidade Católica do Rio de Janeiro.

Porosity and pore space arrangement are essential for heat transfer and the reduction process of iron ore pellets in steelworks. Therefore, the pellet microstructural characterization becomes important for the quality control of the final product, steel, helping in the understanding of its behavior in the blast furnaces. Currently, the most used techniques for characterization are optical microscopy, which offers only two-dimensional results and thus does not represent exactly the reality; and mercury intrusion porosimetry that evaluates only pores connected to the surface, and uses mercury, which is highly harmful to human health. Moreover, they are techniques considered destructive as it is not possible to do other analyzes in the same samples, since they are destroyed. This work proposes to optimize a methodology of three-dimensional characterization of porosity in pellets using the technique of x-ray microtomography (microCT). This is a non destructive technique that provides 3D information, but presents limitations related to the time of analysis and resolution. It was possible to characterize in $3 \mathrm{D}$ pellet samples provided by the Vale company, obtaining the porosity and the pore volume distribution. Open and closed porosity was also measured by a new developed methodology. Thus, the acquisition methodology was optimized, reaching a reduction of time for all the analyzes - it took 3 hours for the analysis of an entire ball. It was confirmed that the resolution had a great impact on the porosity characterization of iron ore pellets, evidenced by the great difference between the porosities measured at the different resolutions reached: $14.83 \%$ for $7.6 \mu \mathrm{m}$, $23.69 \%$ for $4 \mu \mathrm{m}$ and $26.75 \%$ for $2 \mu \mathrm{m}$.

\section{Keywords}

Digital imaging processing; iron ore pellets; three-dimensional characterization; X-ray microtomography. 


\section{Sumário}

1 Introdução 17

2 Objetivos 22

3 Revisão Bibliográfica 23

3.1. Pelotas de Minério de Ferro 23

3.1.1. Pelotização 23

3.1.2. Medidas de Porosidade 26

3.2. Microtomografia Computadorizada de Raios X Aplicada à Área Mineral 30

4 Materiais e Métodos $\quad 40$

4.1. Amostras 40

4.2. Processo de microCT 43

4.3. Processamento Digital de Imagens 3D 49

4.3.1. Visualização 51

4.3.2. Filtragem de Ruído 52

4.3.3. Segmentação de Poros $\quad 54$

4.3.4. Separação de Porosidade Aberta e Fechada 57

4.3.4.1. Operação Morfológica Close ou Fechamento 57

4.3.4.2. Mapa de Distâncias Euclidianas (MDE) 58

$\begin{array}{ll}\text { 4.3.5. Medidas } & 61\end{array}$

4.4. Sequência de Processamento e Análise de Imagens 64

5 Resultados e Discussão 66

5.1. Influência da Resolução 66

5.1.1. Comparação Visual 66

5.1.2. Medidas Comparativas $\quad 72$

5.2. Estudo da Porosidade em Diferentes Regiões de Análise 74

5.3. Porosidade Aberta e Fechada 83

6 Conclusões e Trabalhos Futuros $\quad 88$ 
7 Referências bibliográficas 


\section{Lista de figuras}

Figura 1 - Tipos de minério de ferro de acordo com sua granulometria. (CSN, 2016)

Figura 2 - Pelotas de minério de ferro ("VALE").

Figura 4 - Influência da adição de água na formação das pelotas cruas (MEYER, 1980).

Figura 5 - Ilustração esquemática de uma seção em duas dimensões de um sólido poroso e as respectivas classificações dos diferentes tipos de poros: (a) e (b) poros fechados; (c) poro aberto e poro cego; (d) e (e) poros abertos interconectados; (f) rugosidade da superfície (SANTOS et al., 2016).

Figura 6 - Alguns métodos utilizados para determinar porosidade e distribuição do tamanho dos poros. Adaptado de (KLOBES; MEYER; MUNRO, 2016) e (ANOVITZ; COLE, 2015).

Figura 7 - (a) Esquema ilustrativo de microCT, sendo DFD: Distância Fonte - Detector e DFO: Distância Fonte - Objeto (MURPHY; SCHADE; ZWIREN, 2014); (b) Projeções da amostra (ALEKSANDROV et al., 2017).

Figura 8 - Esquema ilustrativo da geometria do sistema de projeção cônica do feixe de raios $X$, onde Dss é a distância fonte-amostra e Dds, distância amostra-detector (ULIANA et al., 2014).

Figura 9 - Projeção cônica com magnificação ótica pelo uso de lente (VERSA, [s.d.]).

Figura 10 - Retroprojeção direta (linha superior) e filtrada (linha inferior). Adaptado de (VAN AARLE et al., 2016)

Figura 11 - Representação de um pixel e de um voxel, (a) no sistema fonte-amostra-detector (INC., 2018), (b) na camada amostral (MANTOVANI, 2013).

Figura 12 - (a) Seção transversal; imagens em (b) densidade, (c) número atômico e (d) mineralogia; histograma de (e) densidade e (f) número atômico; (g) imagem 3D de mineralogia da amostra (ALVES, 2015).

Figura 14 - Pelotas P1-A e P1-B, respectivamente.

Figura 15 - Cortador de precisão Struers Minitom.

Figura 16 - Pelota seccionada: (a) meia pelota; (b) um quarto da pelota; 
(c) um oitavo da pelota (gomo).

Figura 17 - Visão interna do microCT Zeiss Xradia Versa 510: Fonte de raios X (esquerda), detector e conjunto de lentes (direita) e amostra de pelota de minério de ferro (centro);

Figura 18 - Visão Externa do microCT Zeiss Xradia Versa 510.

Figura 19 - a), b), c) e d): Quatro projeções adquiridas em mosaico; e) Representação em 3D; f) Visualização de uma camada em 2D. 48

Figura 20 - Interface gráfica do Dragonfly.

Figura 21 - a) Pelota em 3D; b) Plano xz; c) Plano xy; d) Plano yz. 52

Figura 22 - (a) Imagem original ruidosa; (b) Imagem após aplicação do filtro Non-Local Means.

Figura 23 - (a) Segmentação com limiar =115; (b) Segmentação com limiar $=135$.

Figura 24 - Imagem binária, segmentação da fase sólida com tom de corte de 135.

Figura 25 - Volume de poros da pelota inteira.

Figura 26 - Efeito do fechamento em uma imagem binária (RIVEST;

SOILLE; BEUCHER, 1992).

Figura 27 - ROI do sólido preenchido.

Figura 28 - Inversão da ROI do sólido preenchido. 59

Figura 29 - Mapa de Distâncias Euclidianas (MDE). 60

Figura 30 - Gráfico de mínimas intensidades.

Figura 31 - Diferença do comportamento dos poros abertos em: a) sem uso do close (vermelho); b) com uso do close com kernel de 13 voxels (azul).

Figura 32 - Ampliação de uma das regiões com diferença do comportamento dos poros abertos em: a) sem uso do close (vermelho); b) com uso do close (azul).

Figura 33 - Subtração entre as ROIs A e B para obtenção da ROI referente aos poros.

Figura 34 - ROI referente aos Poros. 64

Figura 35 - Fluxograma do processamento das imagens. 65

Figura 36 - Aquisição em lente de 0,4X da Pelota P1-A, com resolução 
de $7,6 \mu \mathrm{m}$ : a) Fatia 2D; b) Volume 3D.

Figura 37 - Aquisição em lente de 4X da Pelota P1-A, com resolução de $4 \mu \mathrm{m}$ : a) Fatia 2D; b) Volume 3D.

Figura 38 - Aquisição em lente de 4X da Pelota P1-A, com resolução de $2 \mu \mathrm{m}$ : a) Fatia 2D; b) Volume 3D.

Figura 39 - Aquisição em lente de 4X da Pelota P1-A, com resolução de $1 \mu \mathrm{m}$ : a) Fatia 2D; b) Volume 3D.

Figura 40 - Aquisição em lente de $0,4 \mathrm{X}$ do gomo da Pelota P1-A, com resolução de 4 um: a) Fatia 2D; b) Volume 3D.

Figura 41 - Volume de poros dos limiares de segmentação para as resoluções de 2; 4 e 7,6 $\mu \mathrm{m}$.

Figura 42 - Gomo: (a) Segmentação com limiar =125; (b) Segmentação com limiar $=135$.

Figura 43 - Histogramas: a) gomo com $4 \mu \mathrm{m}$ de resolução; b) cilindro com $2 \mu \mathrm{m}$ de resolução; c) cilindro com $4 \mu \mathrm{m}$ de resolução e d) pelota inteira com $7,5 \mu \mathrm{m}$.

Figura 44 - Volume em 3D do cilindro com $4 \mu \mathrm{m}$ (rosa) de resolução em relação à pelota inteira com resolução de 7,6 $\mu \mathrm{m}$ (azul).

Figura 45 - Cilindro com $4 \mu \mathrm{m}$ de resolução em relação à pelota inteira com resolução de 7,6 um: a) Fatia 2D plano XZ; b) Fatia plano XY.

Figura 46 - Sólido de interseção entre a pelota inteira e o cilindro:

a) Fatia 2D; b) Volume 3D.

Figura 47 - Poros do cilindro equivalente resultante: a) Fatia 2D;

b) Volume 3D.

Figura 48 - Porosidade em diferentes regiões: verde, roxa e amarela. 81

Figura 49 - Porosidade em diferentes regiões: laranja, azul e vermelha.

Figura 50 - Visualização em 2D da variação da porosidade ao longo das regiões no cilindro.

Figura 51 - Porosidade aberta e fechada da pelota inteira, poros abertos em verde e poros fechados em rosa.

Figura 52 - Poros fechados da pelota inteira.

Figura 53 - Poros abertos da pelota inteira.

Figura 54 - Seção em 2D com a segmentação da fase sólida. 
Figura 55 - Seção em 2D após a aplicação do ROI Shrink-wrap. 


\section{Lista de tabelas}

Tabela 1 - Consumo, em milhões de toneladas, de minério de ferro em alguns países. Adaptado de (CARVALHO et al, [s.d.]).

Tabela 2 - Composição química da pelotas do tipo P1

(AUGUSTO et al., 2016).

40

Tabela 3 - Condições de aquisição em microCT

Tabela 4 - Configuração geométrica de cada análise

Tabela 5 - Comparação da porosidade com diferentes volumes e resoluções

80

Tabela 6 - Porosidade em diferentes regiões da pelota 


\section{Lista de Abreviaturas e Siglas}

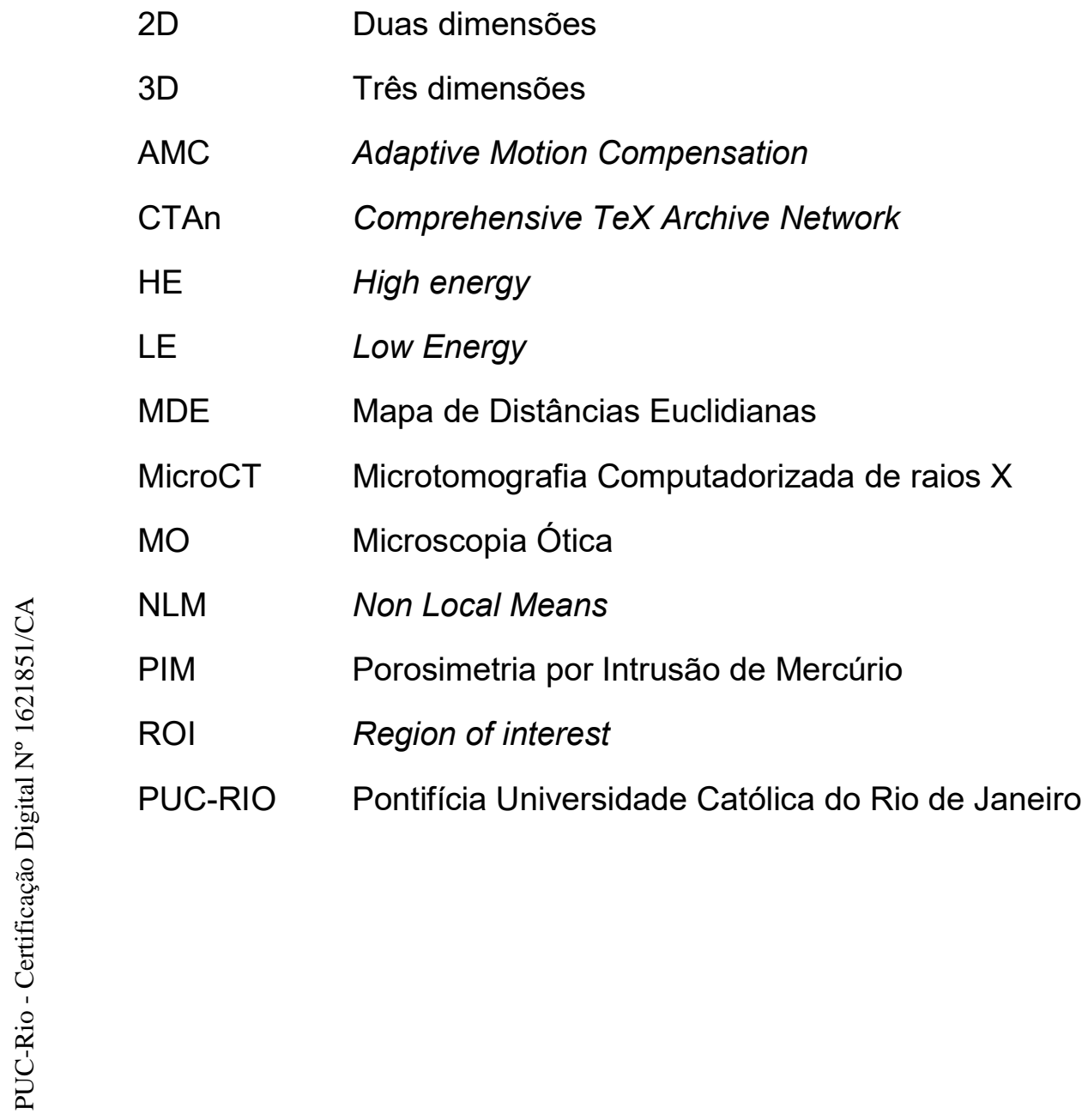




\section{Lista de Símbolos}

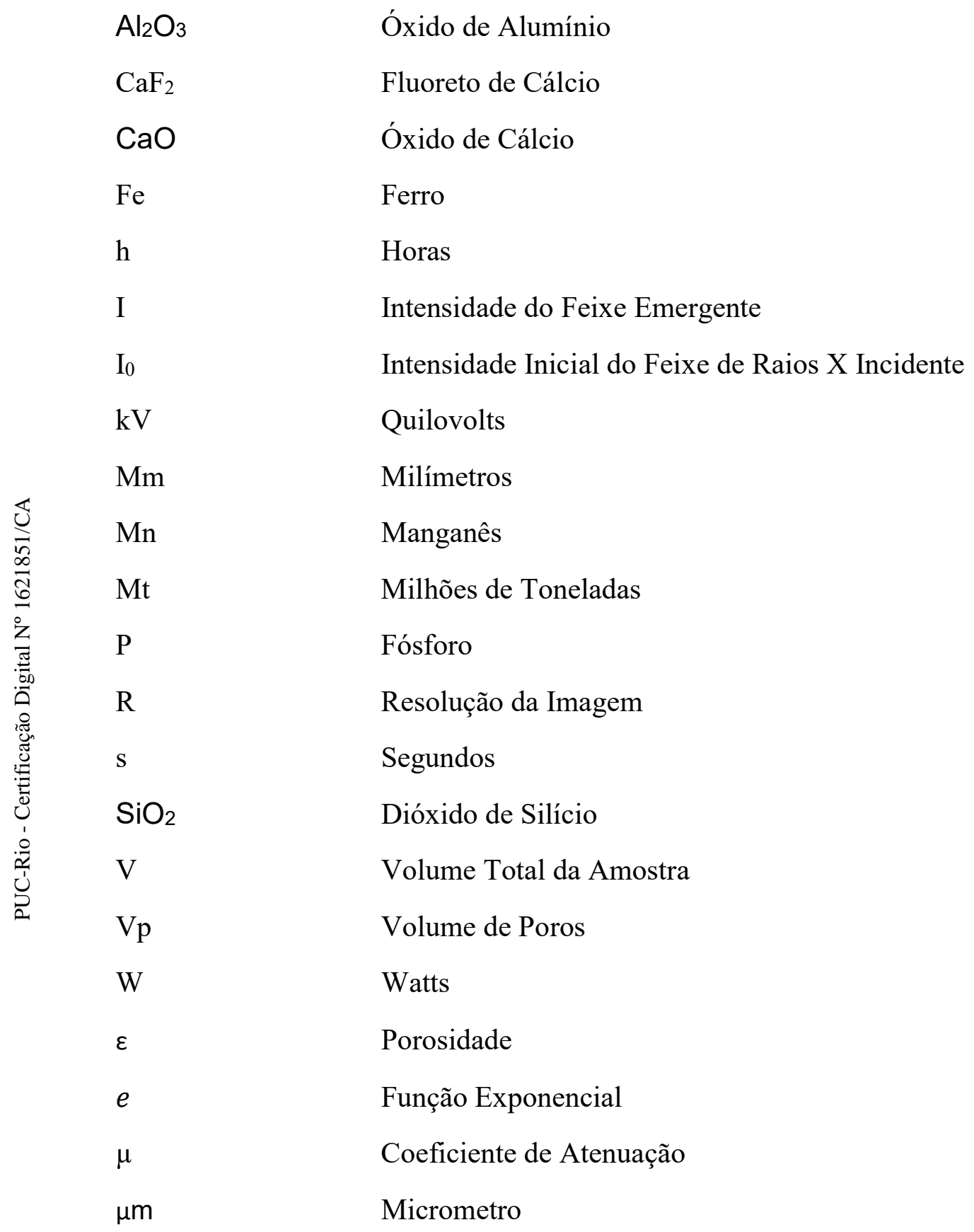




\section{1 \\ Introdução}

Nos processos de mineração de minério de ferro, os finos são gerados ao final das etapas de extração e beneficiamento eram considerados resíduos do processo porque não é possível utilizá-los diretamente nos fornos siderúrgicos de produção de ferro primário. A crescente preocupação com a conservação ambiental é um dos incentivos para o estudo do aproveitamento desses resíduos, seja pelo emprego de novas tecnologias de beneficiamento ou pela utilização dos próprios rejeitos para outras aplicações. Além disso, a exaustão das reservas de alto teor de ferro também influencia o crescimento dos processos de aglomeração dos finos como a pelotização, visto que a oferta de minério granulado com alto teor de ferro e baixa concentração de sílica diminui com os anos de exploração das minas. Deste modo, a utilização desses processos de aglomeração tem como objetivo alcançar a granulometria necessária para que posteriormente seja possível a utilização dos aglomerados como percursor em outros processos, como por exemplo na siderurgia.

Os processos de sinterização e pelotização consistem em um tratamento térmico da parcela fina do minério chamados de sinter feed ${ }^{l}$ e pellet feed ${ }^{2}$ (figura 1), em altas temperaturas $\left(1300^{\circ} \mathrm{C}-1350^{\circ} \mathrm{C}\right)$ (MILANEZ; SANTOS, 2016) para que o material alcance as propriedades físicas e mecânicas apropriadas, formando um sólido poroso e resistente. A pelota, que é o foco deste trabalho, possui adequação físico-química para carga em altos fornos. Com isso, a alimentação de minério de ferro em altos-fornos é constituída, geralmente, por: granulado, sínter e pelotas.

\footnotetext{
${ }^{1}$ Finos de minério de ferro concentrados com granulometria entre $0,15 \mathrm{~mm}$ e $6.3 \mathrm{~mm}$. ${ }^{2}$ Finos de minério de ferro concentrados com granulometria abaixo de $0,15 \mathrm{~mm}$.
} 

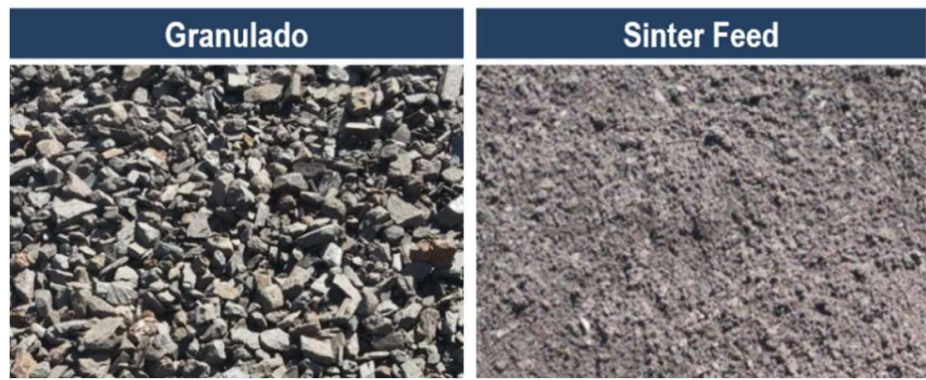

Pellet Feed

Figura 1 - Tipos de minério de ferro de acordo com sua granulometria. (CSN, 2016)

A pelotização ganhou força mundial devido a sua eficácia no aproveitamento dos finos residuais, que possuem alta concentração de ferro, e que anteriormente eram descartados pois não tinham valor econômico para as mineradoras. O processo possui vantagens de localização em relação à aglomeração por sinterização, uma vez que usinas pelotizadoras tendem a se localizar próximas a portos, fazendo uso de combinações ou blends de minério e concentrado de diferentes minas (COSTA, 2008). A introdução das pelotas implica o aumento da produtividade e em um melhor aproveitamento dos granulados de minério de ferro. Milhões de toneladas de pelotas são produzidas anualmente e o crescimento da produção e consumo de pelotas tem-se acelerado nos últimos tempos, especialmente na China como pode ser visualizado na tabela 1 .

A publicação anual de 2018 da U.S. Geological Survey mostrou que o Brasil é um dos maiores exportadores mundiais de minério de ferro (U.S. GEOLOGICAL SURVEY, 2018). A empresa Vale é uma das maiores mineradoras do mundo e líder em produção mundial de minério de ferro e pelotas de minério de ferro. Segundo seu relatório anual do primeiro trimestre de 2018, atingiu-se um volume recorde de vendas de pelotas e a produção totalizou $12,8 \mathrm{Mt}$, alcançando assim o primeiro melhor trimestre da história da empresa. Deste modo, a Vale tem o objetivo de investir em pesquisa e desenvolvimento para a melhoria do processo de produção e da qualidade dos seus produtos, incluindo as pelotas, que inclusive foram cedidas para o estudo quantitativo e qualitativo do presente trabalho. 
Tabela 1 - Consumo, em milhões de toneladas, de minério de ferro em alguns países. Adaptado de (CARVALHO et al, 2018).

\begin{tabular}{|c|c|c|c|c|c|c|c|c|c|}
\hline Pais/regiào & Tipo & 2010 & 2011 & 2012 & 2013 & $2014^{\circ}$ & $2015^{\circ}$ & $2016^{\circ}$ & $2017^{\circ}$ \\
\hline \multirow[t]{4}{*}{ China } & Min. ferro & 906,27 & 965,38 & 993,08 & $1.038,40$ & $1.089,64$ & $1.128,99$ & $1.162,40$ & $1.194,09$ \\
\hline & Finos & 654,81 & 691,41 & 703,39 & 737,22 & 773,63 & 802,71 & 827,61 & 851,34 \\
\hline & Pelotas & 157,52 & 170,91 & 180,49 & 193,19 & 206,41 & 216,43 & 224,73 & 232,81 \\
\hline & Granulado & 93,95 & 103,06 & 109,20 & 107,99 & 109,59 & 109,85 & 110,06 & 109,94 \\
\hline \multirow[t]{4}{*}{ Japão } & Min. ferro & 125,38 & 123,25 & 123,60 & 120,51 & 121,48 & 126,13 & 134,15 & 136,38 \\
\hline & Finos & 86,87 & 84,12 & 84,30 & 81,50 & 82,17 & 84,11 & 86,72 & 88,47 \\
\hline & Pelotas & 8,00 & 8,43 & 11,40 & 11,94 & 12,03 & 12,46 & 12,89 & 13,13 \\
\hline & Granulado & 30,51 & 30,70 & 27,90 & 27,07 & 27,28 & 29,56 & 34,54 & 34,78 \\
\hline \multirow{5}{*}{$\begin{array}{l}\text { Coreia do } \\
\text { Sul }\end{array}$} & Min. ferro & 51,99 & 62,57 & 61,75 & 68,05 & 71,02 & 73,66 & 74,44 & 74,98 \\
\hline & & & & & & & & & \\
\hline & Finos & 39,52 & 47,70 & 44,12 & 49,58 & 51,75 & 53,67 & 54,23 & 54,58 \\
\hline & Pelotas & 2,68 & 3,56 & 6,44 & 6,11 & 6,38 & 6,62 & 6,69 & 6,77 \\
\hline & Granulado & 9,80 & 11,31 & 11,18 & 12,36 & 12,90 & 13,38 & 13,52 & 13,64 \\
\hline \multirow[t]{4}{*}{ Brasil } & Min. ferro & 44,83 & 48,25 & 39,22 & 51,33 & 53,61 & 55,89 & 57,82 & 59,13 \\
\hline & Finos & 25,27 & 27,20 & 22,08 & 28,91 & 30,23 & 31,54 & 32,72 & 33,46 \\
\hline & Pelotas & 8,67 & 9,35 & 6,76 & 8,91 & 9,33 & 9,82 & 10,02 & 10,25 \\
\hline & Granulado & 10,89 & 11,70 & 10,38 & 13,51 & 14,05 & 14,53 & 15,08 & 15,42 \\
\hline
\end{tabular}

Para ser utilizada, a pelota precisa ser porosa para aumentar a transferência de calor além de permitir a permeabilidade dos gases, com isso auxiliar no processo de redução e elevando a eficiência do processo. Porém, a pelota também precisa ter resistência física a fim de suportar etapas de manuseio e transporte. Desta forma, a caracterização microestrutural das pelotas de minério de ferro contribui para a compreensão dos fenômenos de aglomeração, de suas propriedades e de seu comportamento nos processos de redução nos altos-fornos. $\mathrm{O}$ equilíbrio entre boa redutibilidade do material e boa resistência mecânica faz a caracterização da porosidade e estrutura da pelota ser uma etapa essencial para o controle de qualidade do produto final.

As técnicas clássicas de caracterização de porosidade são destrutivas e não conseguem obter informações tridimensionais da amostra. Atualmente usa-se 
amplamente duas principais análises: a microscopia ótica (MO) e a porosimetria por intrusão de mercúrio (PIM).

A PIM permite identificar e avaliar poros que estão conectados a superfície, mas perde-se informações sobre os poros não-conectados. Além disso, o mercúrio é extremamente tóxico oferecendo riscos ao meio ambiente e à saúde humana. $\mathrm{O}$ microscópio ótico de luz refletida vem sendo utilizado há muitos anos na caracterização de minérios, porém é uma análise limitada ao espaço bidimensional e, como a pelota apresenta heterogeneidade em sua porosidade e propriedades, uma técnica que não consegue identificar informações no espaço tridimensional não é suficiente.

Dessa forma, a caracterização de porosidade via Microtomografia computadorizada de raios X (microCT) vem ganhando espaço com diversos trabalhos sendo realizados, dentre eles: (MANTOVANI, 2013), (ZANDOMENEGHI et al., 2010), (PALOMBO et al., 2015), (AUGUSTO; PACIORNIK, 2018). A microCT é uma técnica bem estabelecida que fornece informações verdadeiramente em 3D, permitindo avaliar a estrutura interna e externa de materiais sólidos, sendo possível caracterizar os poros em microescala. Augusto (AUGUSTO et al., 2016) em sua tese de doutorado, desenvolveu uma metodologia de caracterização de porosidade de pelotas de minério de ferro, mas que ainda necessita ser otimizada para que seja possível utilizá-la no setor industrial.

Por conseguinte, a presente dissertação está segmentada em sete capítulos. O primeiro é este capítulo introdutório o qual inicia o leitor ao tema estudado. O segundo capítulo, intitulado de Objetivos, demonstra o que se deseja alcançar com o trabalho proposto. O terceiro capítulo é a Revisão Bibliográfica, nele é apresentado um breve resumo dos conceitos os quais a dissertação está fundamentada, apresenta também alguns trabalhos encontrados na literatura com temas relacionados ao abordado. O capítulo quatro, Materiais e Métodos, esclarece o processo experimental incluindo: as amostras, a metodologia, os equipamentos, os softwares e todo material necessário para o desenvolvimento da pesquisa. $\mathrm{O}$ capítulo cinco, Resultados e Discussão, expõe detalhadamente os resultados obtidos e as respectivas discussões necessárias. O capítulo seis, Conclusões e Trabalhos Futuros, ilustra as conclusões finais e inclui propostas de continuidade ao tema em 
trabalhos futuros. O sétimo e último capítulo informa as referências bibliográficas utilizadas para compor o texto. 


\section{2 \\ Objetivos}

A presente dissertação propõe otimizar uma metodologia de caracterização tridimensional desenvolvida por Augusto (AUGUSTO; PACIORNIK, 2018), utilizando amostras de pelotas de minério de ferro cedidas pela empresa Vale, com o intuito de obter as avaliações quantitativa e qualitativa do material. A metodologia consiste na aquisição de imagens por Microtomografia Computadorizada de Raios$\mathrm{x}($ microCT) e posteriormente pelo processamento e análise das imagens adquiridas.

Neste contexto os objetivos específicos são:

- Testar novas condições de aquisição de imagens para obter melhores resoluções e otimizar o tempo de análise;

- Avaliar qualitativamente a estrutura 3D das pelotas;

- Medir e caracterizar a porosidade comparando diferentes resoluções e identificar poros abertos e fechados; 


\section{3 \\ Revisão Bibliográfica}

\subsection{Pelotas de Minério de Ferro}

As pelotas são pequenos aglomerados de minério de ferro aproximadamente esféricas medindo entre 8 e 19 mm (CAVALCANTI; TAVARES, 2018), possuem alta concentração de ferro e são uma das matérias-primas essenciais para a fabricação do aço. As propriedades e qualidade das pelotas de minério de ferro são influenciadas pela tipologia e natureza do minério ou concentrado, pelos aditivos utilizados e pelo subsequente tratamento térmico para produção das pelotas queimadas. Elas são produzidas a partir do processo de pelotização, uma tecnologia que utiliza os finos de minério de ferro.

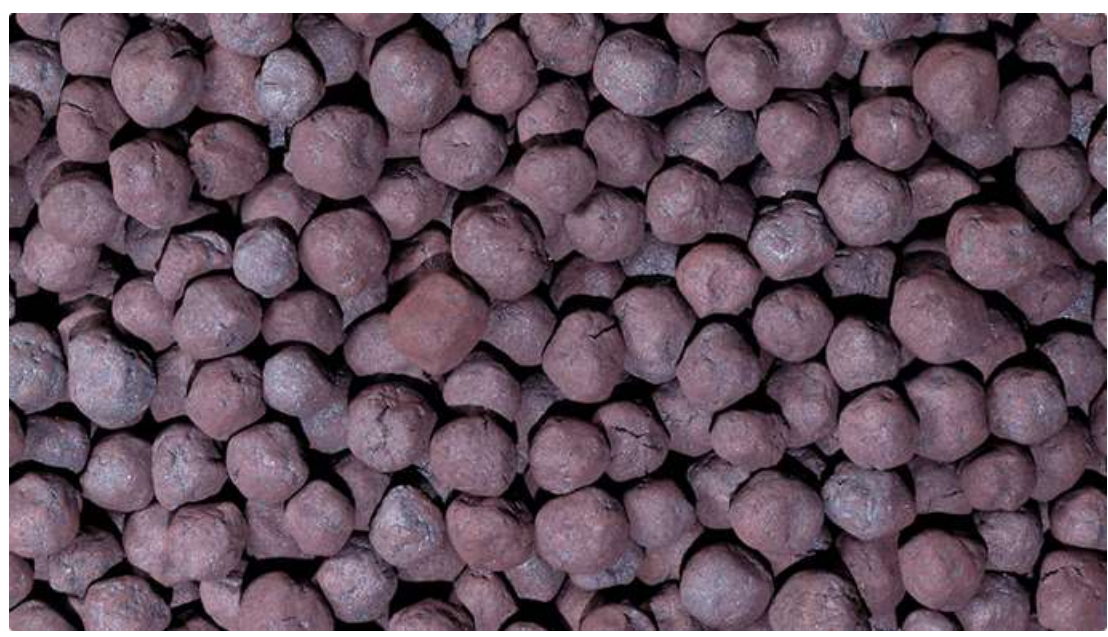

Figura 2 - Pelotas de minério de ferro (“VALE”).

\subsubsection{Pelotização}

O processo de pelotização consiste em aglomerar os finos de minério de ferro formando uma pelota crua ou green pellet. As pelotas cruas são submetidas a tratamento térmico em um forno para que ocorra a sinterização das partículas e endurecimento do aglomerado. Este processo promove a aquisição das características físicas e químicas necessárias para que as pelotas possam ser 
utilizadas nos altos-fornos e nos reatores de redução direta das usinas siderúrgicas. A figura 3 representa um exemplo de um fluxograma específico do processo de pelotização referente à usina Vale-Tubarão.

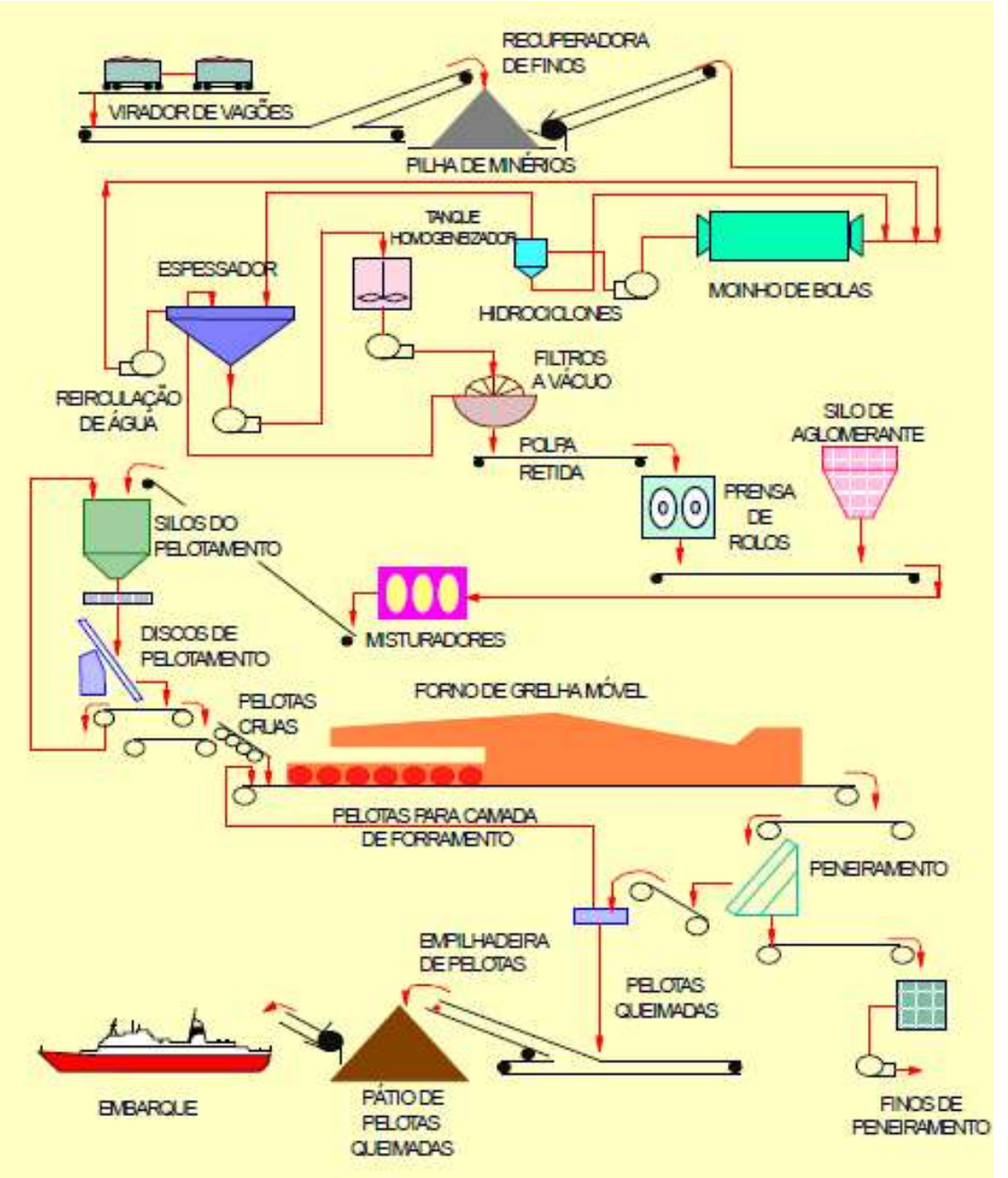

Figura 3 - Fluxograma do processo de pelotização utilizado na Usina Vale Tubarão (MACHADO; CASAGRANDE, 2015).

Portanto, o processo é composto por três estágios principais, sendo eles: preparo da matéria-prima, formação das pelotas cruas e queima.

A pelotização inicia-se com a preparação e produção das matérias-primas, sendo o pellet feed o principal componente da mistura. Estes são provenientes do beneficiamento do minério de ferro e são adicionados majoritariamente com fundentes, para auxiliar no ajuste da basicidade das pelotas, e aglomerantes, que auxiliam na formação das pelotas, que assim podem seguir para as etapas posteriores. Em alguns processos também pode ser adicionado um combustível 
sólido, eventualmente auxiliando na produção da pelota queimada (MOURÃO, 2017).

Durante o segundo estágio, no qual ocorre a formação das pelotas cruas, há a adição de água em dispositivos adequados como tambores e discos. O líquido possui o papel fundamental de manter as partículas aglomeradas através da força de capilaridade causada pela tensão superficial como pode ser observado na figura 4 .

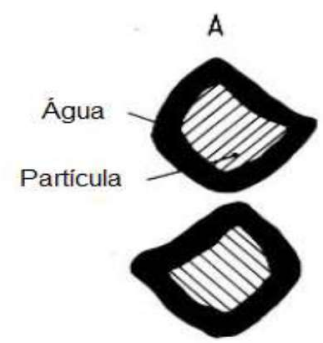

D

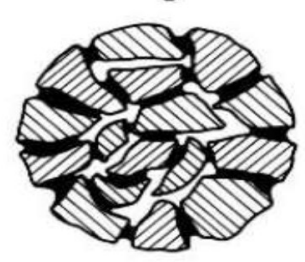

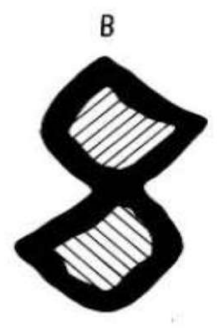

$\mathrm{E}$

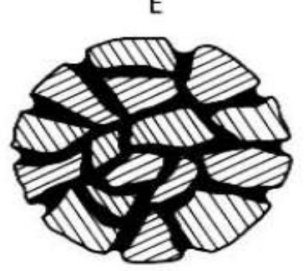

c
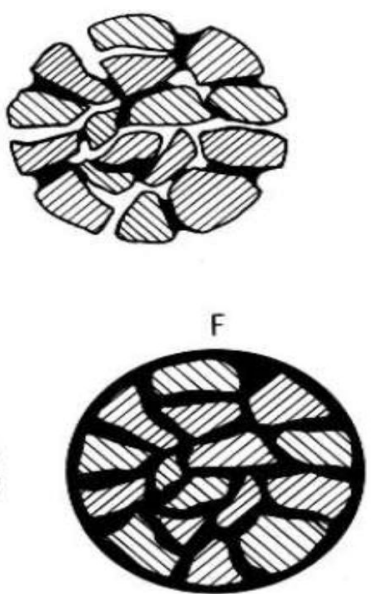

Figura 4 - Influência da adição de água na formação das pelotas cruas (MEYER, 1980).

Esta etapa tem como principal operação unitária o pelotamento do fino de minério, onde ocorre a aglomeração através do movimento de rotação dos discos ou tambores. Este movimento força a matéria-prima a rolar sobre a superfície onde os grãos úmidos (com percentagem de umidade de até 9,5\%) (MOURÃO, J. M.; NAPOLEÃO, 1993) tendem a aglutinar as demais partículas atingindo assim a forma de esfera. Os discos de pelotização são os mais utilizados devido à sua maior simplicidade e são dispostos com certa inclinação que influencia o tempo de retenção das pelotas, isto é, quanto mais inclinado menor será o tempo de retenção reduzindo o tamanho da pelota. Existem outras variáveis, além da inclinação, que interferem no tamanho da pelota, como a velocidade de rotação do disco (quanto maior a velocidade, maior a pelota), taxa de produção, entre outras. Essas variáveis devem ser analisadas e adequadas para garantir o tamanho necessário ao final do pelotamento (MEYER, 1980). Antes de entrarem no forno, as pelotas cruas são peneiradas, sendo retirados os finos e os grossos, os quais são recirculados no processo. 
O terceiro e último estágio é a queima e consolidação final sendo a etapa com maior custo de capital e operacional. Nela ocorrem: a secagem, o preaquecimento, a queima e o resfriamento do produto. Para que as pelotas adquiram resistência mecânica e propriedades metalúrgicas adequadas, as pelotas cruas são submetidas a altas temperaturas $\left(1250-1350^{\circ} \mathrm{C}\right.$ ) dentro dos fornos (MOURÃO, 2017). Todos os processos desta etapa precisam ser bastante controlados para minimizar o aparecimento de rachaduras e fragmentações nas pelotas. Durante a queima ocorre a fusão parcial de alguns componentes e acontece o surgimento de novas pontes cristalinas. Com isso a pelota adquire resistência e segue com tamanho adequado para serem usadas posteriormente na siderurgia.

\subsubsection{Medidas de Porosidade}

A rigor, qualquer sólido apresenta um grau de porosidade, detectável ou não, resultante da presença de cavidades, canais ou interstícios. A porosidade de um material exerce influência sobre suas propriedades físicas, tais como: densidade, condutividade térmica e resistência mecânica. Como consequência, o controle da estrutura porosa é de grande importância industrial (RETHWISCH, D. G.; CALLISTER JUNIOR, 2013). Os poros são definidos como defeitos volumétricos ou de massa e são introduzidos durante as etapas de processamento e de fabricação. De maneira geral, a porosidade é a propriedade física pertinente ao espaço disponível para o armazenamento de fluidos em um meio poroso e mede a relação entre volume de poros e o volume total do corpo sólido (KLOBES; MEYER; MUNRO, 2006).

Os poros podem ser classificados quanto a sua acessibilidade frente a um fluido externo, como pode ser observado na figura 5. Poros Abertos possuem uma extremidade na superfície do sólido e com isso um canal de comunicação com fluidos no exterior. No caso da pelota, estes tipos de poros causam grande impacto na redutibilidade do material nos fornos da siderurgia uma vez que estes permitem a difusão dos gases e fornecem área superficial para as reações que ocorrem.

Os poros considerados fechados são inativos quanto ao fluxo de líquidos e gases, porém podem se tornar conectados durante as reações. Estes exercem 
principalmente influência sobre as propriedades mecânicas, a densidade e a condutividade térmica, ou seja, nas propriedades macroscópicas.

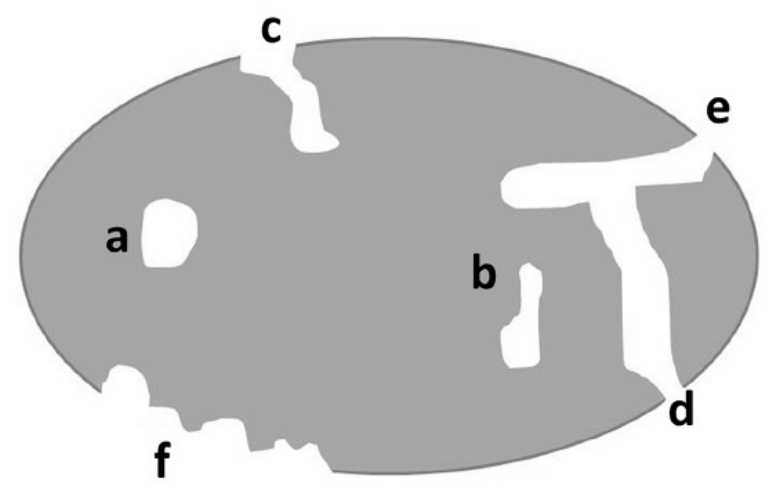

Figura 5 - Ilustração esquemática de uma seção em duas dimensões de um sólido poroso e as respectivas classificações dos diferentes tipos de poros: (a) e (b) poros fechados; (c) poro aberto e poro cego; (d) e (e) poros abertos interconectados; (f) rugosidade da superfície (SANTOS et al., 2016).

Os poros abertos ainda podem ser chamados de cegos, porque possuem abertura para uma extremidade podendo dar uma falsa impressão de ser um poro interconectado, porém em nenhum momento da estrutura ele se conecta com outro, sendo simplesmente um poro aberto. Tecnicamente as pequenas irregularidades na superfície também são poros cegos, porém é mais adequado tratá-las como um atributo diferente, chamado de rugosidade (LOPES et al., 2012).

Quantitativamente, a porosidade pode ser medida através da fração de volume específico dos poros na amostra, ou seja:

$$
\varepsilon=\frac{\mathrm{Vp}}{V}
$$

O valor desta fração depende do método utilizado para determinar o volume específico aparente, $\mathrm{V}$, que exclui os vazios interpartículas, e do método utilizado para determinação do volume específico de poro, Vp (KLOBES; MEYER; MUNRO, 2006).

Existem diversas técnicas para medir e caracterizar a porosidade dos materiais. Alguns métodos só possuem acesso a poros abertos, como os que utilizam fluidos para testar a acessibilidade ao interior do material, outros possuem informações sobre a porosidade total, incluindo poros abertos e fechados muitas vezes sem distingui-los. Algumas das técnicas mais utilizadas estão exemplificadas 
na figura 6 , onde pode ser visualizada a faixa aproximada de tamanho dos poros que cada uma alcança.

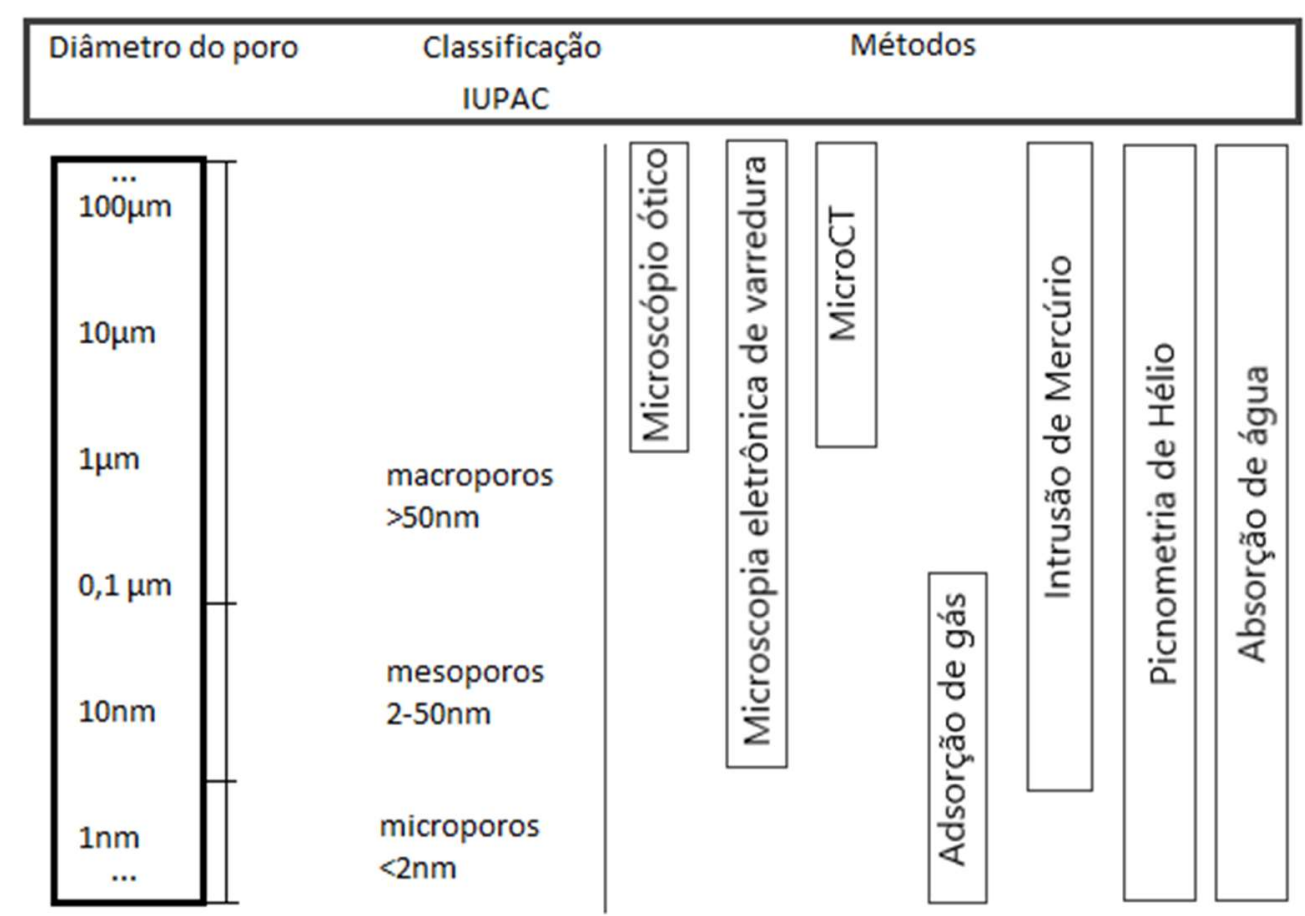

Figura 6 - Alguns métodos utilizados para determinar porosidade e distribuição do tamanho dos poros. Adaptado de (KLOBES; MEYER; MUNRO, 2016) e (ANOVITZ; COLE, 2015).

Para determinar porosidade aberta, emprega-se principalmente as técnicas de:

- Porosimetria por intrusão de mercúrio, que é uma técnica simples e por isso é bastante utilizada. Porém, é uma técnica destrutiva, inutilizando a amostra após a análise, e a legislação está cada vez mais restritiva quanto o uso de mercúrio por ser tóxico aos humanos.

- A Absorção de água é simples e barata, mas não apresenta resultados muito precisos devido ao preenchimento das cavidades ser dependente das condições de medidas adequadas (ANDREOLA et al., 2000).

- Absorção de gás, utiliza-se a Teoria de Adsorção Multimolecular BET que se baseia em considerações termodinâmicas das isotermas e em equações empíricas, sendo uma generalização do conceito de Lagmuir, é a mais completa teoria de adsorção existente. Porém 
possui uma avaliação complexa dos resultados devido a definição dos respectivos parâmetros (PARK et al., 2008).

Para determinar porosidade total, têm-se:

- Picnometria de Hélio na qual utiliza-se a densidade dos materiais, para detectar a porosidade total. No entanto não é possível diferenciar entre porosidade aberta e fechada.

- Microscopia Ótica, na qual utiliza-se um feixe de luz incidente na amostra e obtêm-se informações de uma sessão da amostra. Portanto, não apresenta dados precisos quanto a amostra completa (em três dimensões). O Microscópio Eletrônico de Varredura oferece melhor resolução pois utiliza um feixe de elétrons no lugar do feixe de fótons do Microscópio Ótico, podendo identificar poros de menor tamanho, porém também traz informações apenas bidimensionais.

Um assunto que vem sendo intensamente explorado é a análise da qualidade do minério de ferro e seus respectivos finos devido à importância para a siderurgia, já que o minério de ferro granulado e seus finos são importantes precursores da produção de aço. Considerando este fato, sua caracterização é de extrema importância para determinar a qualidade do produto final, o aço. Através de projetos de pesquisa da Vale em conjunto com a PUC-Rio, foram desenvolvidos alguns trabalhos baseados em microscopia ótica digital e análise de imagens para caracterização de minério de ferro. Entre eles destacam-se: (WAGNER et al., 2009); (AUGUSTO et al., 2012), (CASTELLANOS et al., 2018) e (IGLESIAS et al., 2018).

Wagner (2009), estudou rotinas de análise de imagens a fim de melhorar a caracterização qualitativa e quantitativa das pelotas por meio de microscopia ótica digital. Assim, foi desenvolvida uma metodologia de aquisição e análise de imagens com resultados que comprovaram a viabilidade para obter informações da amostra, com resultados de variação radial quanto à porosidade e à variação das fases.

Augusto (2012), desenvolveu um sistema automático de identificação do grau de maturação de pelotas envolvendo microscopia digital e processamento e análise 
de imagens, através da extração de atributos capazes de descrever características intrínsecas. Estes foram utilizados para treinar um classificador automático obtendo assim um método computacional que foi capaz de caracterizar e classificar quanto ao grau de maturação, o que anteriormente era realizado visualmente por um operador humano.

Castellanos (2018), fez uma abordagem correlativa utilizando microscopia ótica e microscopia eletrônica de varredura para quantificação de poros e fases em pelotas de minério de ferro. Seus resultados mostraram uma melhora nessa discriminação e confirmou que o método correlativo possui vantagens quanto ao uso das técnicas utilizadas individualmente.

Iglesias (2018), criou um sistema automático de caracterização mineralógica para minérios de ferro baseado em microscopia digital e análise de imagens. Através de classificadores distintos, foi possível identificar e quantificar as diferentes texturas e minerais, além de reconhecer partículas não-compactas e compactas de hematita, e ainda distinguir partículas policristalinas de monocristalinas.

Porém, como mencionado anteriormente, a microscopia ótica é uma técnica destrutiva e que fornece apenas informações bidimensionais. Também é importante salientar que todas as técnicas possuem vantagens e desvantagens quanto ao uso. Assim, é preciso identificar qual a mais adequada para cada material e tipo de estudo.

\subsection{Microtomografia Computadorizada de Raios X Aplicada à Área Mineral}

A microtomografia computadorizada de raios $\mathrm{X}$ (microCT) é uma técnica não destrutiva que permite a visualização interna e tridimensional de uma amostra submetida a uma fonte de radiação ionizante com necessidade praticamente nula de preparações física e química da amostra.

A microCT está baseada nos mesmos princípios de uma radiografia convencional, onde cada parte de uma amostra absorve de maneira distinta os raios X. Desta maneira, é possível estudar as seções transversais bidimensionais de uma 
forma não destrutiva e através de princípios matemáticos, é possível reconstruí-las de modo a construir o respectivo modelo tridimensional da amostra, possibilitando assim a visualização e quantificação da estrutura interna do material (figura 7).

A tomografia computadorizada produz uma imagem muito próxima da realidade por apresentar a atenuação média de cada pequeno elemento de volume, ordenando a informação de atenuação do feixe de raios e traduzindo a informação de forma quantitativa (BECKMANN, 2006).

Os raios X são o tipo de radiação usado em tomografias. São uma forma de radiação eletromagnética, no espectro invisível e possuem energia para ionizar átomos e romper ligações moleculares. São produzidos pela desaceleração de elétrons, gerados por um catodo e acelerados por um campo elétrico dentro de um tubo de vácuo, quando estes colidem com um alvo, o anodo. Os raios $\mathrm{X}$ interagem com a matéria principalmente por absorção fotoelétrica (efeito fotoelétrico) onde o fóton é absorvido pelo átomo e um elétron atômico é liberado para se mover no material, e espalhamento Compton (espalhamento inelástico) no qual ocorre o espalhamento de um fóton por um elétron livre do material, de uma camada mais afastada do núcleo e parte da energia do fóton é transferida para o elétron que interagiu (YOSHIMURA, 2009). A principal interação vai depender da composição elementar do objeto avaliado e da energia dos raios $\mathrm{X}$.

Apesar de ter sido fundamentada e tendo sua teoria lançada no início do século XX, a tomografia se tornou viável graças ao desenvolvimento da tecnologia computacional moderna. Em meados da década de 60, Godfrey Newbold Hounsfield teve a ideia de analisar o que há dentro de um objeto olhando para radiografias em várias direções. Em sua visão, considerando um objeto tridimensional como uma caixa formada por uma série de camadas, a reconstrução da imagem seria mais fácil do que o tratando como um volume. Para simular na prática o que descobriu na teoria, Hounsfield construiu um computador que pudesse obter as informações de entrada da absorção dos raios $\mathrm{X}$ após terem sido atenuados por uma amostra em diversos ângulos e processou todas essas informações usando um algoritmo de reconstrução iterativo, se surpreendendo com a incrível precisão do resultado (LANDIS; KEANE, 2010). A Figura 7 (a) a seguir mostra o esquema de um tomógrafo com fonte de raios $\mathrm{X}$ no lado esquerdo e o detector sensível à energia no lado direito. 

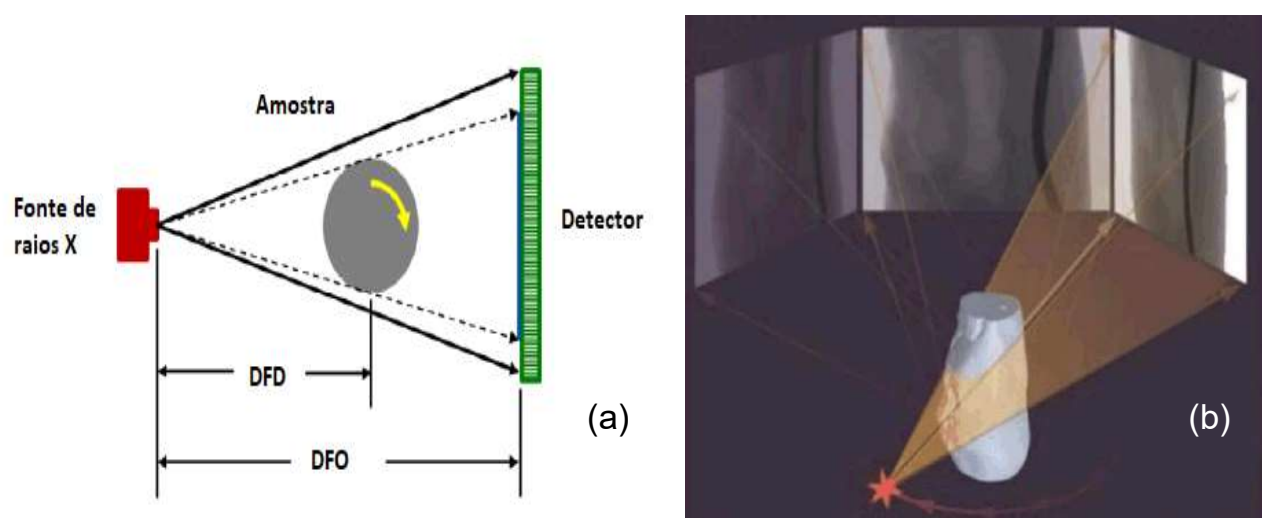

Figura 7 - (a) Esquema ilustrativo de microCT, sendo DFD: Distância Fonte - Detector e DFO: Distância Fonte - Objeto (MURPHY; SCHADE; ZWIREN, 2014); (b) Projeções da amostra (ALEKSANDROV et al., 2017).

A amostra fica localizada entre a fonte e o detector e é girada em um eixo que permite a aquisição de imagens em vários ângulos durante uma revolução completa. As imagens são coletadas, armazenadas e reconstruídas para obter uma representação tridimensional da amostra, como descrito mais adiante. A magnificação da imagem gerada é alterada por vários fatores, sendo o mais importante a posição da amostra em relação à fonte de raios X. Mover a amostra para mais perto da fonte aumenta a ampliação e a resolução da imagem, pois o que é projetado no detector representa uma área de amostra menor.

Os diferentes tons de cinza nas projeções (figura 7-b) refletem o enfraquecimento dos raios $\mathrm{X}$ devido aos efeitos de dispersão e absorção do sinal transmitido através da amostra. Portanto, a atenuação dependerá da espessura e densidade do objeto estudado bem como de seu número atômico. Este efeito é descrito pela Lei de Beer-Lambert, que determina a atenuação do feixe de radiação monocromático propagando-se em um meio absorvedor, sendo representada pela equação (ALEKSANDROV et al., 2017):

$$
I(x)=I_{0} e^{-\mu x}
$$

Onde, I é a intensidade do feixe emergente, $\mathrm{I}_{0}$ a intensidade inicial do feixe de raios $\mathrm{X}$ incidente; $\mathrm{x}$ é a espessura do material e $\mu$ o coeficiente de atenuação linear total.

Os equipamentos de microCT geralmente utilizam dois tipos de geometria de feixe, paralela ou cônica. O modelo Zeiss usado nesta dissertação possui o sistema 
de projeção cônica, que é o mais usado comercialmente e permite maximizar o aproveitamento do feixe de raios $\mathrm{X}$ devido a reconstrução do espaço 3D diretamente de dados de projeção 2D. O emprego da projeção cônica permite que a distância entre a fonte emissora e a amostra possa ser tão pequena quanto possível, possibilitando uma melhor resolução devido à proximidade. Porém a resolução espacial ainda é limitada pelo tamanho da fonte, pois amostras muito próximas da fonte podem apresentar efeitos de sombra em suas projeções provocados pela dimensão da fonte. (ULIANA et al., 2014).

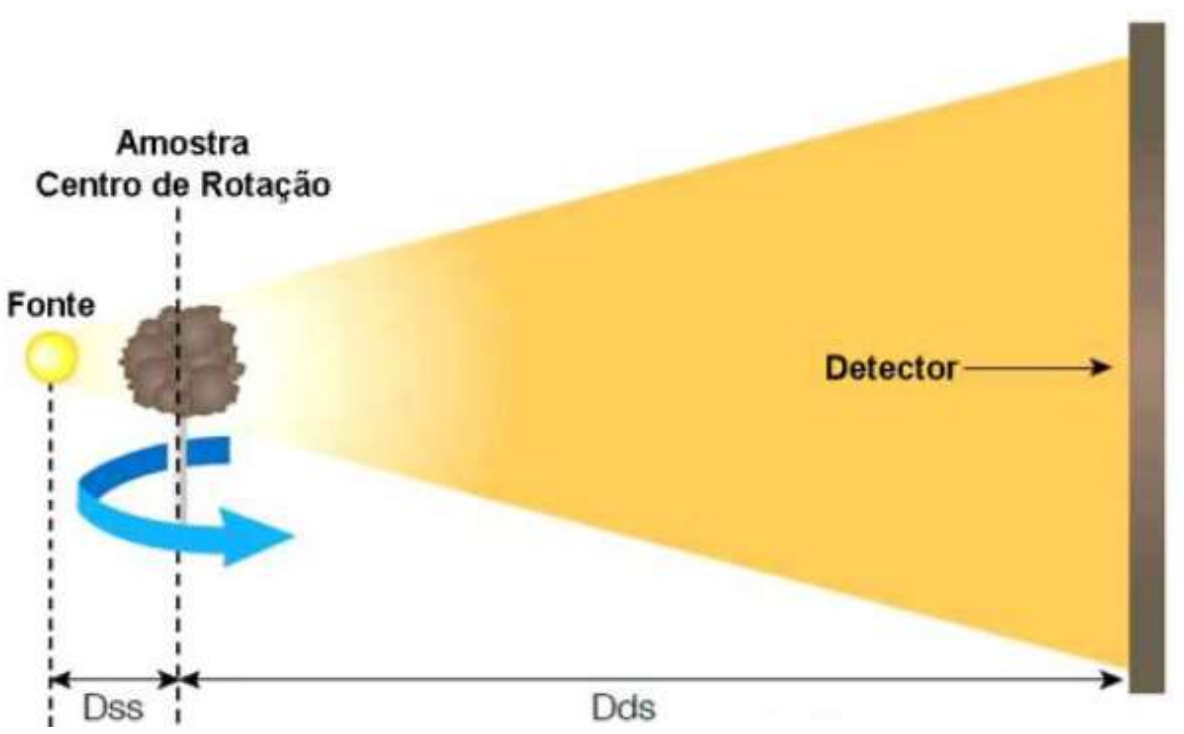

Figura 8 - Esquema ilustrativo da geometria do sistema de projeção cônica do feixe de raios $\mathrm{X}$, onde Dss é a distância fonte-amostra e Dds, distância amostra-detector (ULIANA et al., 2014).

A resolução da imagem é proporcional ao tamanho dos pixels (x) da imagem tomográfica, e inversamente proporcional ao fator de magnificação (M), de acordo com a seguinte relação (MANTOVANI, 2013):

$$
R=\frac{x}{M}
$$

$\mathrm{O}$ fator $\mathrm{M}$ depende das distâncias fonte-amostra (Dss) e amostra-detector (Dds) (figura 8), de acordo com a expressão (MANTOVANI, 2013):

$$
M=\frac{D s s+D d s}{D s s}
$$

No microtomógrafo utilizado nesta dissertação, além da magnificação geométrica, é possível utilizar a magnificação ótica dada por um conjunto de lentes objetivas acopladas ao sistema de detecção. As lentes dispõem de um cintilador na sua entrada, que converte os raios X em luz visível. Portanto, é possível optar em 
utilizar tanto um quanto outro tipo de magnificação ou fazer uso da combinação das duas (geométrica e ótica). O sistema de lentes permite preservar a resolução para objetos com maior espessura, e consequentemente mais distantes da fonte, selecionando um subvolume de interesse a ser tomografado.

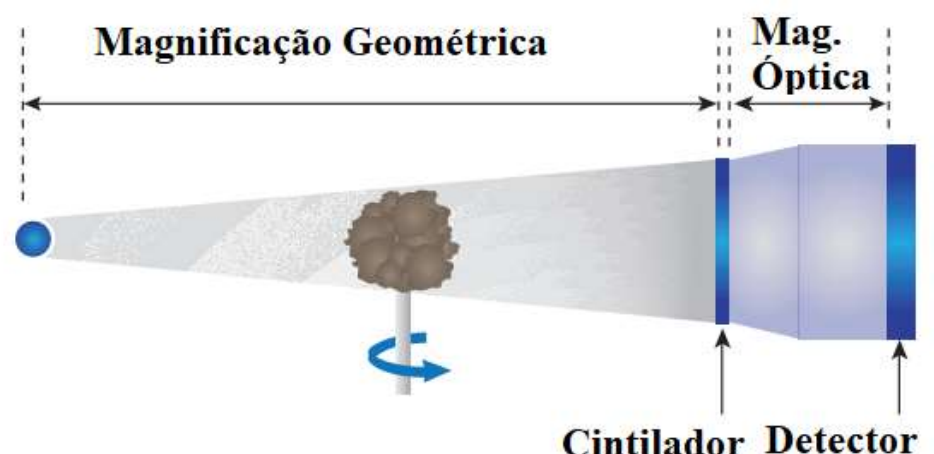

Figura 9 - Projeção cônica com magnificação ótica pelo uso de lente (VERSA, [s.d.]).

A reconstrução matemática é obtida a partir da transformação do perfil de intensidades relativo a cada projeção (sinograma) em fatias bidimensionais. Neste momento o pixel é matematicamente transformado em voxel e este é capaz de representar um valor de absorção de raios X para cada posição $x-y-z$ da amostra. Através de algoritmos computacionais é possível reconstruir estas fatias em seu respectivo modelo tridimensional. A técnica de reconstrução mais difundida é a chamada retroprojeção filtrada, na qual cada projeção é retroprojetada e sobreposta sucessivamente em diferentes ângulos e orientações para recriar sua representação 3D. À medida que mais projeções são usadas, a reconstrução se torna mais precisa. Após a retroprojeção, é utilizado um filtro passa-alta que compensa a perda de informação de alta frequência advinda do processo de retroprojeção. Este tipo de reconstrução pode ser melhor compreendido com a figura 10. 


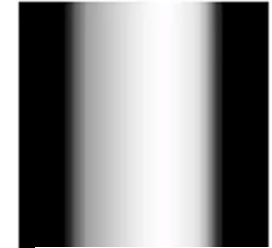

1 ângulo

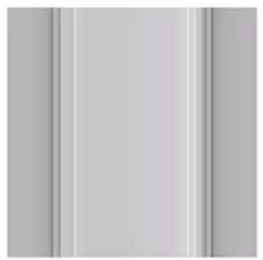

\begin{abstract}
2 ângulos
\end{abstract}

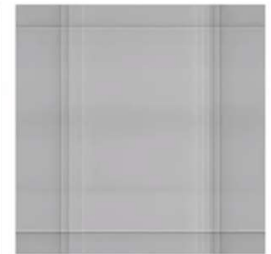

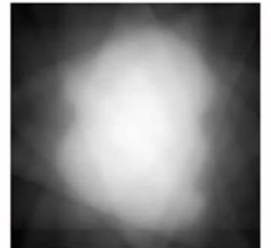

8 ângulos

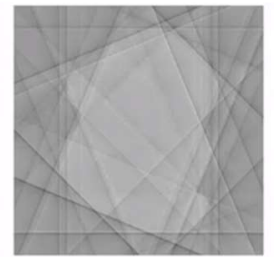

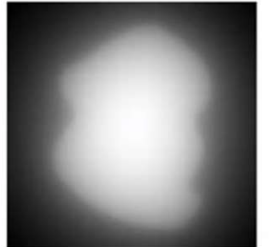

45 ângulos

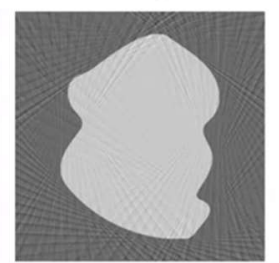

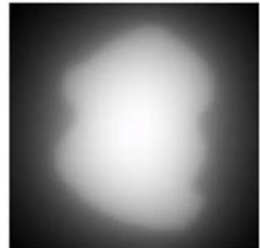

180 ângulos

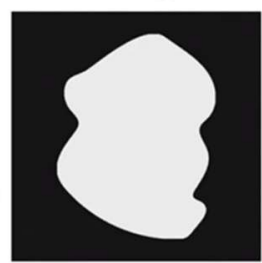

Figura 10 - Retroprojeção direta (linha superior) e filtrada (linha inferior). Adaptado de (VAN AARLE et al., 2016)

O tamanho do voxel (3D) ou pixel (2D) é um cálculo que se refere a uma área da seção transversal da amostra que é representada em um único pixel do detector (figura 11)
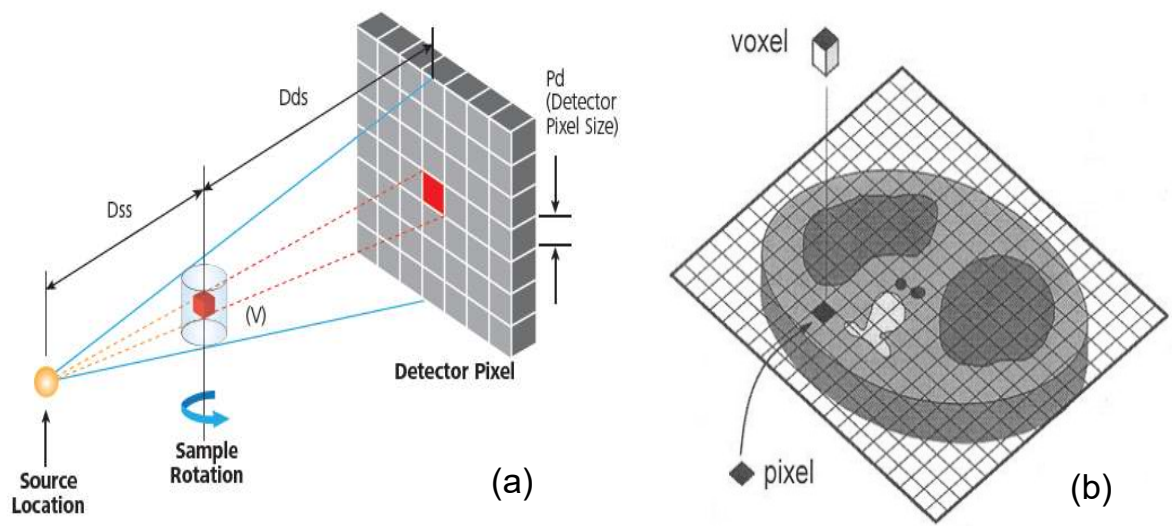

Figura 11 - Representação de um pixel e de um voxel, (a) no sistema fonte-amostradetector (INC., 2018), (b) na camada amostral (MANTOVANI, 2013).

Como as imagens são em tons de cinza, cada pixel corresponde a um valor de cinza que será proporcional ao coeficiente de atenuação (número atômico e densidade).

Por muitos anos, a microCT era utilizada em aplicações na área da medicina. Com o avanço das pesquisas descobriu-se que é uma poderosa técnica de análise da estrutura interna de materiais, fornecendo imagens verdadeiramente tridimensionais, o que levou à rápida adaptação da técnica em outros campos, incluindo a área mineral e a de ciência dos materiais (LANDIS; KEANE, 2010). 
Por conseguinte, as vantagens da aplicação da microCT na área mineral são:

- A possibilidade de analisar as características internas do minério ou de seus particulados e visualizá-las em três dimensões;

- A técnica não ser destrutiva, permitindo analisar mais de uma vez a mesma amostra mineral, além de conseguir avaliar materiais com pouca resistência física, como por exemplo as pelotas cruas;

- Permite fazer medições quantitativas a partir das imagens digitais, dentre elas a distribuição espacial e fração volumétrica de poros e fases.

- Permite uma avaliação da amostra de maneira não invasiva da estrutura a partir de análises externas;

- Boa versatilidade quanto ao tamanho da amostra além da facilidade ou total ausência de preparo prévio.

Porém, a metodologia apresenta duas limitações importantes, sendo elas: a resolução espacial, que não foi satisfatória o suficiente para identificar toda a faixa de tamanho de poros, e o tempo de análise que se mostrou muito extenso. Sendo assim, otimizando-se os parâmetros citados existe a possibilidade que a análise por microCT, posteriormente, venha a substituir as técnicas clássicas de caracterização.

Alguns trabalhos utilizando a técnica de microCT na área mineral foram publicados nos últimos anos. É possível citar o estudo do processamento de imagens a partir da microtomografia de rochas, sendo importante a segmentação para a identificação de estruturas para análise, Anderson (2012) concluiu que é perceptível a dependência dos resultados com a resolução espacial fornecida pela microtomografia (ANDERSON, C.M.et al, 2012).

Alves (2015) estudou a caracterização mineralógica de rochas, utilizando a microtomografia com dupla energia. Ele propôs melhorar a interpretação de imagens a partir de amostras heterogêneas desenvolvendo uma nova metodologia de caracterização não destrutiva usando a aplicação da dupla energia nas imagens microtomográficas. Para isso, dividiu a metodologia em três etapas, sendo elas: a validação da proposta metodológica, a avaliação do espectro do tubo de raios X e 
a aplicação da metodologia para calibração do sistema tomográfico utilizando amostras geológicas e minerais com valores de densidade e número atômico efetivo conhecidos (ALVES, 2015).

A figura 12 mostra a possibilidade de uma identificação mineralógica de amostras de composição heterogênea, de forma qualitativa, através das informações obtidas de densidade e número atômico efetivo associadas aos histogramas de distribuição destes parâmetros. Seus resultados expuseram que a metodologia proposta estava de acordo com o esperado teoricamente, através de desvios dos dados inferiores a 5\% com relação aos dados teóricos. E concluiu que a técnica de dupla energia é eficaz para a identificação mineralógica, permitindo a identificação dos parâmetros diretamente em imagens calibradas de Microtomografia (ALVES, 2015).
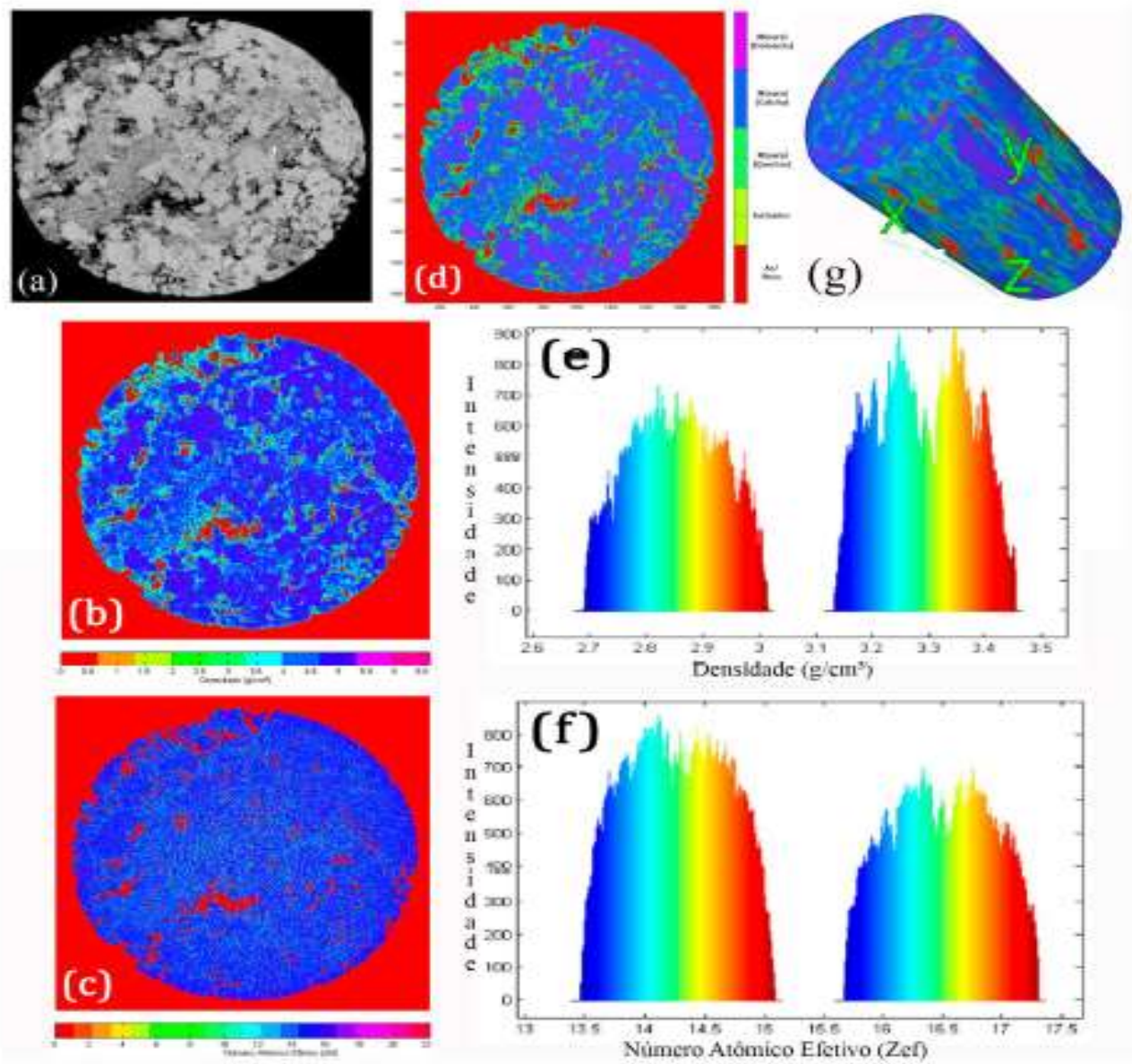

Figura 12 - (a) Seção transversal; imagens em (b) densidade, (c) número atômico e (d) mineralogia; histograma de (e) densidade e (f) número atômico; (g) imagem 3D de mineralogia da amostra (ALVES, 2015). 
Uliana (2014) estudou a microtomografia de alta resolução no setor mineral, abrangendo os recentes avanços da técnica e os aplicou nas análises de porosidade e aplicações na tecnologia mineral. Seu trabalho apresentou um panorama dos avanços da microtomografia, sendo eles: a projeção cônica, permitindo uma menor distância entre a fonte de raios X e a amostra possibilitando uma melhor resolução espacial, a geometria cônica proporciona uma imagem ampliada no detector; melhoria ótica com a combinação da projeção cônica com o uso de lentes, possibilitando uma melhora significativa na resolução e no contraste. Seu artigo citou algumas das aplicações de microCT na área mineral, como: a utilização para a determinação em 3D de danos causados às partículas, como trincas e fraturas internas, após uma cominuição; a possibilidade de estimar a recuperação de determinado elemento/mineral com base em dados reais de liberação comparando com a eficiência esperada para uma concentração perfeita; análise da lavabilidade do carvão através do monitoramento do comportamento do material e seu rendimento no processo (ULIANA et al., 2014).

Tendo em vista as vantagens da técnica de microCT, principalmente devido ao auxílio na melhoria da visualização interna e tridimensional do material, Augusto e Paciornik (2017) desenvolveram uma metodologia de caracterização de porosidade em pelotas de minério de ferro utilizando a microCT. O trabalho consiste no processamento e análise das imagens adquiridas através da microtomografia. Foi feita a comparação dos resultados (figura 13) com as demais técnicas de caracterização utilizadas comumente na indústria que são a porosimetria por intrusão de mercúrio e a microscopia ótica. (AUGUSTO; PACIORNIK, 2018).
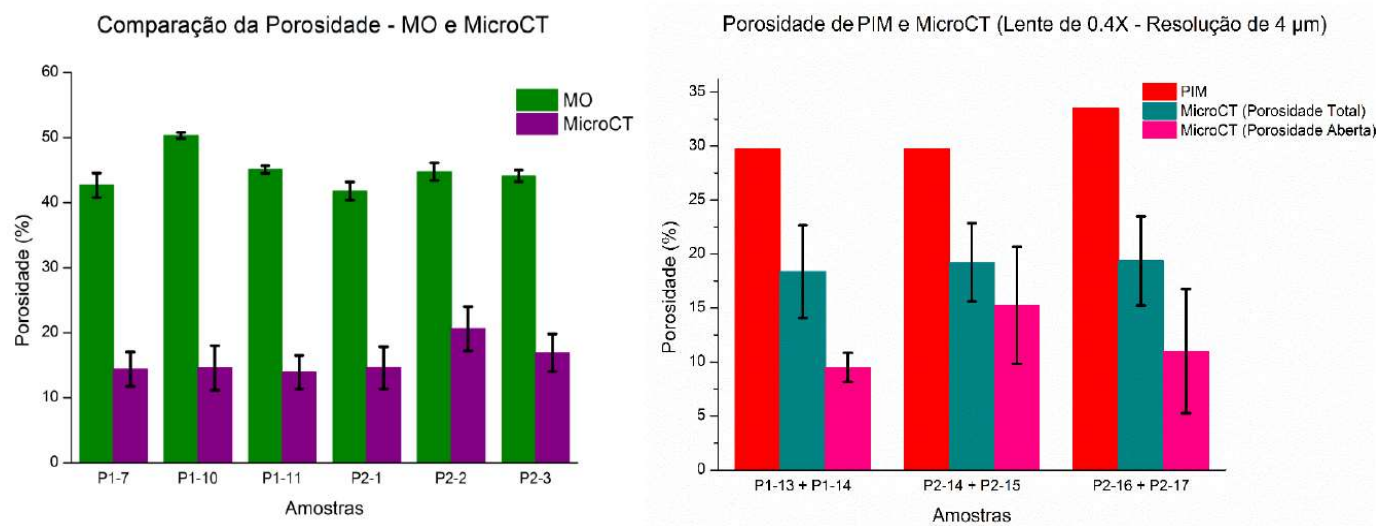

Figura 13 - Resultados das comparações de medidas de porosidade, total e aberta, da metodologia proposta com as técnicas clássicas (MO e PIM) (AUGUSTO; PACIORNIK, 2017). 
Foi concluído que a técnica é limitada quanto à resolução espacial e por isso não apresentou valores de porosidade próximos aos medidos com PIM e MO. Com a melhora da resolução, através do uso de lentes ou de geometria otimizada do sistema fonte - amostra - detector, os valores de porosidade se aproximaram do esperado, mas para isso foi necessário também aumentar o tempo de aquisição que também é uma limitação a ser considerada (AUGUSTO; PACIORNIK, 2017).

Quanto a metodologia de caracterização em microCT, algumas condições de aquisição foram otimizadas no trabalho supracitado e que serão consideradas na presente dissertação. De acordo com Augusto (2017), utilizar-se de rotação completa $\left(360^{\circ}\right)$ na realização das tomografias e número de projeções a partir de 1600 proporcionam imagens com melhor qualidade. As imagens nessas condições são menos ruidosas, seus respectivos histogramas apresentam picos bem definidos e sem picos intermediários. Portanto esses parâmetros melhoram a análise e, consequentemente, facilitam a etapa de segmentação das fases. (AUGUSTO; PACIORNIK, 2018)

Em suma, a técnica de microCT trouxe muitos avanços quanto a visualização e caracterização microestrutural, porém com algumas limitações que incluem a capacidade de penetração dos raios $\mathrm{X}$ em relação à densidade da amostra, dificuldade de distinção de fases quando as mesmas apresentam pouca diferença na absorção dos raios X, possuir resolução espacial limitada e extensos tempos de aquisição das imagens (LANDIS; KEANE, 2010). 


\section{4 \\ Materiais e Métodos}

\subsection{Amostras}

As amostras utilizadas neste trabalho foram fornecidas pela Vale. As pelotas de minério de ferro que foram utilizadas, são adequadas para serem processadas no alto-forno e foram produzidas em usinas diferentes a partir de minérios distintos. A composição química das pelotas utilizadas, é especificada na tabela 2 a seguir.

Tabela 2 - Composição química da pelotas (AUGUSTO et al., 2016).

Composição

\begin{tabular}{|c|c|}
\hline $\mathrm{Fe}(\%)$ & 65,51 \\
\hline $\mathrm{SiO}_{2}(\%)$ & 2,57 \\
\hline $\mathrm{Al}_{2} \mathrm{O}_{3}(\%)$ & 0,59 \\
\hline $\mathrm{CaO}(\%)$ & 2,80 \\
\hline $\mathbf{P}(\%)$ & 0,032 \\
\hline $\mathrm{Mn}(\%)$ & 0,07 \\
\hline $\mathrm{B}_{2}\left(\mathrm{CaO} / \mathrm{SiO}_{2}\right)$ & 1,09 \\
\hline
\end{tabular}

Utilizou-se 2 pelotas do mesmo tipo como amostras para as tomografias. Para isso, as pelotas foram fixadas em uma haste de alumínio a fim de facilitar a varredura, o que permite uma boa fixação da amostra com pouca perda de região de análise, garante que não há movimentos indesejados durante a análise e possibilita uma maior aproximação dos dispositivos fonte e detector. As pelotas utilizadas de códigos P1-A e P1-B podem ser visualizadas na figura 14 a seguir. 


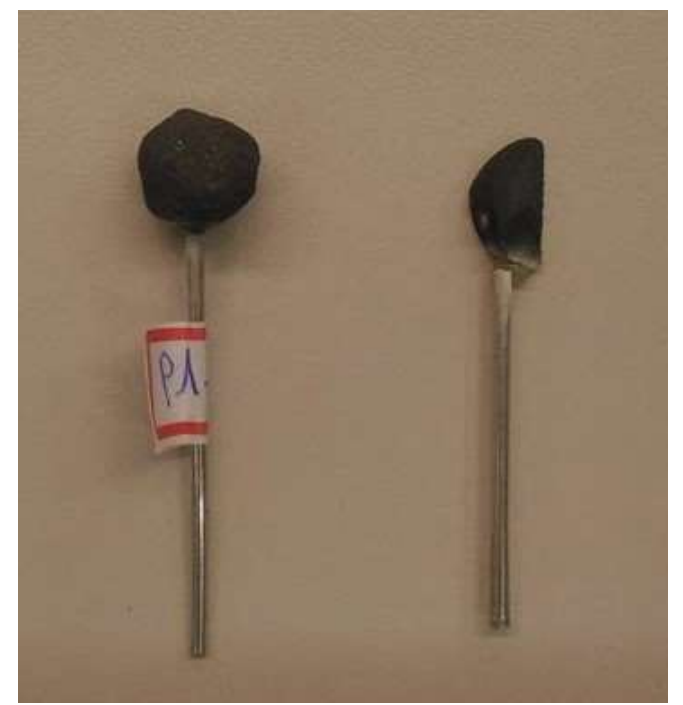

Figura 14 - Pelotas P1-A e P1-B, respectivamente.

A P1-A foi utilizada para comparar as diferentes condições de aquisição que serão detalhadas ainda neste capítulo. Já a pelota P1-B foi seccionada em 8 "gomos" que abrangiam o diâmetro da pelota original com o intuito de diminuir a espessura do material e conseguir alcançar resoluções melhores com o menor tempo de análise possível.

Este corte foi feito utilizando o equipamento Struers Minitom (figura 15), que permite fazer cortes metalúrgicos com precisão de até $0,01 \mathrm{~mm}$. O uso de discos diamantados permite um resultado de corte com pouca rugosidade e com uma superfície praticamente lisa, o que mostra que há pouca perda de material. 


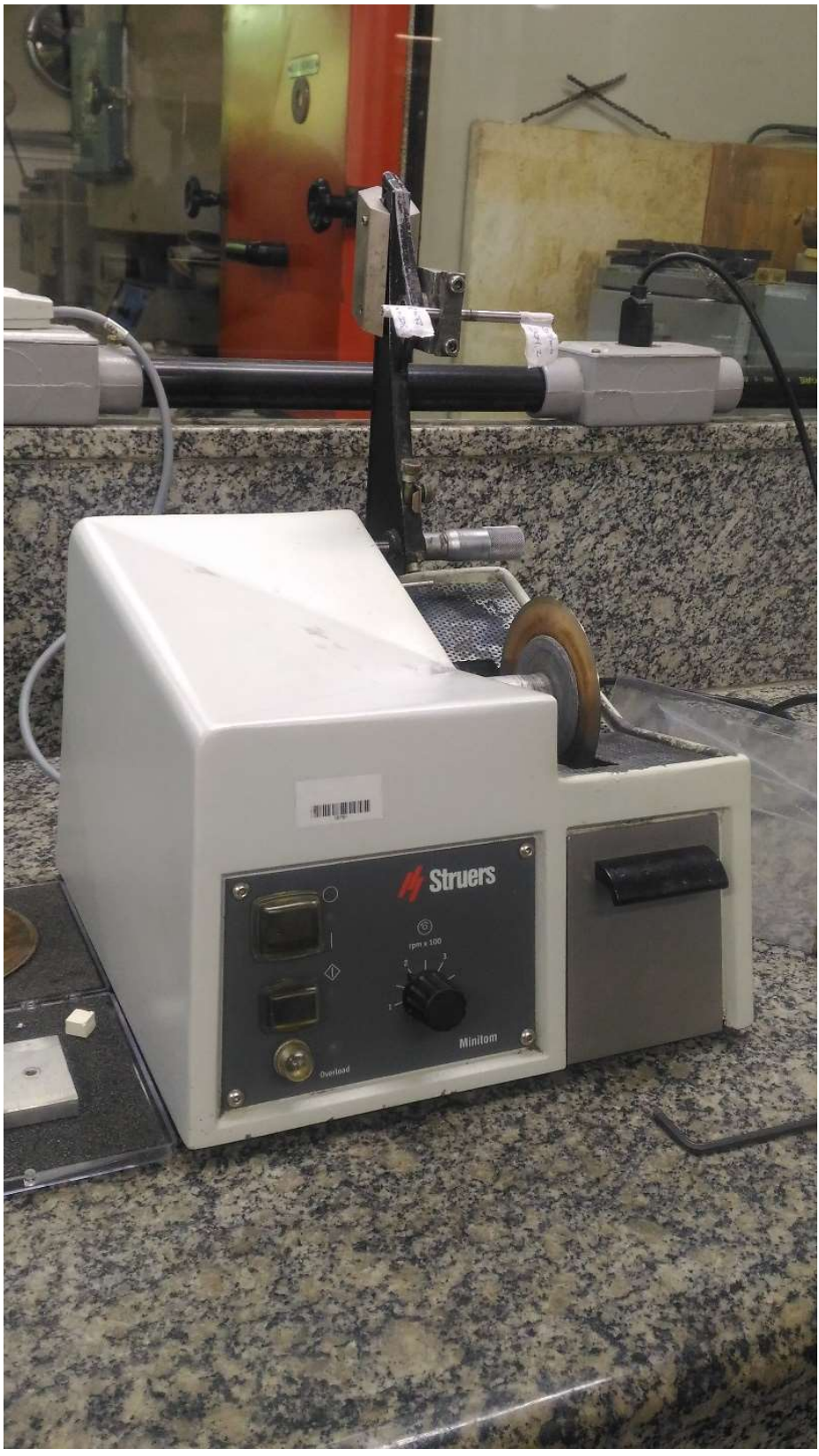

Figura 15 - Cortador de precisão Struers Minitom.

Para garantir que o corte seja de uma região representativa de um oitavo do total e contendo o diâmetro da pelota original, cortou-se primeiro a pelota ao meio, essa metade foi cortada pela metade e assim foi obtida a oitava parte da pelota, que é um "gomo" como mostrado na figura 16 a seguir. 

(a)
(b)
(c)

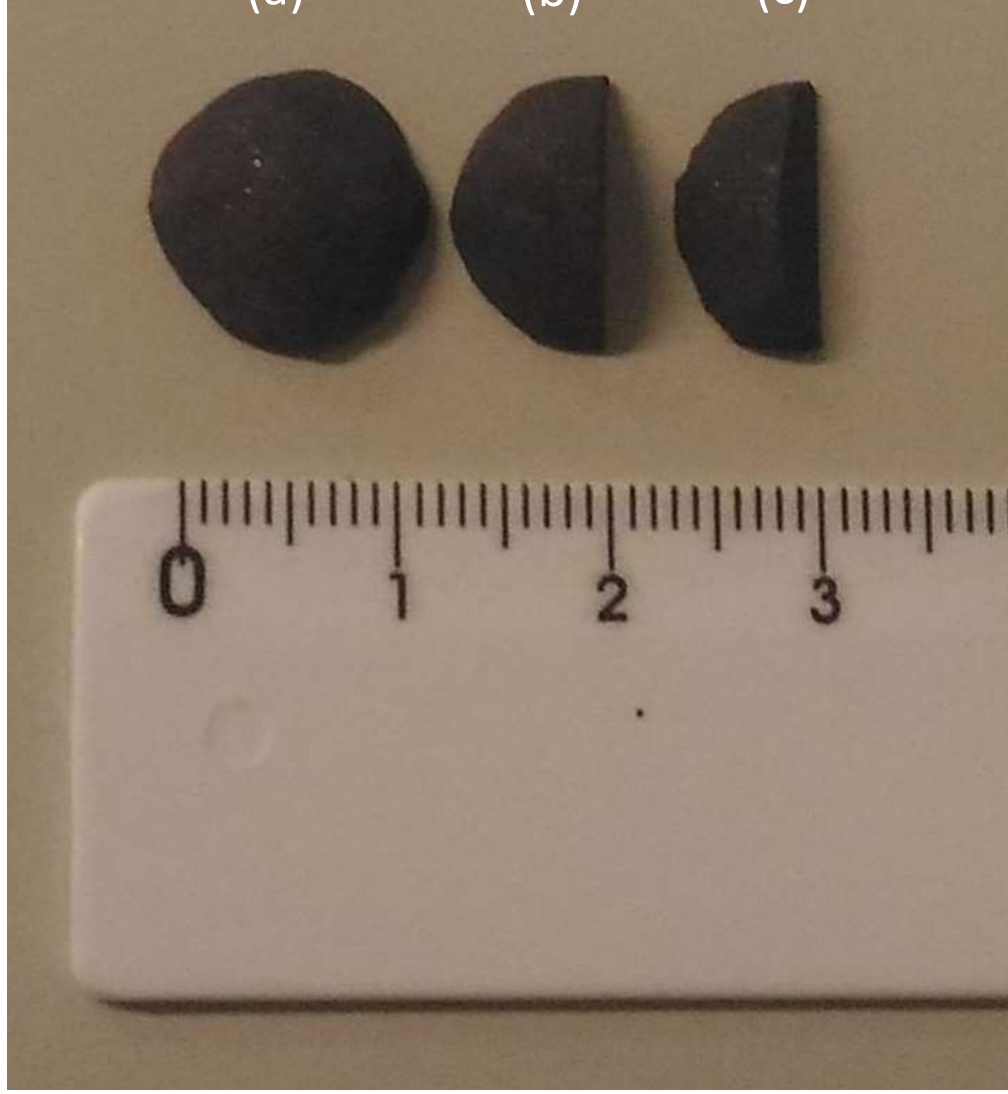

Figura 16 - Pelota seccionada: (a) meia pelota; (b) um quarto da pelota; (c) um oitavo da pelota (gomo).

\subsection{Processo de microCT}

O modelo do microtomógrafo utilizado foi ZEISS Xradia 510 Versa (figura 17 e figura 18) com o auxílio do software de aquisição próprio do sistema Zeiss, chamado de Scout-and-Scan ${ }^{T M}$ Control System. 


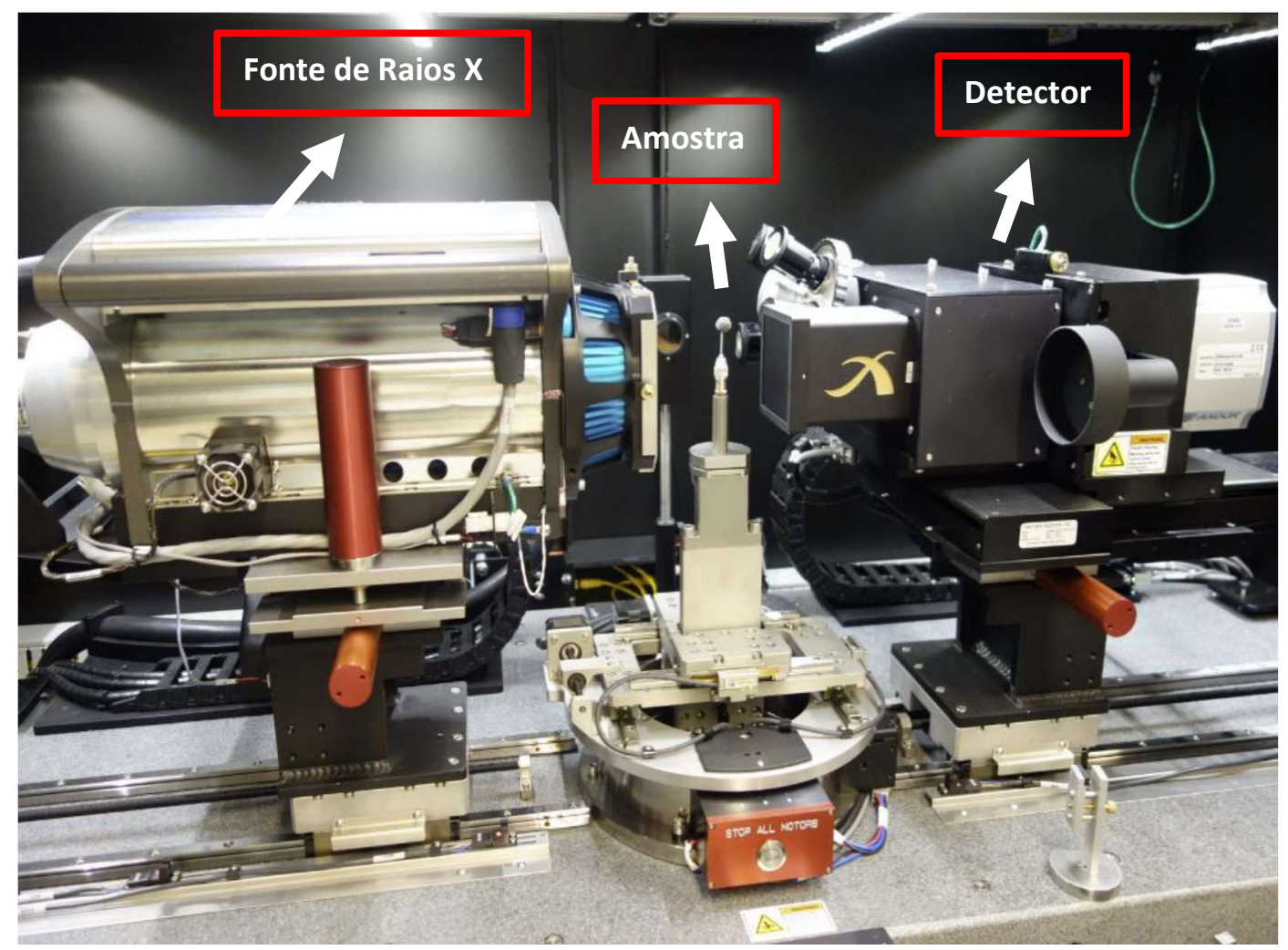

Figura 17 - Visão interna do microCT Zeiss Xradia Versa 510: Fonte de raios $X$ (esquerda), detector e conjunto de lentes (direita) e amostra de pelota de minério de ferro (centro); 


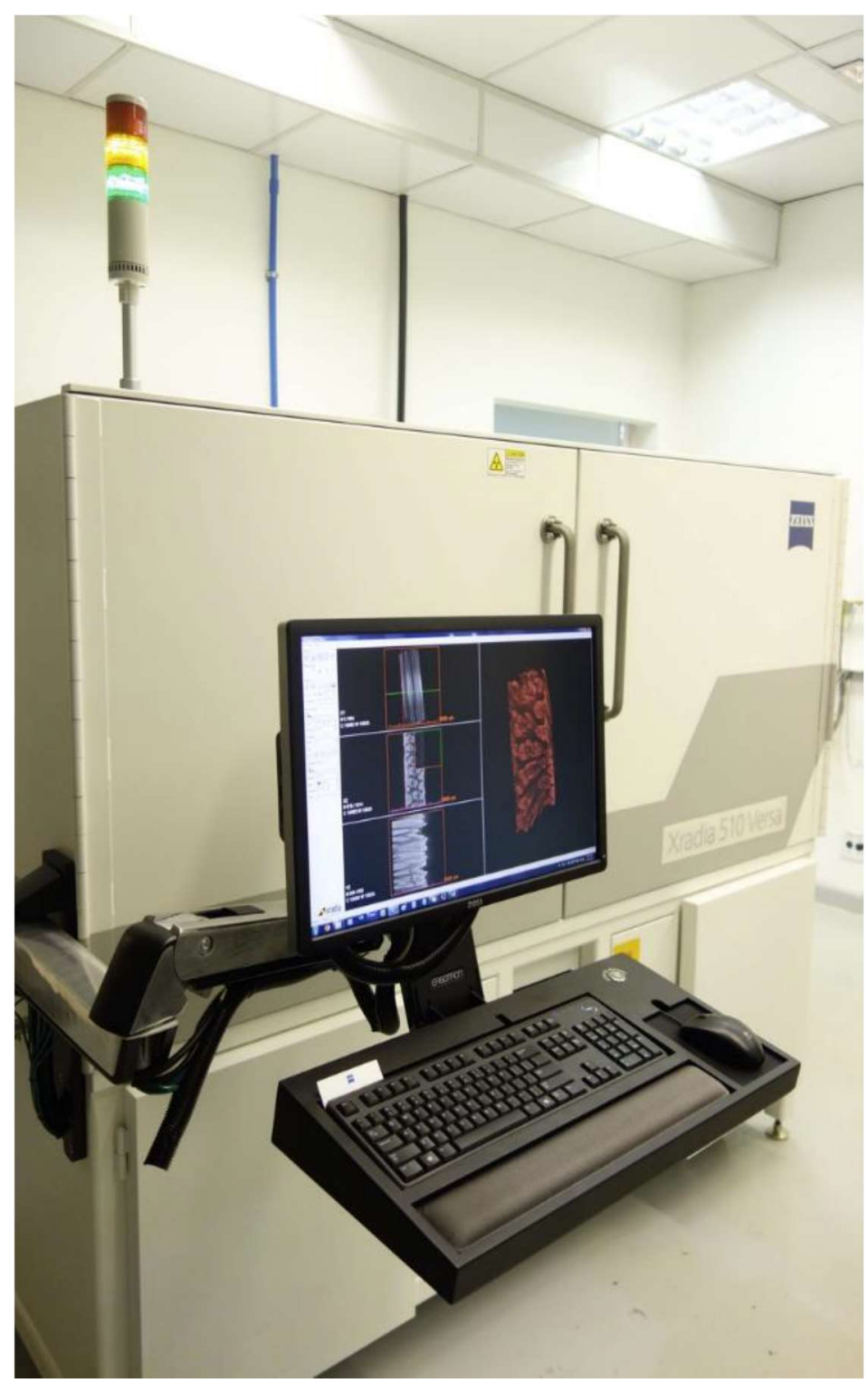

Figura 18 - Visão Externa do microCT Zeiss Xradia Versa 510.

A tabela 3 mostra os parâmetros de aquisição em microCT utilizados. Foram analisadas diferentes resoluções a fim de discutir a influência do pixel size nas medidas de porosidade $-1 \mu \mathrm{m}$ foi a melhor resolução alcançada devido à própria limitação da resolução espacial do microtomógrafo que é $0,7 \mu \mathrm{m}$. Todas as tomografias foram realizadas utilizando a potência máxima do equipamento de 10 W com uma rotação da amostra de $360^{\circ}$. 
Tabela 3 - Condições de aquisição em microCT

\begin{tabular}{|c|c|c|c|c|c|}
\hline Parâmetros & \multicolumn{4}{|c|}{ P1-A } & \multirow{2}{*}{$\frac{\text { P1-B }}{5}$} \\
\hline Análise & 1 & 2 & 3 & 4 & \\
\hline Lente $(\mathrm{X})$ & 0,4 & \multicolumn{3}{|c|}{4} & 0,4 \\
\hline Tensão (kV) & \multicolumn{4}{|c|}{160} & 120 \\
\hline Potência (W) & \multicolumn{5}{|c|}{10} \\
\hline Projeções (№) & \multicolumn{5}{|c|}{1601} \\
\hline $\begin{array}{c}\text { Pixel Size } \\
\text { aproximado }(\mu \mathrm{m})\end{array}$ & 7,6 & 4,0 & 2,0 & 1,0 & 4,0 \\
\hline Filtro & HE3 & \multicolumn{2}{|c|}{ HE5 } & HE6 & HE1 \\
\hline Binning & 1 & 2 & \multicolumn{3}{|c|}{1} \\
\hline Mosaico/Stitching & 0 & \multicolumn{2}{|c|}{4} & 0 & 0 \\
\hline $\begin{array}{c}\text { Tempo de } \\
\text { Exposição (s) }\end{array}$ & 2,6 & 3 & 12 & 32 & 2 \\
\hline $\begin{array}{c}\text { Tempo de } \\
\text { Varredura (h) }\end{array}$ & 2,90 & 8,93 & 27,38 & 16,50 & 3,12 \\
\hline
\end{tabular}

Cada aquisição necessitou de um de filtro apropriado para análise. Esses filtros são utilizados para correção do efeito de endurecimento de feixe (Beam Hardening), que ocorre pela atenuação dos fótons de baixa energia nas bordas da amostra. Com isso, os filtros físicos funcionam absorvendo os raios $\mathrm{X}$ da faixa de menor energia, os quais seriam preferencialmente absorvidos próximo a superfície tornando esta região mais clara que o restante da pelota, antes que incidam sobre a mesma. O uso dos filtros não elimina totalmente o Beam Hardening, tornando necessário uma correção do efeito na etapa de reconstrução.

A escolha do filtro é feita de acordo com o valor da transmissão o qual relaciona a intensidade do sinal de raios $\mathrm{X}$ recebidos pela amostra com seu valor sem a presença da amostra no microCT. O número do filtro é proporcional a espessura do material que o compõe, os de baixa energia (Low Energy - LE) são compostos por óxido de silício $\left(\mathrm{SiO}_{2}\right)$ e os de alta energia (High Energy - HE) são feitos de fluoreto de cálcio $\left(\mathrm{CaF}_{2}\right)$. Porém foram utilizados apenas os do tipo HE, 
porque são filtros mais espessos indicados para análises de materiais densos devido à necessidade de um alto valor de energia para o feixe de raios $\mathrm{X}$.

A pelota P1-B é uma amostra que consiste na oitava parte de uma pelota inteira mantendo seu diâmetro original, como foi especificado anteriormente, e por isso a tensão utilizada na análise foi menor, visto que é uma amostra menos espessa. Uma maior voltagem implica em uma maior percentagem de transmissão dos raios $\mathrm{X}$, portanto o valor de $120 \mathrm{kV}$ foi o suficiente para a realização do procedimento de microCT.

O número de projeções foi pré-estabelecido como 1601. De acordo com trabalhos anteriores (AUGUSTO; PACIORNIK, 2016), a partir de 1600 projeções a qualidade das imagens pouco muda. O número de projeções precisa ser múltiplo de 20 e somado de uma unidade para que seja possível utilizar o modo Adaptive Motion Compensation (AMC) durante a tomografia. Este modo permite que sejam corrigidos desvios da amostra com os eixos, com o detector, com a fonte de raios $\mathrm{X}$ ou qualquer desvio retilíneo que possa ocorrer durante a varredura (ZEISS, 2016). Com isso, 1601 projeções é a quantidade mínima suficiente para uma análise satisfatória visto que o número de projeções influencia no tempo total de análise.

O binning é referente a um processo de agrupamento de pixels. Quanto maior o valor do binning menor a resolução espacial, que por sua vez afeta o valor do pixel size. Em contrapartida, um maior valor de binning melhora a relação sinalruído, reduzindo o tempo de análise.

O mosaico/stitching consiste em várias aquisições com o intuito de cobrir completamente o diâmetro da amostra no sentido vertical. Para as análises apresentadas foram necessárias 4 aquisições (figura 19), o que ocasionou maiores tempos de aquisição. 
(a)
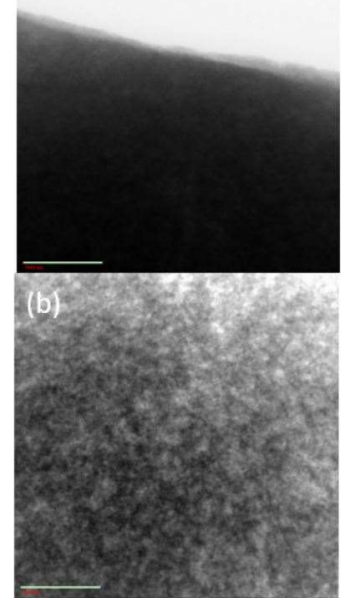

(c)
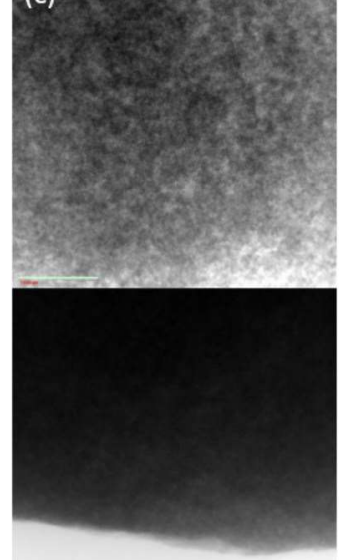

$\underline{1000 \mu \mathrm{m}}$

(e)
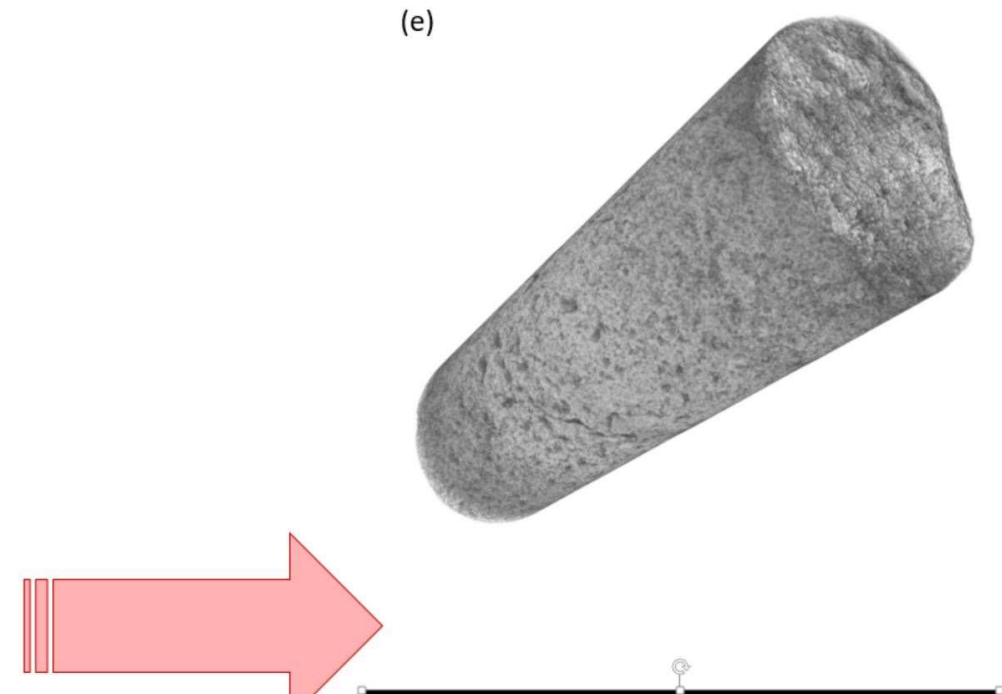

\section{(f)}

Figura $19-a$ ), b), c) e d): Quatro projeções adquiridas em mosaico; e) Representação em 3D; f) Visualização de uma camada em 2D.

As lentes ampliam a visualização e permitem alcançar um menor pixel size, o que implica em uma melhora na resolução espacial porque é possível observar uma menor região da amostra. Em contrapartida, não é possível visualizar a pelota inteira, apenas um subvolume. Para tomografar uma pelota inteira, a melhor resolução foi a de 7,6 $\mu$ m pela limitação do campo alcançado da lente, sendo o valor limítrofe para não perder nenhuma área da pelota e não apresentar o efeito de sombra nas imagens. A configuração geométrica para cada análise pode ser visualizada na tabela 4 . 
Tabela 4 - Configuração geométrica de cada análise

\begin{tabular}{|c|c|c|c|c|}
\hline Análise & Lente & $\begin{array}{c}\text { Resolução } \\
(\boldsymbol{\mu m})\end{array}$ & $\begin{array}{c}\text { Distância fonte- } \\
\text { amostra }(\mathbf{m m})\end{array}$ & $\begin{array}{c}\text { Distância amostra- } \\
\text { detector }(\mathbf{m m})\end{array}$ \\
\hline $\mathbf{1}$ & $0,4 \mathrm{X}$ & 7,6 & $-21,4$ & 76 \\
\hline $\mathbf{2}$ & $4 \mathrm{X}$ & 4 & $-16,8$ & 11,3 \\
\hline $\mathbf{3}$ & $4 \mathrm{X}$ & 2 & $-16,8$ & 11,3 \\
\hline $\mathbf{4}$ & $4 \mathrm{X}$ & 1 & $-16,8$ & 38 \\
\hline $\mathbf{5}$ & $0,4 \mathrm{X}$ & 4 & -14 & 106 \\
\hline
\end{tabular}

\subsection{Processamento Digital de Imagens 3D}

A representação das informações microestruturais da amostra se dá através da imagem digital. Uma imagem 2D pode ser definida como uma função bidimensional, $\mathrm{f}(\mathrm{x}, \mathrm{y})$, onde $\mathrm{f}$ é a intensidade ou nível de cinza no ponto $\mathrm{x}, \mathrm{y}$. No domínio $3 \mathrm{D}$, a representação da amostra é feita por coordenadas $(\mathrm{x}, \mathrm{y}, \mathrm{z})$ que correspondem ao espaço. Neste caso a forma em 3D é na verdade uma sequência de imagens 2D ao longo do eixo espacial z. (GONZALEZ, 2004)

Estas imagens podem ser processadas através de operações matemáticas alterando valores dos pixels da imagem com o intuito de corrigir defeitos e melhorar a visualização das regiões de interesse. Assim, é possível extrair atributos e analisar dados quantitativos seguindo uma sequência padrão de análise e processamento digital que se inicia com a aquisição da imagem e consiste, normalmente, em: Préprocessamento, segmentação, pós-processamento, extração de atributos e classificação.

A aquisição da imagem foi realizada através do microCT, convertendo um objeto real tridimensional em uma imagem digital, como foi detalhado anteriormente.

Para a etapa de pré-processamento geralmente utilizam-se filtros para a redução de ruídos inerentes às imagens de microCT, bem como para a correção de outros defeitos como irregularidades de fundo. 
$\mathrm{Na}$ segmentação, ocorre a divisão da imagem em partes ou objetos constituintes. É uma das etapas mais importantes e difíceis pois influencia diretamente no sucesso ou não do processamento e do respectivo reconhecimento dos objetos. Neste trabalho a segmentação é feita para separar a imagem em objetos de interesse (branco) e fundo (preto), formando uma imagem binária e na qual fazse as medidas necessárias.

A imagem resultante da segmentação ainda pode apresentar problemas e com isso a etapa de pós-processamento é importante para detectar e corrigir os possíveis defeitos restantes.

Após a etapa de pós-processamento, a imagem finalmente segue para a etapa de extração de atributos na qual são obtidos os dados quantitativos de interesse. Nela é possível entender e avaliar os dados numéricos provenientes da imagem e posteriormente, inclusive, podendo seguir para uma etapa de classificação e reconhecimento de padrões, porém esta última não se encontra nos objetivos deste trabalho.

As etapas de processamento e de análise das imagens digitais deste trabalho foram realizadas com o auxílio do Software Dragonfly Pro desenvolvido pela Object Research Systems (ORS, 2004a) para a inspeção intuitiva de dados de imagens de diversos tipos. Os avançados recursos de imagens 3D oferecem ferramentas para pesquisa e exploração em múltiplas escalas e dimensões para o entendimento das estruturas e propriedades dos mais diferentes tipos de materiais como pode ser visualizado na figura 20 . 


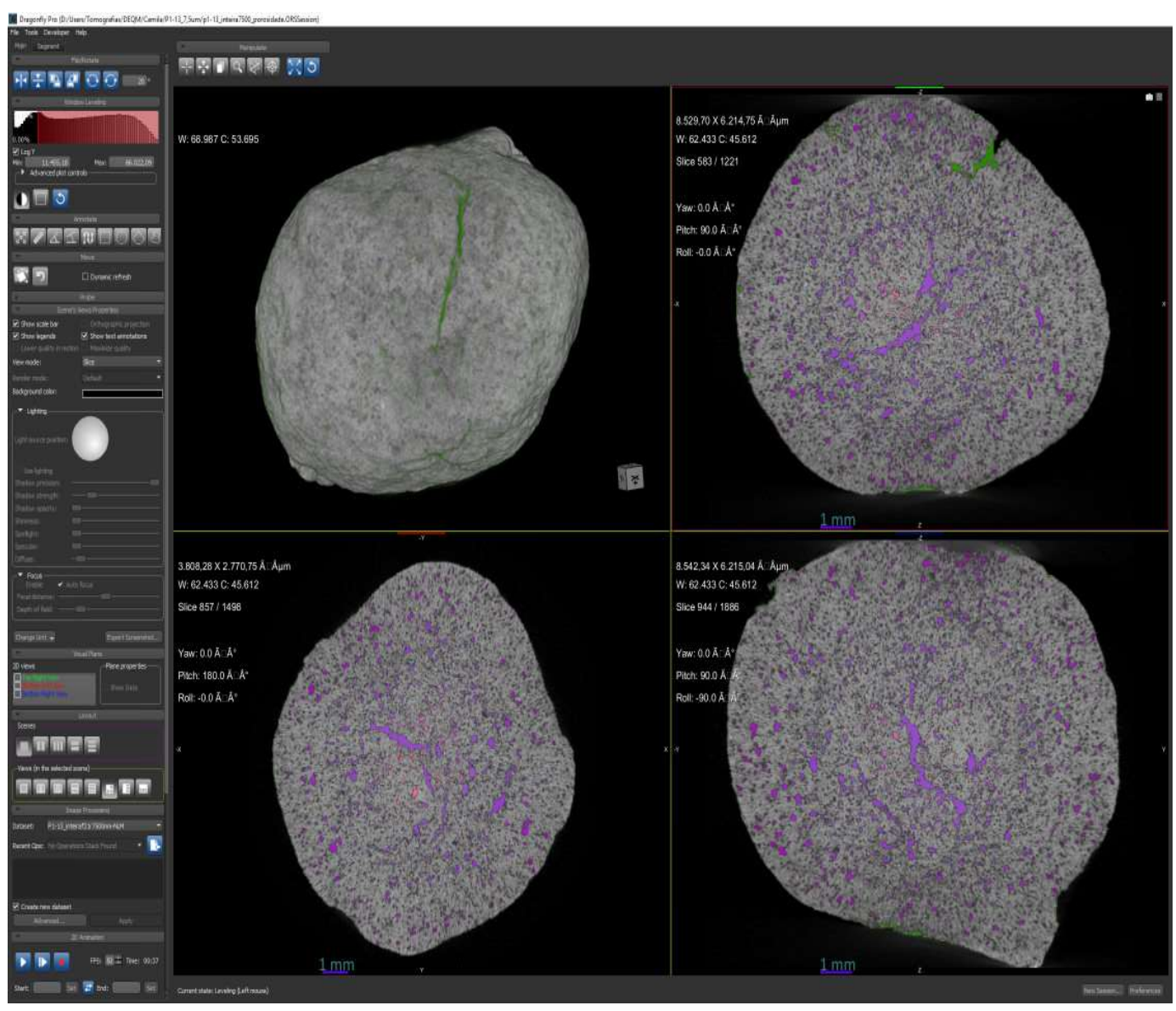

Figura 20 - Interface gráfica do Dragonfly.

\subsubsection{Visualização}

O software Dragonfly possui diversas ferramentas para auxiliar na visualização que facilitam o processamento digital das imagens. É possível identificar os diferentes planos da amostra dividindo o espaço de trabalho em várias cenas, cada uma representando um eixo (figura 21). Esse modo de exibição facilita a interpretação das imagens, visto que trabalhar com imagens tridimensionais normalmente provoca dificuldades de entendimento no usuário. 


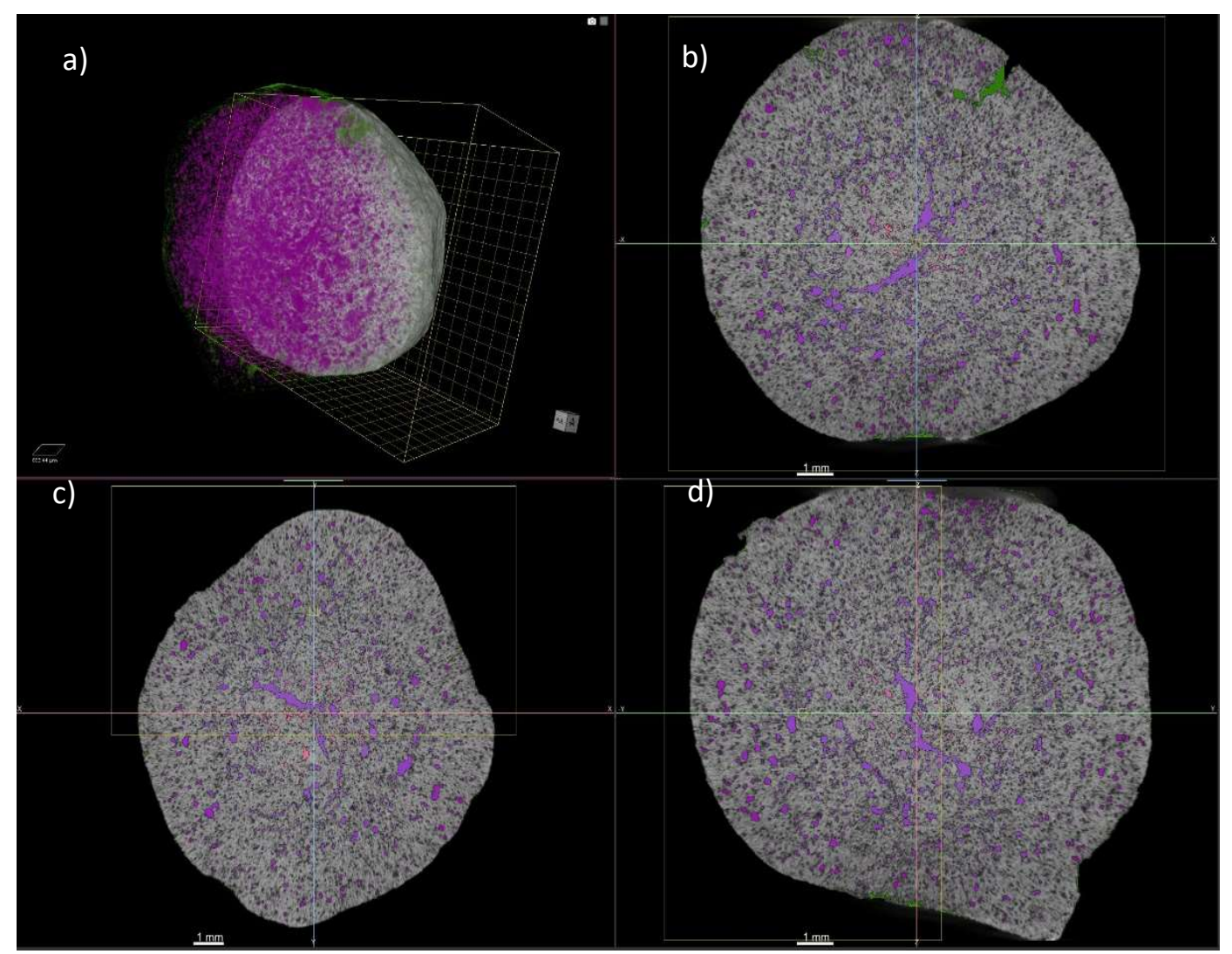

Figura 21 - a) Pelota em 3D; b) Plano xz; c) Plano xy; d) Plano yz.

As visões em 2D permitem avaliar dados de imagem como objetos e regiões de interesses, malhas (meshes), além de poder apresentar anotações de texto, barra de escala, legendas. Em 3D também é possível visualizar os mesmos dados de imagem que aparecem nas visões $2 \mathrm{D}$ e relacionar como de fato estes dados são em três dimensões.

\subsubsection{Filtragem de Ruído}

As imagens provenientes das análises de microCT são comumente ruidosas, estes ruídos estão relacionados principalmente com: o número de fótons detectados, o tamanho da matriz de aquisição, a espessura de corte tomográfico, o algoritmo de reconstrução utilizado, o sistema eletrônico de detecção, a radiação espalhada e o tamanho do objeto adquirido (HOFFMANN, 2011). Os ruídos aparecem na imagem como um fundo granuloso, sendo assim necessária uma etapa de filtragem para reduzi-los, visto que dificultam a segmentação das fases. Os filtros normalmente calculam uma estimativa do valor do pixel sem ruído como uma média ponderada dos pixels de uma vizinhança local. Na maioria dos casos, ao eliminar ruído de alta 
frequência, estes filtros também borram a imagem, reduzindo a definição das bordas dos objetos.

O algoritmo de médias não-locais, "Non Local Means" (NLM), propõe que este cálculo de estimativa seja feito a partir de uma média ponderada utilizando partes distintas da imagem e não apenas local como é feito normalmente. A técnica NLM é considerada como uma das ferramentas mais inovadoras e eficientes para a filtragem dos ruídos em imagens digitais, preservando as bordas dos objetos (BUADES; COLL; A, 2005).

Matematicamente, o valor estimado da imagem sem ruído [NL[v](i)] pode ser calculado através da equação a seguir:

$$
N L[v](i)=\sum_{j \epsilon I} w(i, j) v(j)
$$

onde $v=\{v(i) \mid i \in I\}$, e representa a imagem ruidosa, $\{w(i, j)\}_{j}$ são os pesos que dependem da similaridade entre as diferentes regiões da imagem e satisfazem as condições: $0 \leq w(i, j) \leq 1$ e $\sum_{j} w(i, j)=1$.

A similaridade entre dois pixels $\mathrm{i}$ e $\mathrm{j}$ pode ser calculada através de uma função decrescente da distância Euclidiana entre os vetores $v\left(\mathrm{~N}_{\mathrm{i}}\right)$ e $\mathrm{v}\left(\mathrm{N}_{\mathrm{j}}\right)$, onde $\mathrm{N}_{\mathrm{k}}$ denota uma vizinhança fixa centrada no pixel $\mathrm{k}$, assim:

$$
w(i, j)=\frac{1}{Z(i)} e^{\frac{-\left\|v\left(N_{i}\right)-v\left(N_{j}\right)\right\|_{2, a}^{2}}{h^{2}}}
$$

onde,

$$
Z(i)=\sum_{j} e^{\frac{-\left\|v\left(N_{i}\right)-v\left(N_{j}\right)\right\|^{2}}{h^{2}}}
$$

$\mathrm{O}$ parâmetro $\mathrm{h}^{2}$ atua no decaimento da função exponencial da equação 6 e seu valor é proporcional à quantidade de ruído que é filtrado, o que permite controlar o impacto do filtro. Porém, valores elevados tendem a tornar a imagem borrada, podendo ocasionar a perda de informações e detalhes (NUNES et al., 2014).

A figura 22 a seguir mostra que com a aplicação do filtro Non Local Means através do software Fiji/ImageJ (Fiji/ImageJ, 2009), é possível obter uma melhor distinção entre as fases, podendo ser confirmada por seus respectivos histogramas. 
Os picos do histograma da imagem filtrada (b) são mais bem definidos do que a imagem original ruidosa (a), facilitando assim a etapa de segmentação.
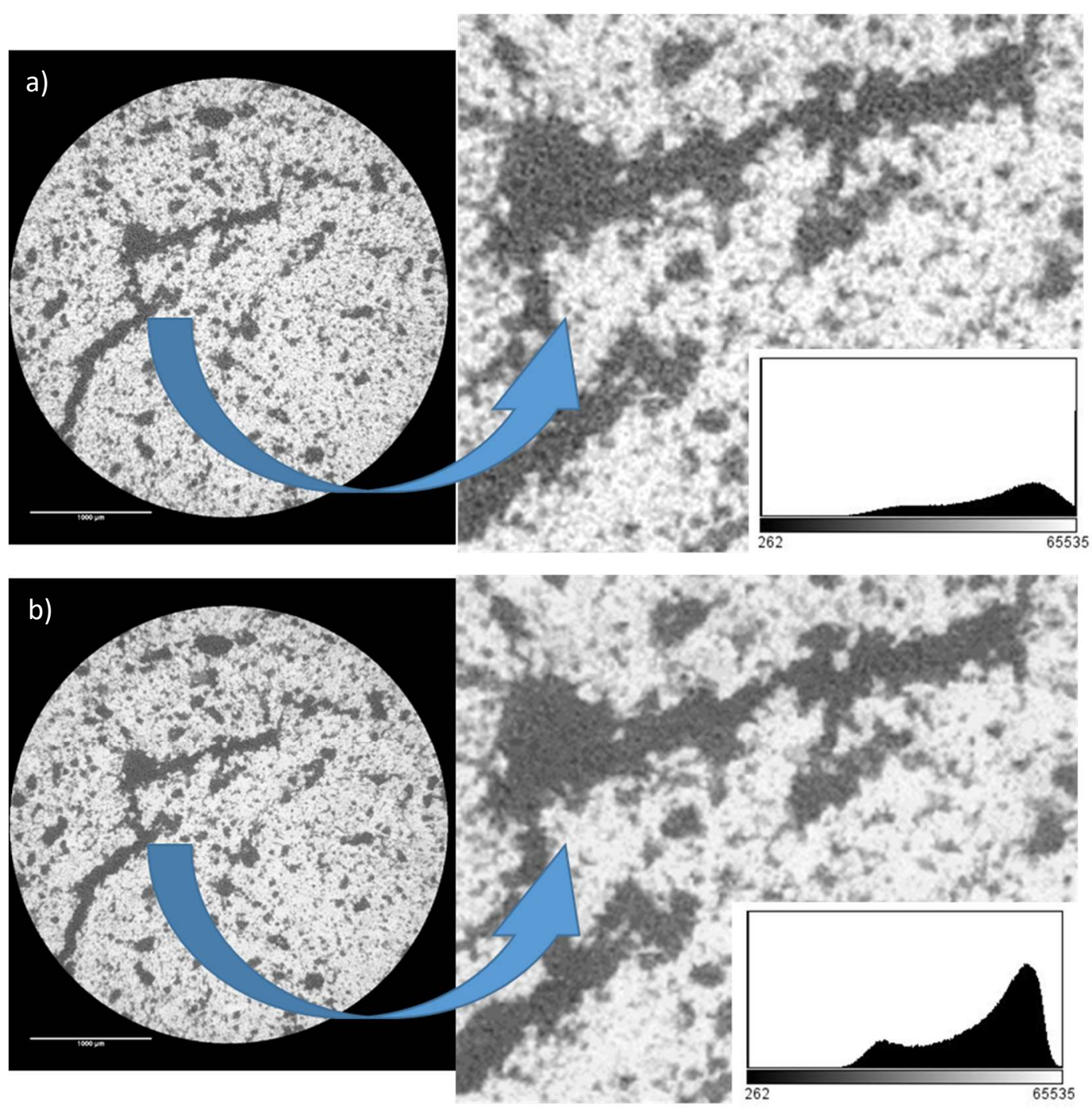

Figura 22 - (a) Imagem original ruidosa; (b) Imagem após aplicação do filtro Non-Local Means.

\subsubsection{Segmentação de Poros}

A segmentação dos poros foi feita com o auxílio do software livre FIJI/ImageJ. Foi determinado visualmente um limite inferior onde alguns poros não são selecionados, e um limite superior, onde os poros que não foram preenchidos anteriormente passam a serem selecionados, porém também começa a ocorrer a segmentação de resíduo da parte sólida, sendo esse limiar (máximo ou mínimo) fixo para todas as camadas das amostras. A determinação do limiar é importante pois causa grande impacto na obtenção da percentagem de porosidade das pelotas de 
minério de ferro. A figura 23 mostra uma região ampliada da amostra, considerando o valor de corte máximo como 135 e o valor mínimo de 115 para a amostra.
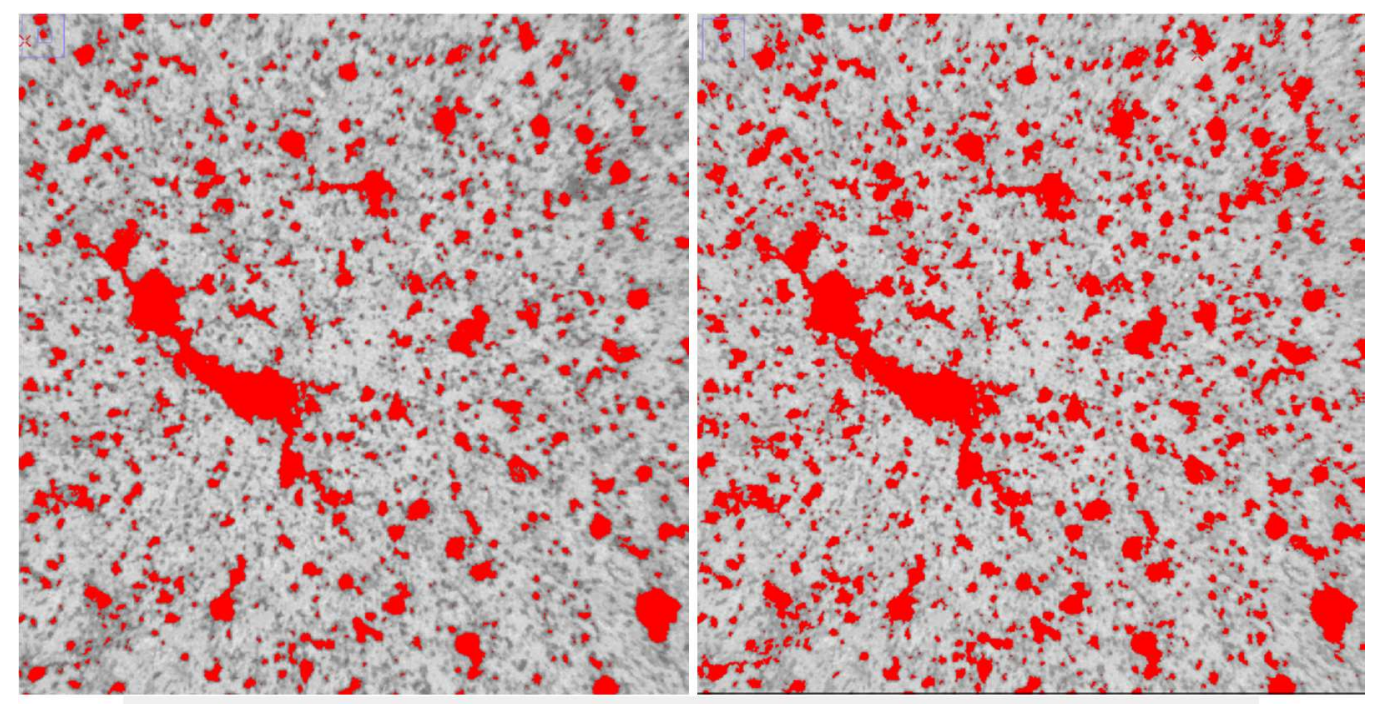

a)
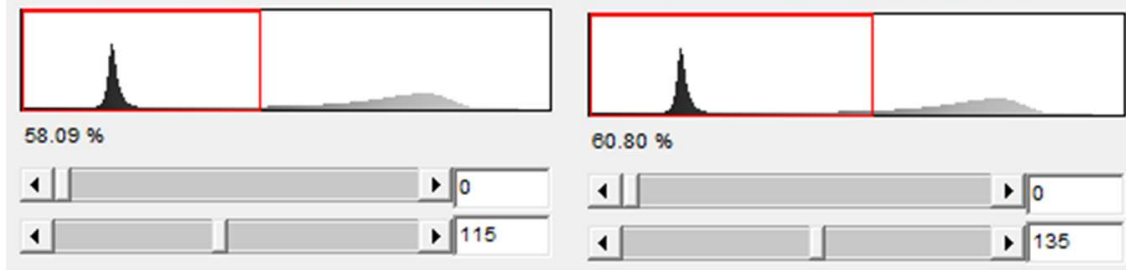

b)

Figura 23 - (a) Segmentação com limiar =115; (b) Segmentação com limiar = 135.

Neste caso, o valor de porosidade variou entre 7,91 e 13,77\%. Esta variação mostra que a definição do tom de corte influencia substancialmente no valor percentual da porosidade, e por isso esta etapa se torna a mais difícil e importante do trabalho. Uma solução para isso seria a aplicação de um teste de sensibilidade variando continuamente o valor do limiar, para verificar se há um certo comportamento indicando o melhor valor de corte para a segmentação. No entanto, dado grande tempo envolvido no processamento das imagens $3 \mathrm{D}$, às vezes da ordem de 24 a 48 horas, este tipo de teste de sensibilidade não foi realizado neste trabalho.

Assim é possível obter uma imagem binária resultante da segmentação (figura 24), possibilitando a visualização da porosidade total da pelota (figura 25). 


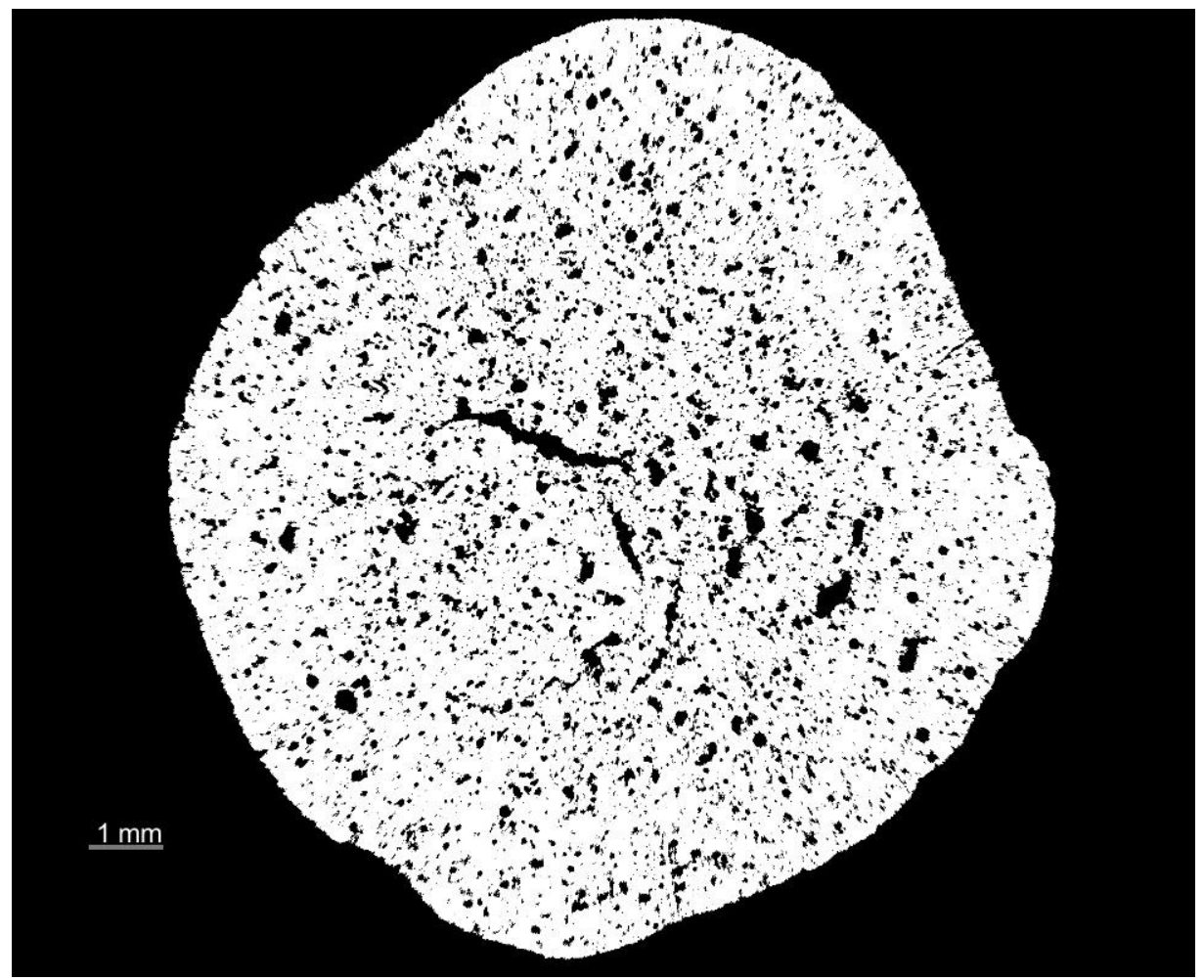

Figura 24 - Imagem binária, segmentação da fase sólida com tom de corte de 135.

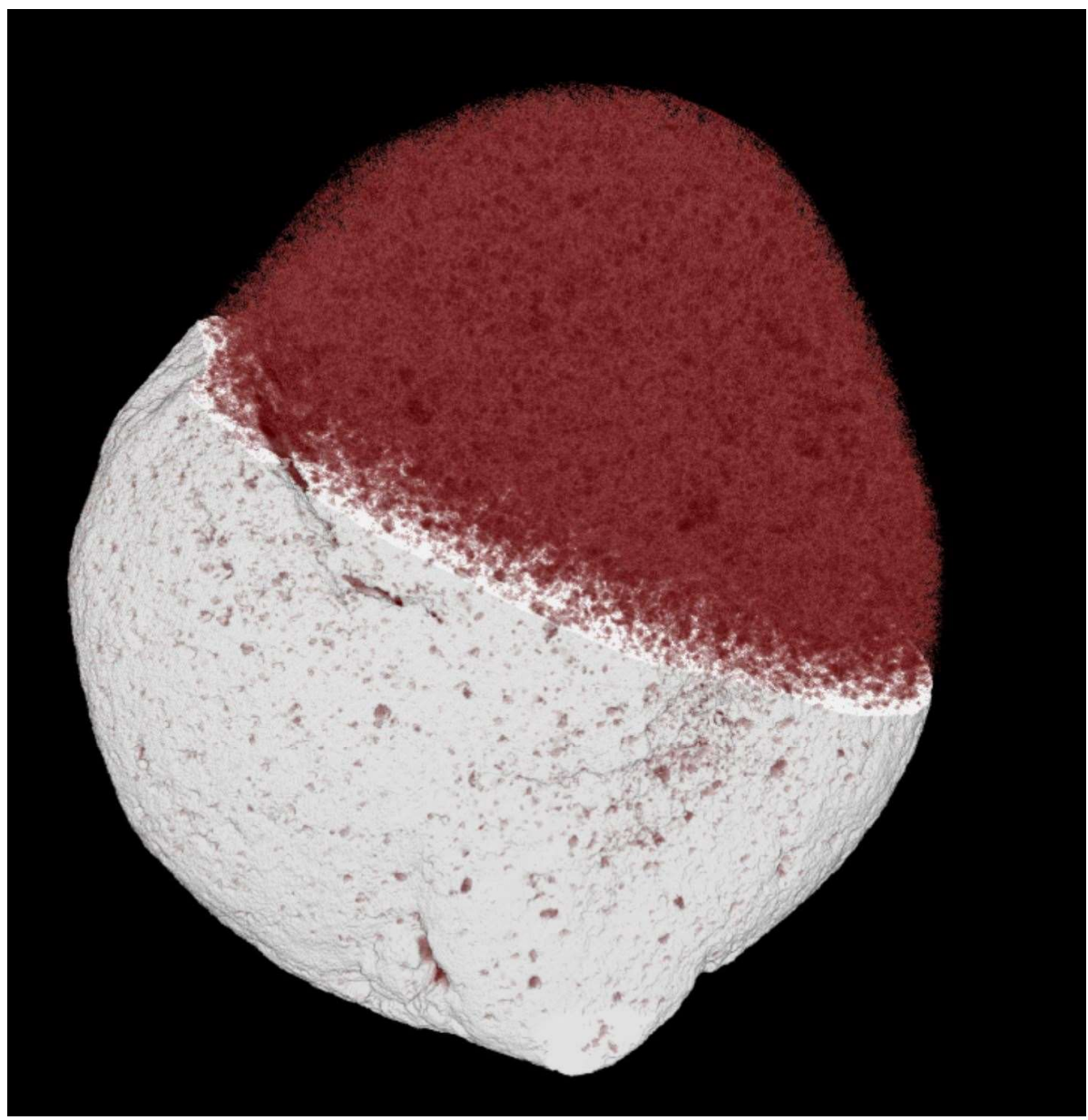

Figura 25 - Volume de poros da pelota inteira. 


\subsubsection{Separação de Porosidade Aberta e Fechada}

Para distinguir porosidade aberta de fechada, utilizou-se operações morfológicas como recurso e testou-se algumas funções do software Dragonfly.

\subsubsection{Operação Morfológica Close ou Fechamento}

Os operadores morfológicos podem ser aplicados para aumentar ou diminuir regiões de imagem, bem como para remover ou preencher pixels de contorno.

Dilatação e erosão são operadores básicos na área da morfologia matemática. O efeito básico da dilatação em uma imagem é ampliar gradualmente os limites de regiões de pixels de primeiro plano, geralmente pixels brancos. A dilatação pode ser usada para detecção de bordas, dilatando uma imagem e, em seguida, subtraindo a imagem original, realçando apenas os novos pixels nas bordas dos objetos que foram adicionados pela dilatação. Da mesma forma, a erosão também pode ser usada para detecção de bordas, erodindo a imagem e subtraindoa da imagem original. Isso realçará apenas os pixels nas bordas dos objetos que foram removidos pela erosão.

O fechamento pode ser definido simplesmente como uma dilatação seguida por uma erosão. $\mathrm{O}$ fechamento é similar em alguns aspectos à dilatação na medida em que tende a ampliar os limites das regiões de primeiro plano (brilhantes) em uma imagem e preenche pequenos buracos de fundo. No entanto, muitas vezes é menos destrutivo da forma limite original. Como com outros operadores morfológicos, a operação exata é determinada por um elemento estruturante. $\mathrm{O}$ efeito do operador é preservar as regiões de segundo plano que possuem uma forma semelhante a esse elemento estruturante, ou que pode conter completamente o elemento estruturante, enquanto elimina todas as outras regiões de pixels de fundo (ORS, 2004b).

$\mathrm{O}$ efeito de fechamento usando um elemento estruturante de $3 \times 3$ pixels em uma imagem binária é mostrado na ilustração a seguir. 

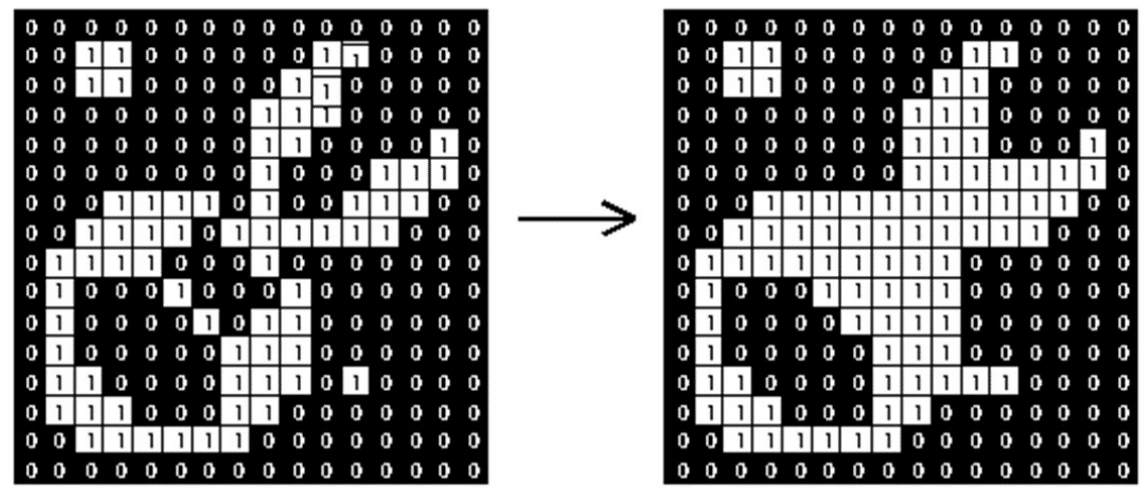

Figura 26 - Efeito do fechamento em uma imagem binária (RIVEST; SOILLE; BEUCHER, 1992).

Com aplicação desta operação é possível delimitar melhor as bordas da pelota. A eficiência da operação dependerá do tamanho do elemento estruturante utilizado. Com isso, seguindo as etapas de processamento, consegue-se atingir o objetivo de diferenciar os poros abertos de poros fechados.

\subsubsection{Mapa de Distâncias Euclidianas (MDE)}

O MDE é outro tipo de operação morfológica realizada sobre uma imagem binária, que tem como resultado uma imagem com intensidade dos pixels da imagem de saída proporcional à distância do pixel até a borda do objeto da imagem de entrada (PACIORNIK, 2018). Neste trabalho, foi utilizado esse conceito para possibilitar a distinção entre poros fechados de abertos. Para utilizar o MDE no software Dragonfly é preciso primeiro obter a ROI (Region Of Interest) do sólido preenchido (figura 27), e em seguida invertê-la para que o programa consiga calcular o mapa de distâncias (figura 28). 


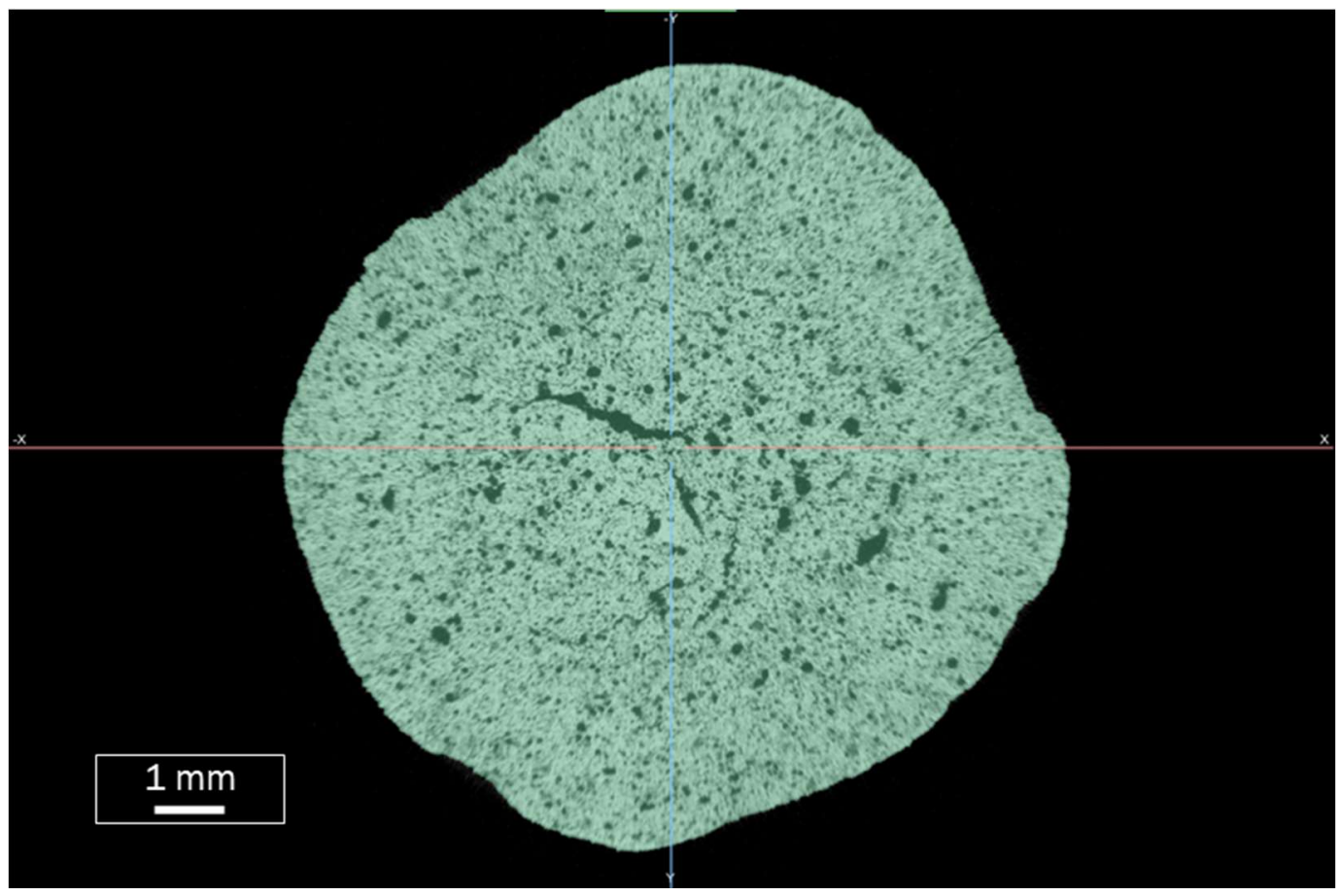

Figura 27 - ROI do sólido preenchido.

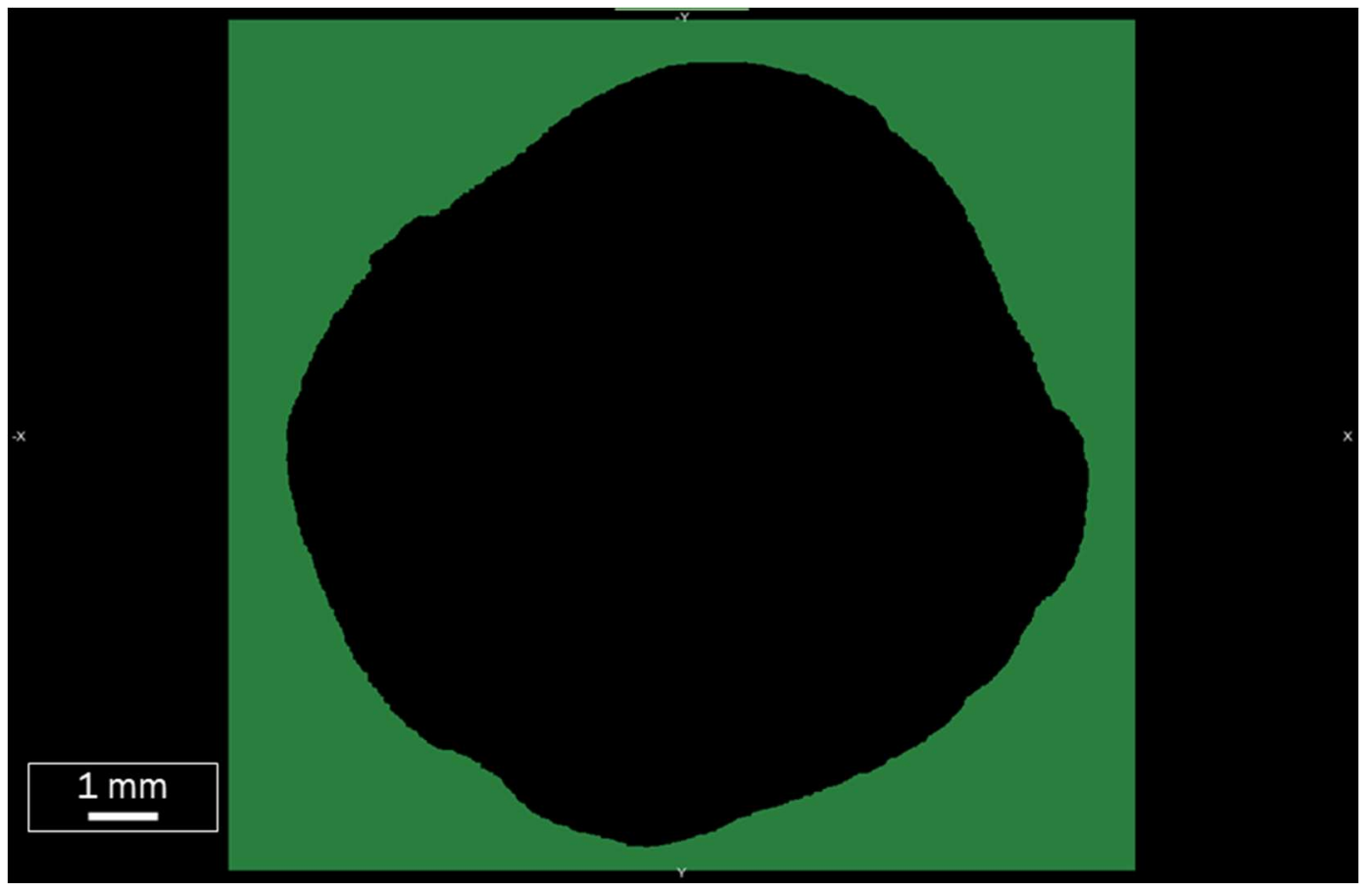

Figura 28 - Inversão da ROI do sólido preenchido.

Em seguida, faz-se uma combinação dos poros segmentados com o MDE de maneira que haja uma sobreposição dos poros no mapa. Com isso, mede-se a intensidade dos pixels do MDE (figura 29) em cada poro e escolhe-se a mínima intensidade, construindo assim um gráfico de intensidades mínimas de cada poro (figura 30). Tendo em vista que a intensidade mínima de um poro próximo a borda 
ainda será menor que a intensidade mínima de um poro no centro da imagem, é possível concluir que os menores valores estão associados aos poros abertos, já que este tipo de poro está em contato com o fundo e, portanto, terá tonalidade baixa no mapa de distâncias.

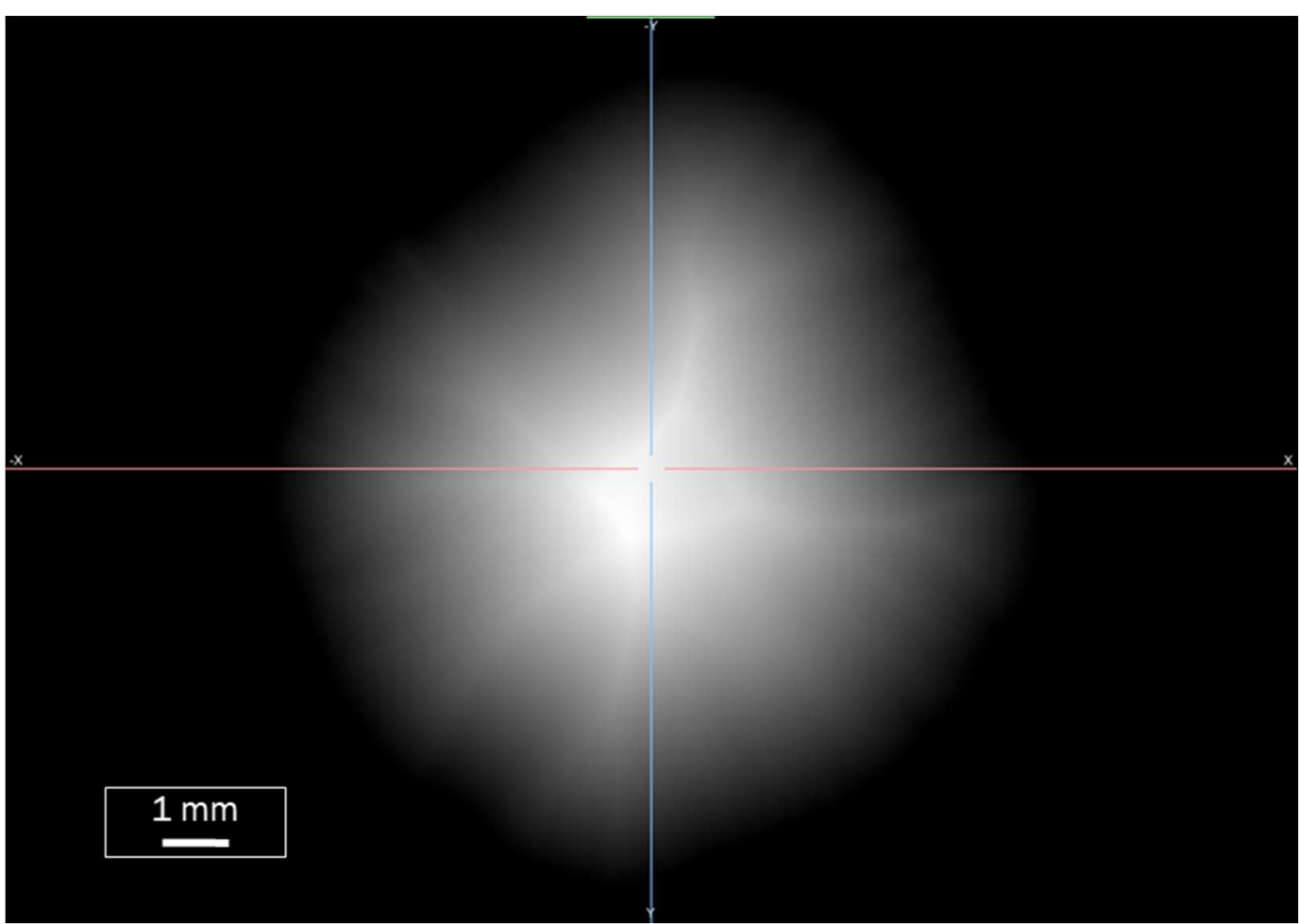

Figura 29 - Mapa de Distâncias Euclidianas (MDE).

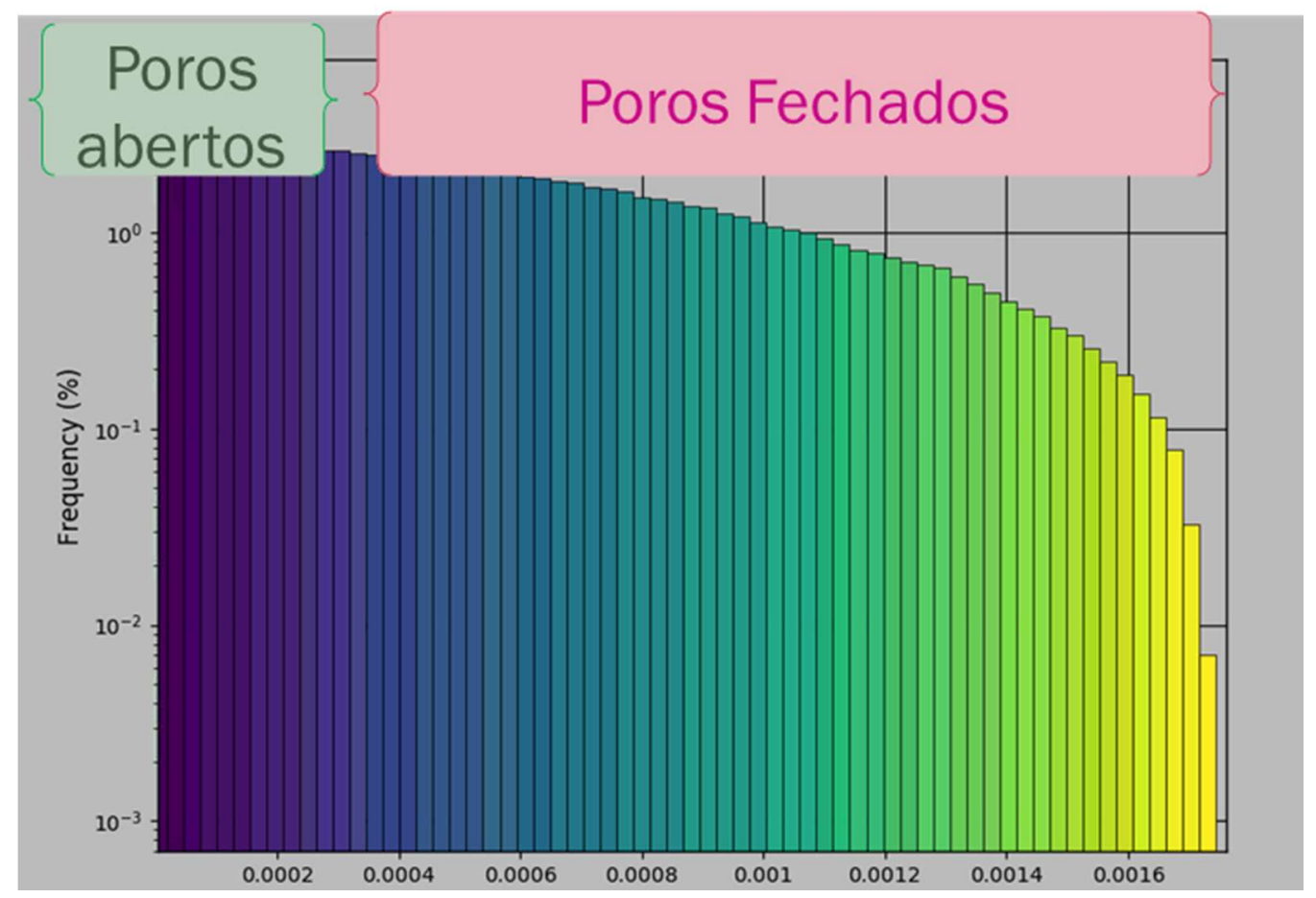

Figura 30 - Distribuição de intensidades mínimas do mapa de distâncias para os poros. 
Uma limitação deste método, observada ao longo dos experimentos, é saber qual o limite de valores para começar a considerar os poros como sendo fechados sendo interessante um possível teste de sensibilidade para determinar o melhor valor para distinguir poros abertos de fechados no gráfico de intensidade mínima. Mais detalhes sobre a aplicação e sobre os resultados obtidos serão discutidos nos capítulos posteriores.

\subsubsection{Medidas}

A extração dos atributos e a visualização dos modelos 3D foram feitas através do software Dragonfly. As medidas de interesse deste trabalho são: o volume percentual total de porosidade; a distribuição de tamanho dos poros; a distribuição de forma (esfericidade) de cada análise; medição e distinção de porosidade aberta e fechada. Estas medidas foram comparadas entre os diferentes tipos de aquisição a fim de entender o impacto da resolução e do tipo de região estudada nos dados quantitativos, os resultados obtidos serão detalhados no capítulo 5 a seguir.

A fim de obter as medidas de porosidade é feita uma segmentação da fase sólida, seguida pelo preenchimento dos poros através da função fill inner areas em todas as direções, com o auxílio da operação close para garantir que os poros das bordas sejam incluídos. Esta operação permite que os poros abertos sejam preenchidos possibilitando uma melhor delimitação da borda da pelota como foi explicado na sessão 4.3.4.1, a diferença pode ser visualizada através das áreas marcadas na figura 31 e na ampliação (figura 32) em uma das regiões na figura seguinte, nas quais em vermelho aparecem os poros sem a utilização do fechamento (close) e em laranja os poros com o uso do fechamento utilizando kernel 13. 

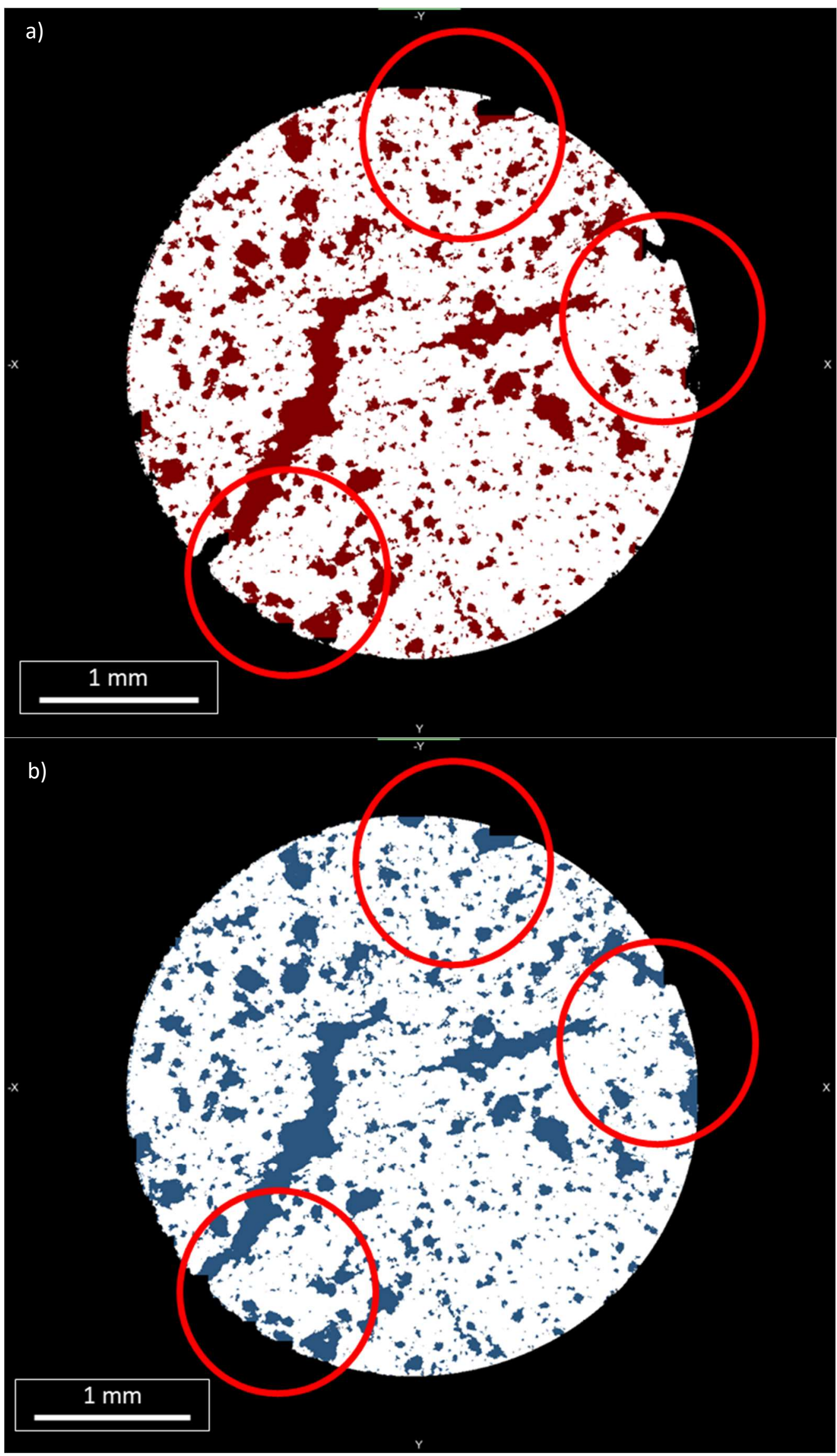

Figura 31 - Diferença do comportamento dos poros abertos em: a) sem uso do close (vermelho); b) com uso do close com kernel de 13 voxels (azul). 


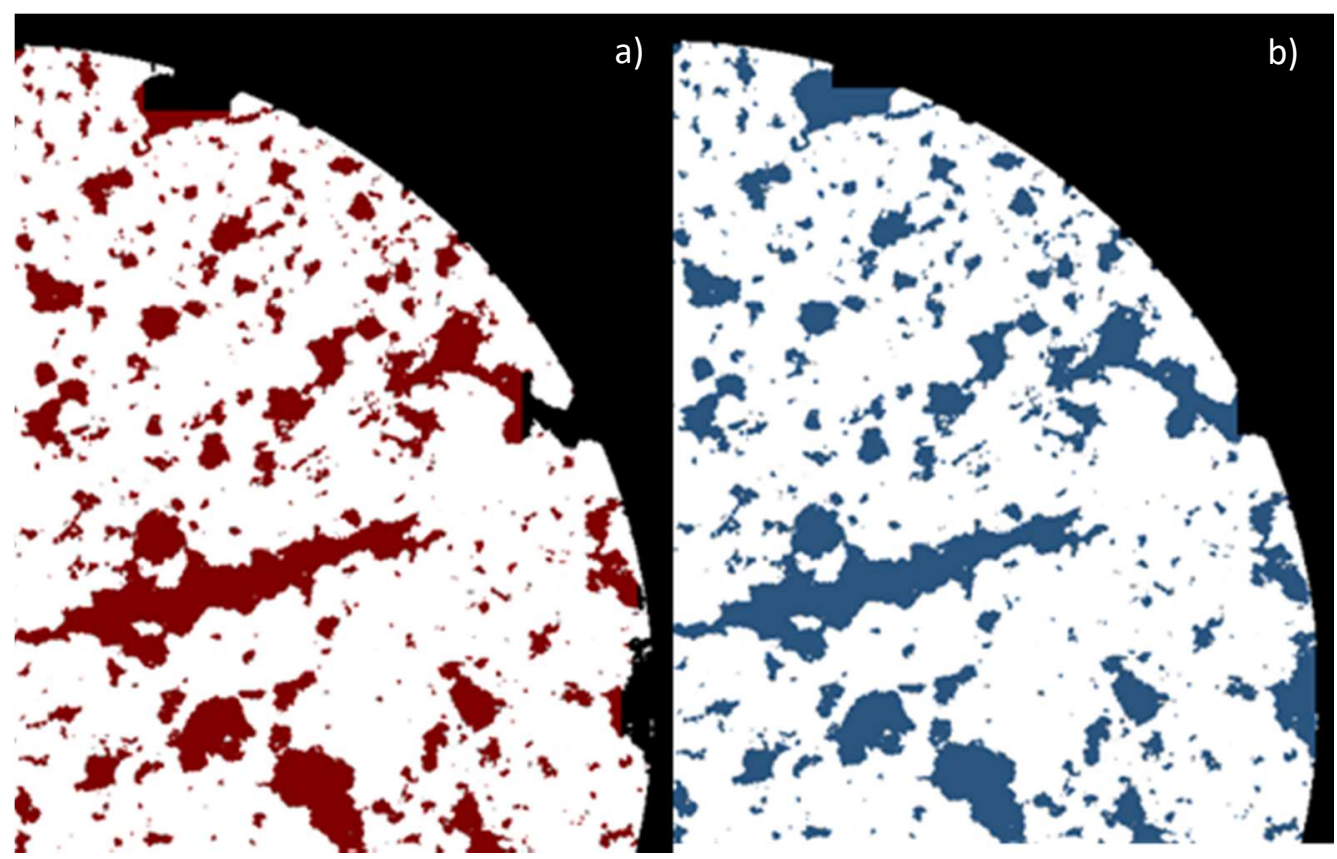

Figura 32 - Ampliação de uma das regiões com diferença do comportamento dos poros abertos em: a) sem uso do close (vermelho); b) com uso do close (azul).

Assim, duas ROIs são obtidas e os poros podem ser visualizados na ROI de subtração do sólido preenchido (A) com o sólido (B), como pode ser visualizado nas figuras 33 e 34 abaixo.

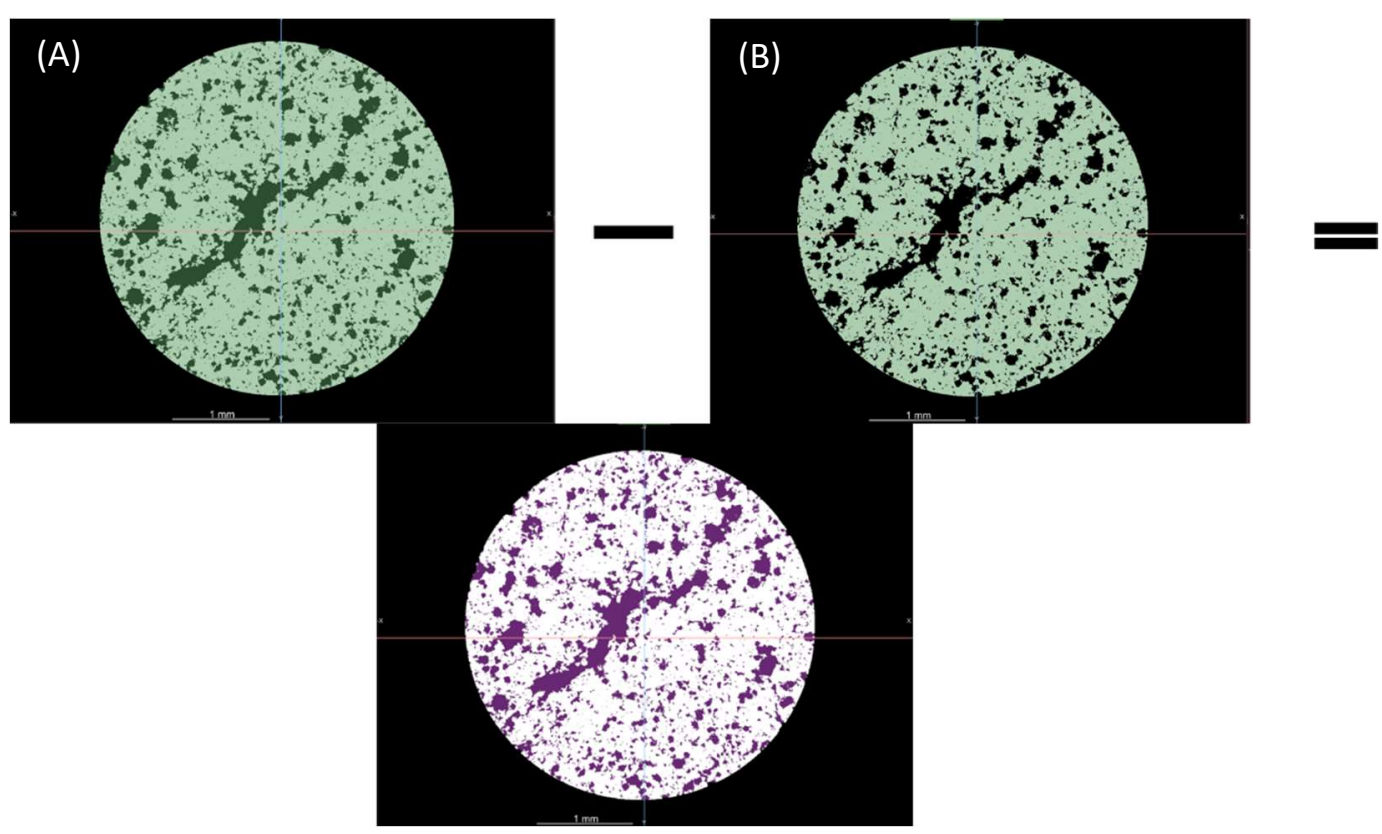

Figura 33 - Subtração entre as ROls A e B para obtenção da ROI referente aos poros. 


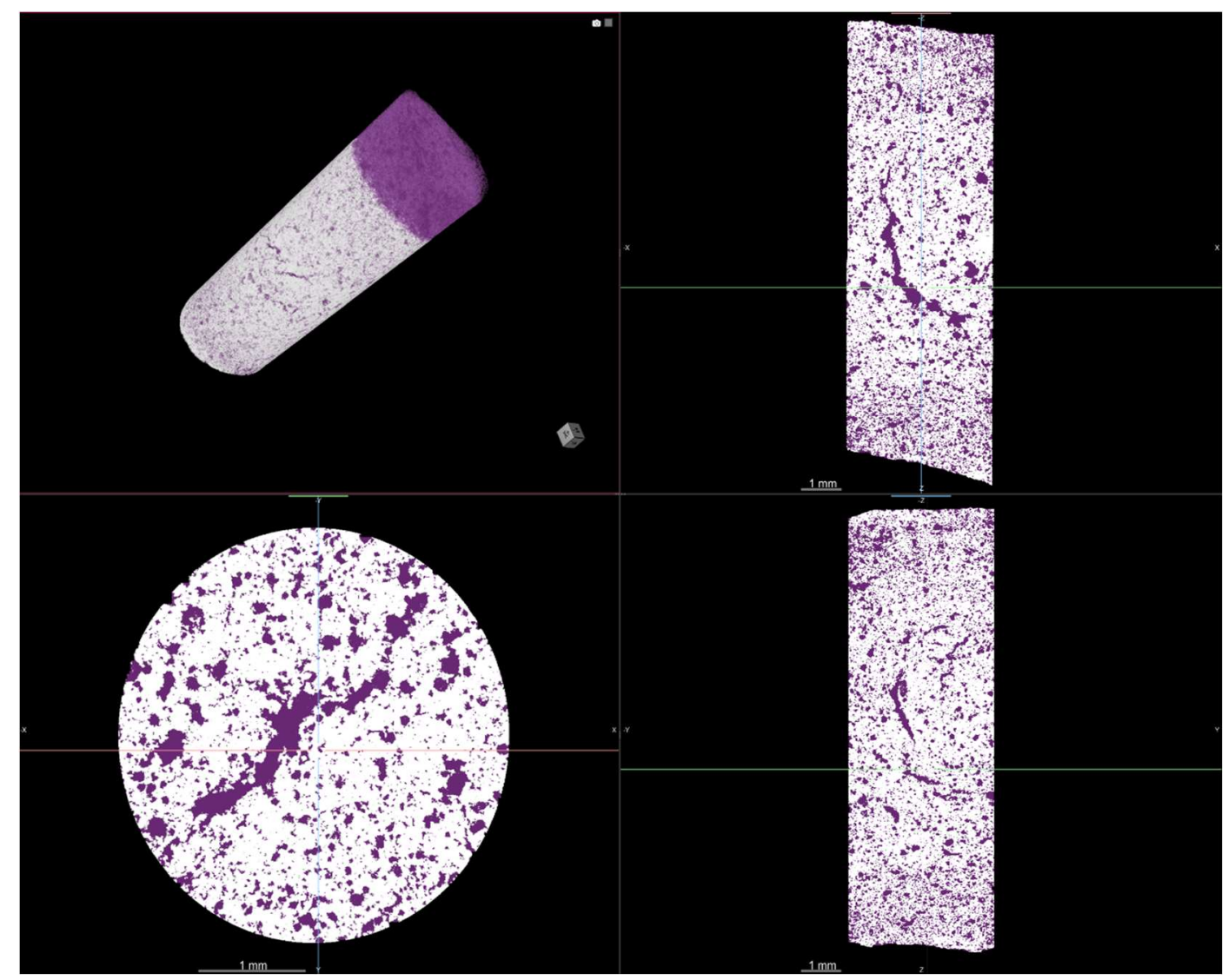

Figura 34-ROI referente aos Poros.

\subsection{Sequência de Processamento e Análise de Imagens}

O fluxograma da figura 35 a seguir sintetiza a sequência de processamento e análise de imagens utilizada nas pelotas de minério de ferro. 


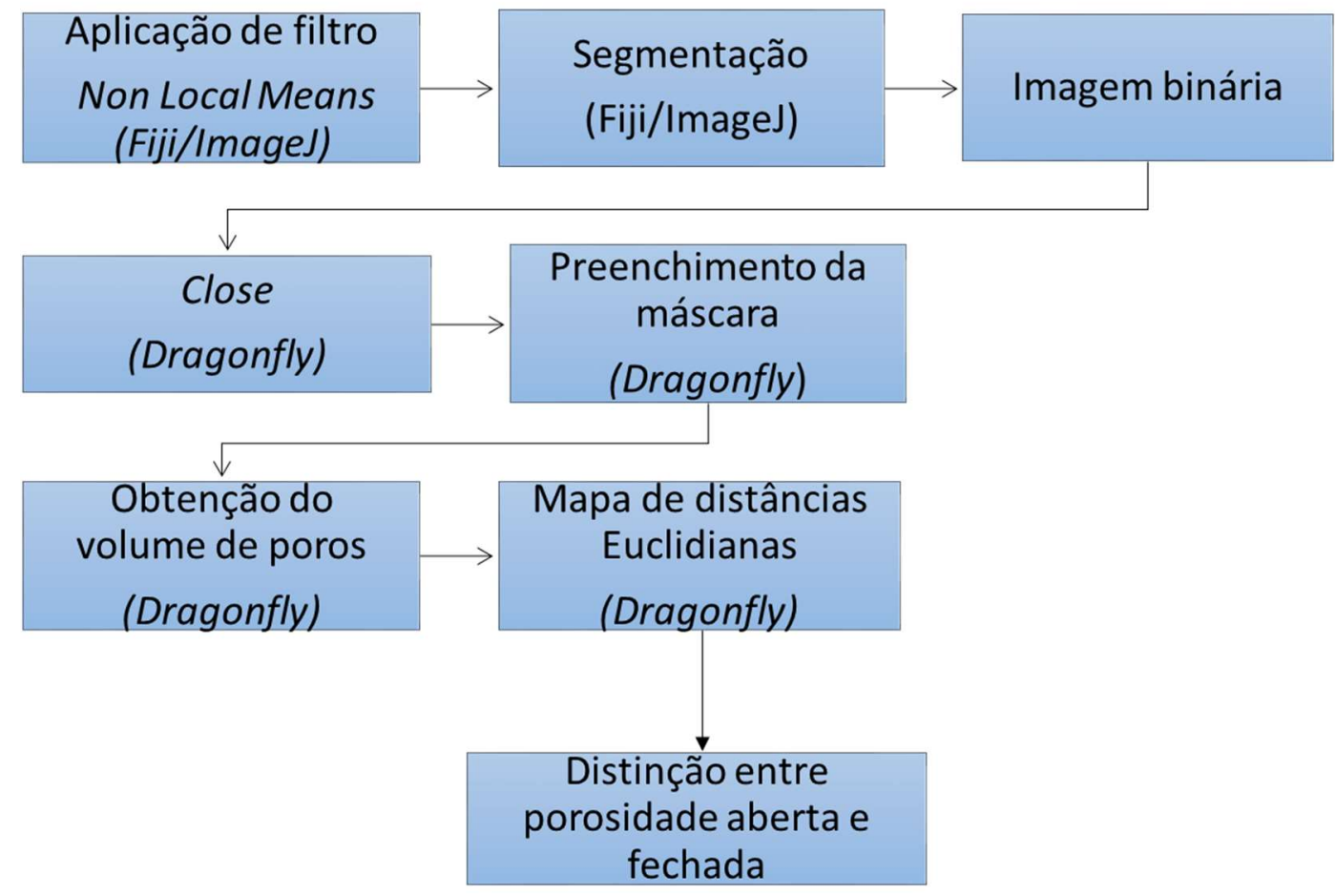

Figura 35 - Fluxograma do processamento das imagens. 


\section{5 \\ Resultados e Discussão}

\subsection{Influência da Resolução}

A fim de compreender como a resolução tomográfica influencia nas medidas de porosidade, foram obtidas diferentes tomografias como detalhado anteriormente no capítulo 4 .

\subsubsection{Comparação Visual}

A melhoria nos valores de resolução proporciona um melhor entendimento do comportamento da porosidade, é possível visualizar poros menores em $1 \mu \mathrm{m}, 2$ $\mu \mathrm{m}$ e $4 \mu \mathrm{m}$ que não são percebidos em 7,6 $\mu \mathrm{m}$. Porém, à medida que a resolução é otimizada, é necessário um maior tempo de exposição para cada projeção o que aumenta o tempo total de aquisição das tomografias. Ademais, a qualidade da imagem que está relacionada à intensidade da fonte de raios $\mathrm{X}$, ou seja, para alcançar uma melhor resolução há necessariamente uma perda no sinal devido as distâncias do sistema fonte $\mathrm{x}$ detector e com isso, o tempo de exposição precisa ser maior. Na tomografia de $1 \mu \mathrm{m}$, por exemplo, foi utilizado um sinal baixo para que a análise fosse feita com o menor tempo possível, o que tornou as imagens ruidosas. A fim de comparar as resoluções e os volumes obtidos nas diferentes condições de aquisição deste trabalho, esta seção apresenta as imagens referentes a cada tipo de análise.

A figura 36 mostra a análise 1 descrita na tabela 3. Foi possível obter a pelota P1-A completa, com uma resolução máxima aproximada de 7,6 $\mu \mathrm{m}$ e tempo total de aquisição de 2 horas e 54 minutos. 

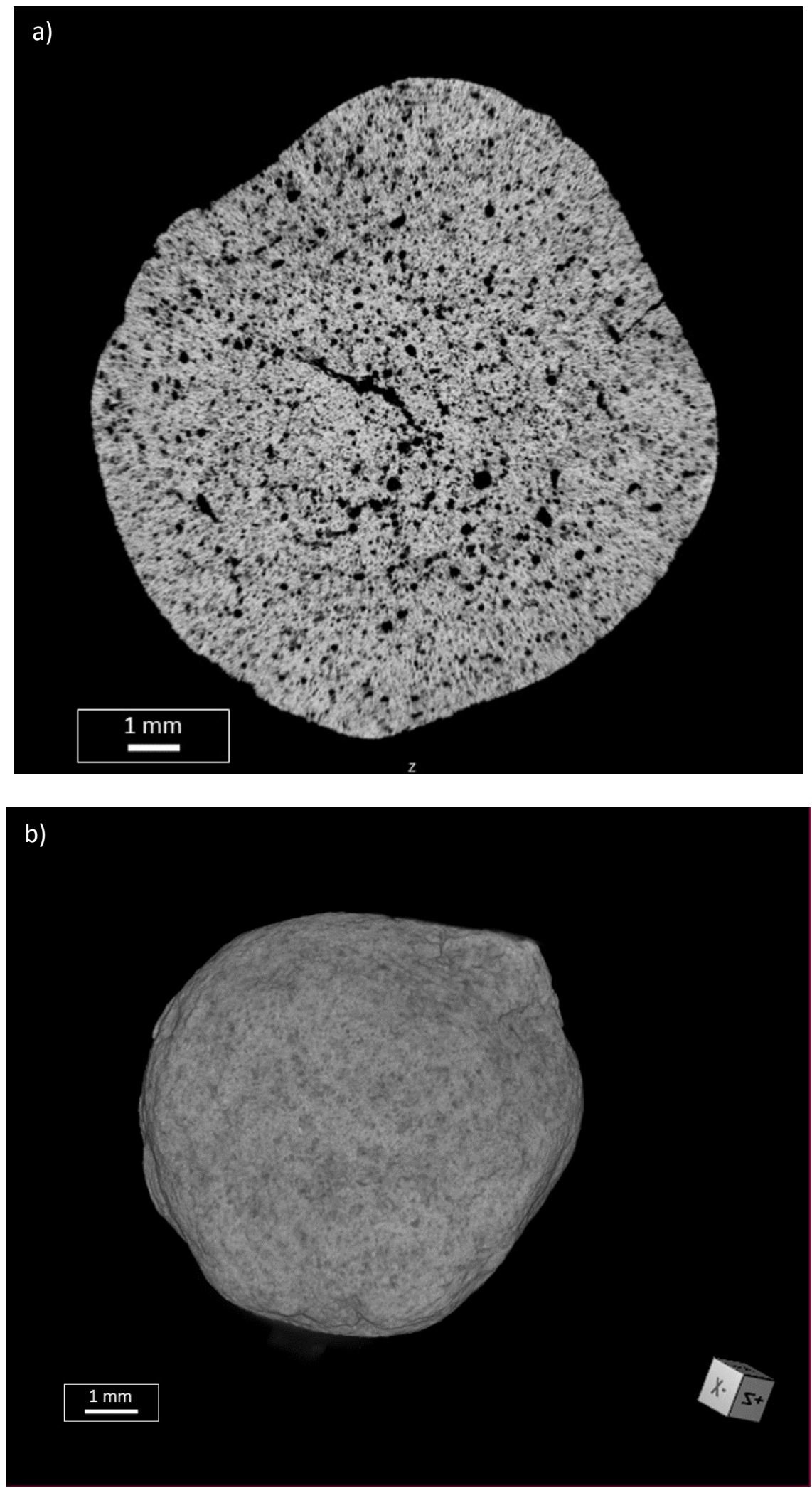

Figura 36 - Aquisição em lente de 0,4X da Pelota P1-A, com resolução de 7,6 $\mu \mathrm{m}$ : a) Fatia 2D; b) Volume 3D. 
A figura 37 mostra a análise 2 descrita na tabela 3. Foi possível obter um subvolume da pelota P1-A, com uma resolução máxima aproximada de $4 \mu \mathrm{m}$ e tempo total de aquisição de 8 horas e 56 minutos.
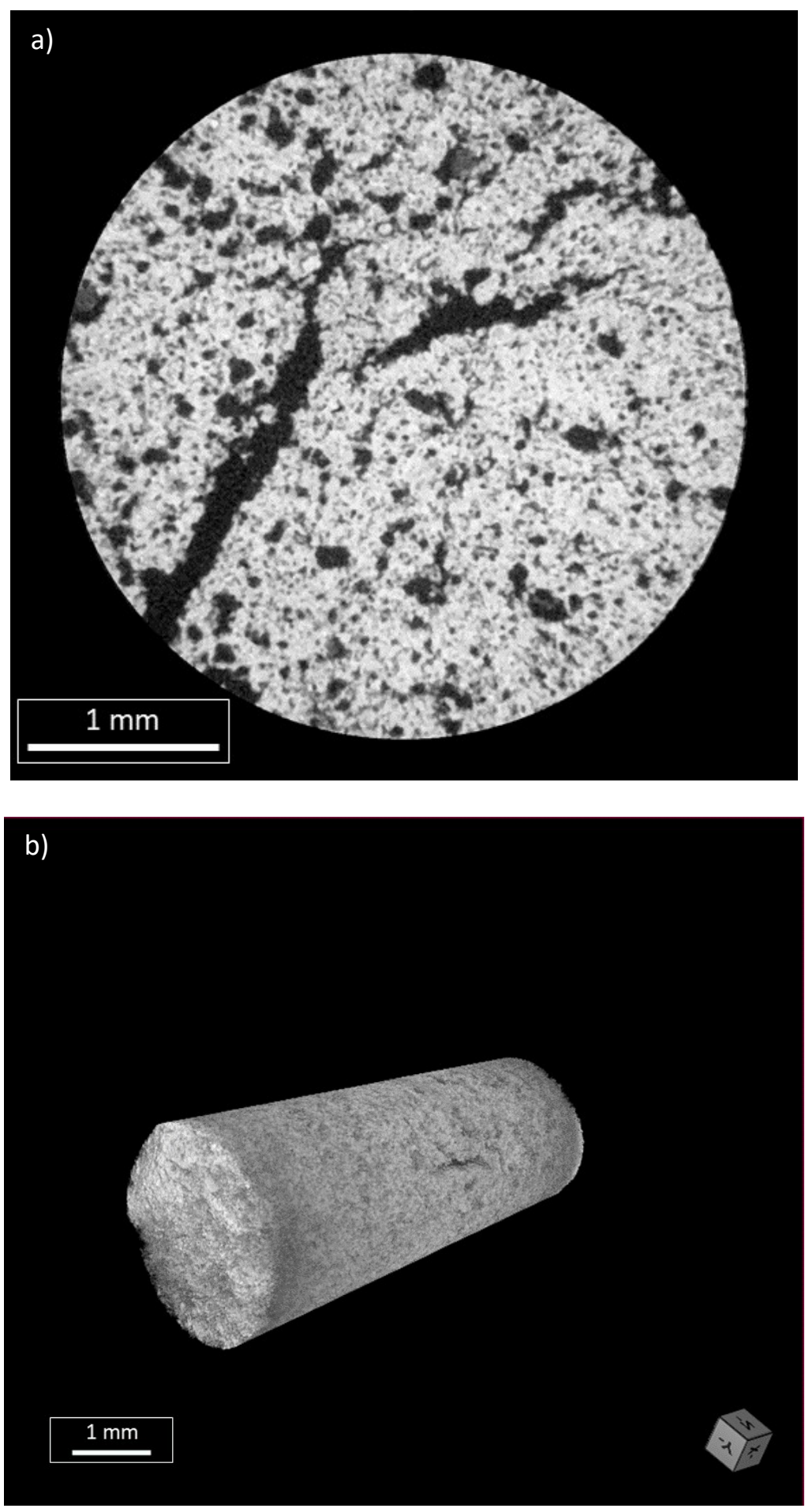

Figura 37 - Aquisição em lente de 4X da Pelota P1-A, com resolução de $4 \mu \mathrm{m}$ : a) Fatia 2D; b) Volume 3D. 
A figura 38 mostra a análise 3 descrita na tabela 3 . Foi possível obter um subvolume da pelota P1-A, com uma resolução máxima aproximada de $2 \mu \mathrm{m}$ e tempo total de aquisição de 27 horas e 23 minutos.
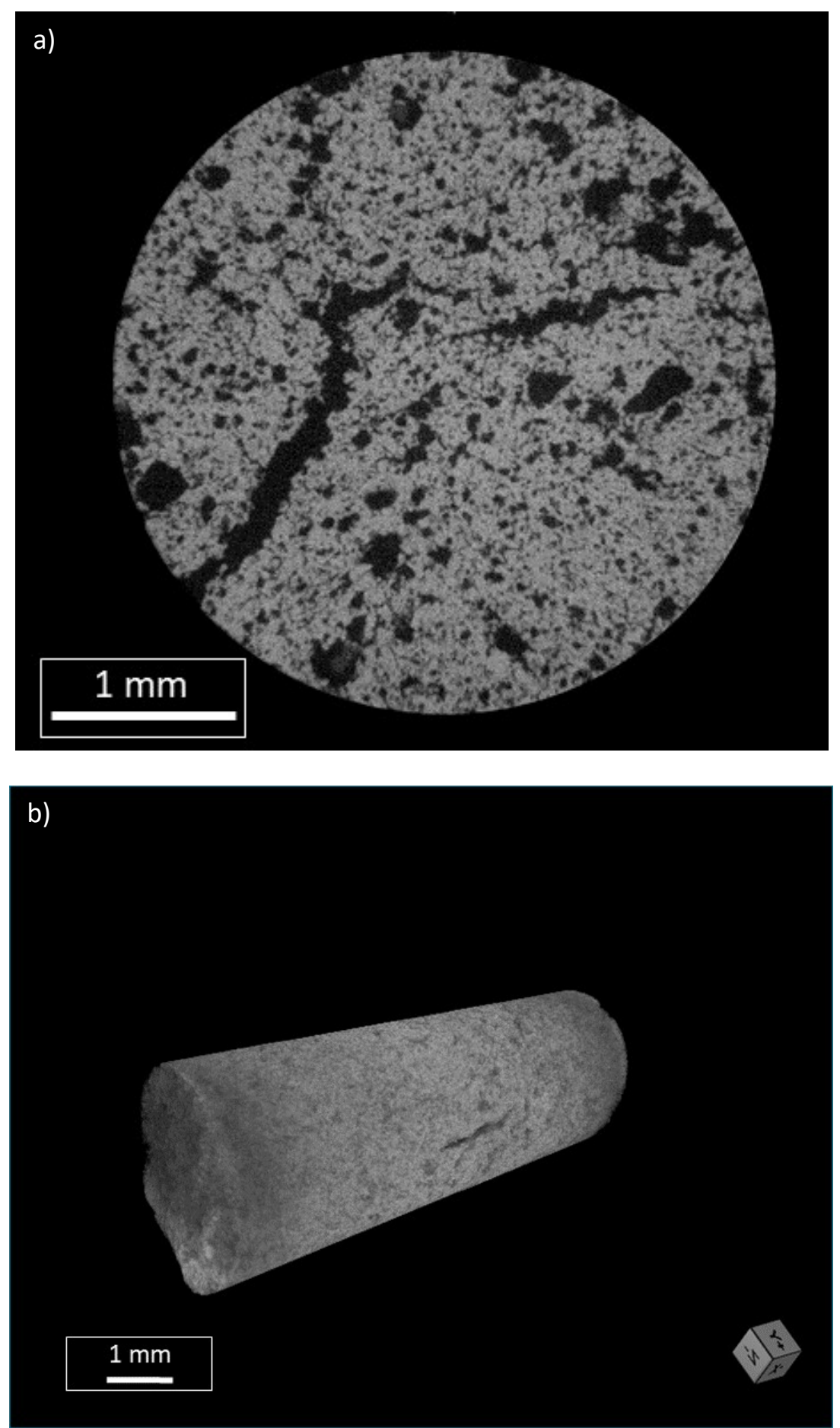

Figura 38 - Aquisição em lente de 4X da Pelota P1-A, com resolução de $2 \mu \mathrm{m}$ : a) Fatia 2D; b) Volume 3D. 
A figura 39 mostra a análise 4 descrita na tabela 3. Foi possível obter um subvolume de apenas uma das extremidades da pelota P1-A, com uma resolução máxima aproximada de $1 \mu \mathrm{m}$ e tempo total de aquisição de 16 horas e 30 minutos.
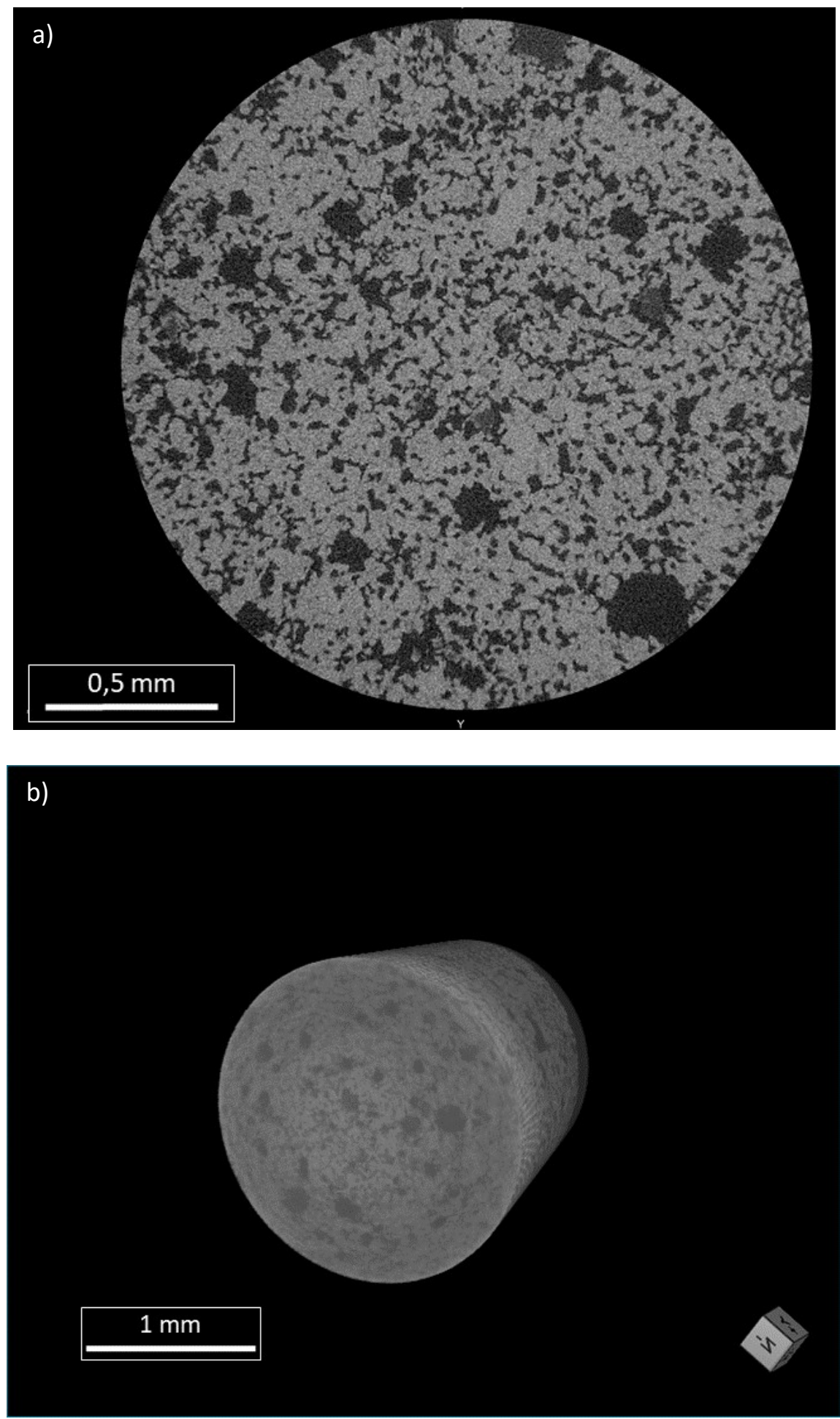

Figura 39 - Aquisição em lente de 4X da Pelota P1-A, com resolução de $1 \mu \mathrm{m}$ : a) Fatia 2D; b) Volume 3D. 
A figura 40 mostra a análise 5 descrita na tabela 3 . Foi tomografado um gomo da pelota $\mathrm{P} 1-\mathrm{B}$, com uma resolução máxima aproximada de $4 \mu \mathrm{m}$ e tempo total de aquisição de 3 horas e 7 minutos.

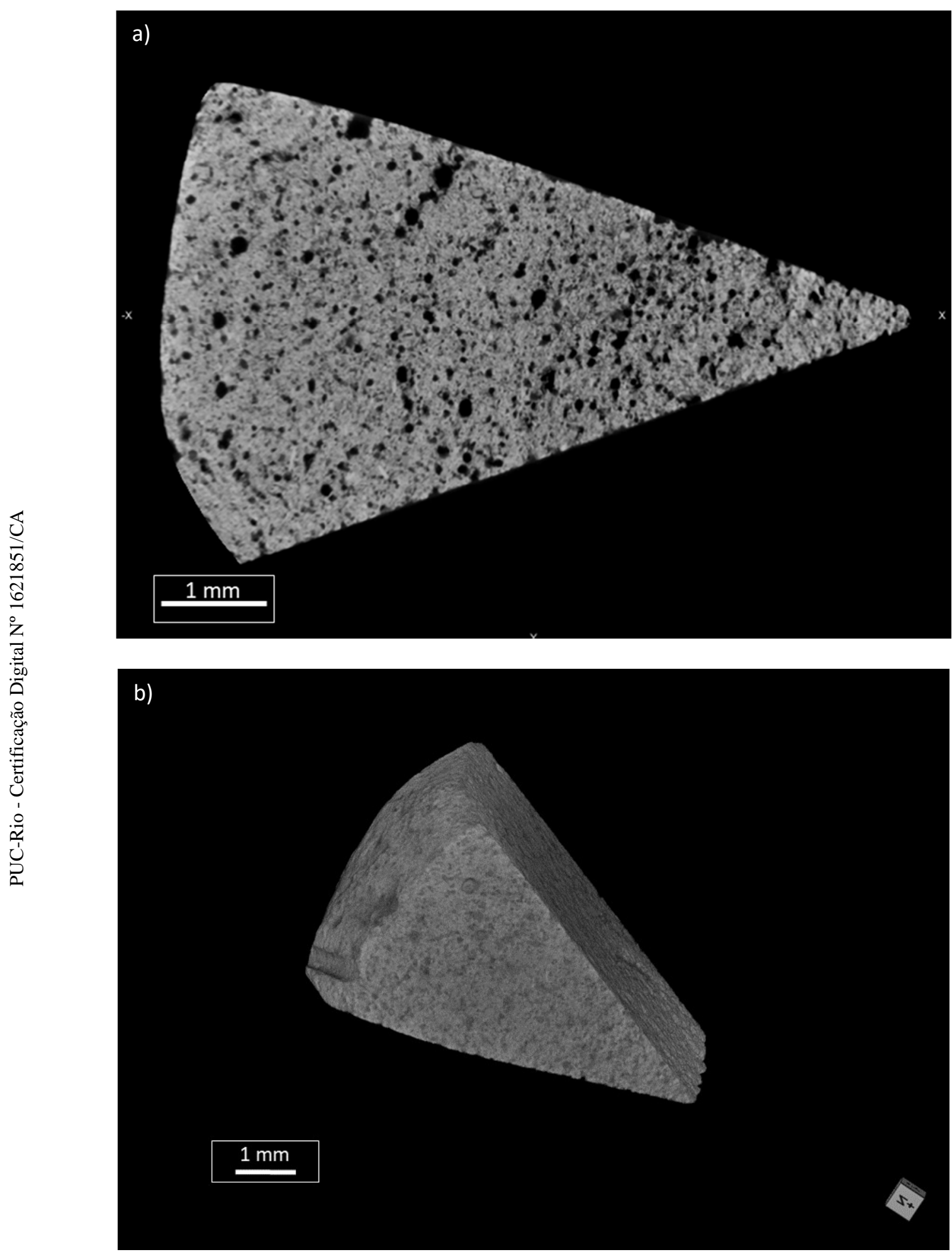

Figura 40 - Aquisição em lente de 0,4X do gomo da Pelota P1-A, com resolução de 4 $\mu \mathrm{m:}$ a) Fatia 2D; b) Volume 3D. 
É possível perceber que a qualidade das imagens do gomo é superior às demais tomografias. Este fato ocorre devido à redução da espessura do material. De acordo com a equação 2, apresentada no capítulo 3, a atenuação dos feixes depende da espessura e da densidade da amostra - diminuindo a espessura aumenta-se a intensidade dos raios $\mathrm{X}$.

\subsubsection{Medidas Comparativas}

A análise das segmentações permitiu a confirmação do impacto na percentagem de volume dos poros devido à mudança de resolução. O gráfico abaixo (figura 41) mostra a análise quantitativa da porosidade para as resoluções de 2; $4 \mathrm{e}$ 7,6 $\mu \mathrm{m}$ considerando dois limares de segmentação, sendo eles respectivamente: 100 e $125 ; 125$ e $150 ; 115$ e 135 .

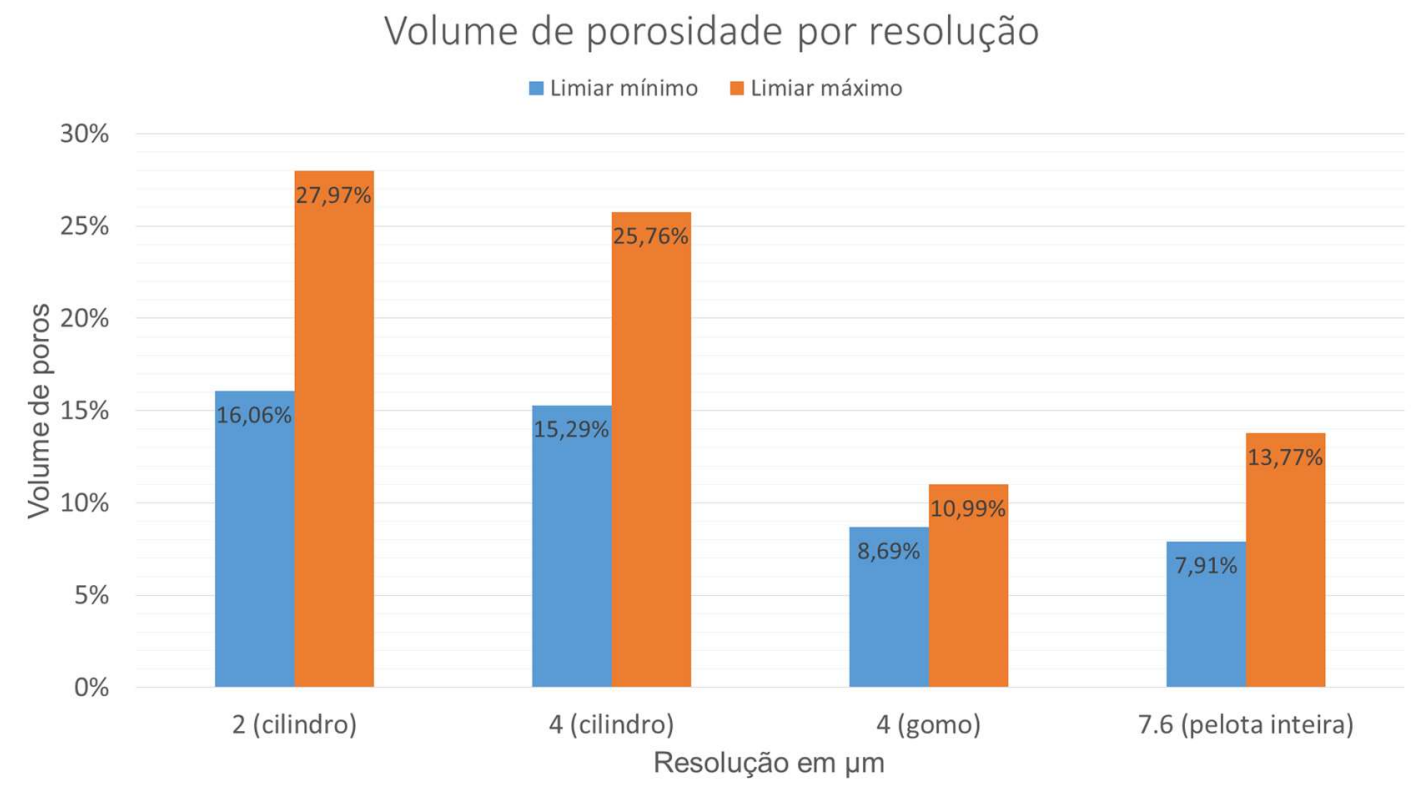

Figura 41 - Volume de poros dos limiares de segmentação para as resoluções de 2; 4 e $7,6 \mu \mathrm{m}$.

O valor de porosidade média na resolução de 7,6 $\mu \mathrm{m}$ é bem menor devido à região de análise e à possível perda de informações pois sabe-se que os tamanhos dos poros das pelotas estão entre $8-11 \mu \mathrm{m}$ e a resolução utilizada é muito próxima ao valor mínimo da faixa de valores $(8 \mu \mathrm{m})$. Vale ressaltar também que a tomografia com resolução de 7,6 $\mu \mathrm{m}$ é referente a pelota inteira e as demais são um subvolume devido ao uso da lente de $4 \mathrm{X}$, fato este que também altera o percentual de 
porosidade como será discutido posteriormente através de uma análise da influência da região amostral. Destaca-se também que o volume da tomografia de $1 \mu \mathrm{m}$ é pouco representativo e, além disso, suas imagens ficaram bastante ruidosas o que dificultou a segmentação e, portanto, não entrou no cálculo de porosidade. Portanto, conclui-se que o valor de $4 \mu \mathrm{m}$ para a resolução é suficiente para analisar a porosidade das pelotas.

O gomo representa razoavelmente bem a variação do centro até a borda, porém é difícil entender a representatividade quanto à caracterização de porosidade deste subvolume em relação à pelota inteira. As imagens possuem um contraste bem definido, o que permitiu uma melhor segmentação do tom de corte. Seu histograma não proporciona tanta dúvida quanto à definição do limiar, consequentemente, o resultado da segmentação se torna pouco variável. Assim, o gráfico demonstra uma pequena variação da percentagem de porosidade devido à proximidade dos limiares em relação as demais análises. Este fato pode ser visualizado através da figura 42 abaixo que demonstra a segmentação do gomo e na figura 43, onde é possível comparar os histogramas de cada análise.

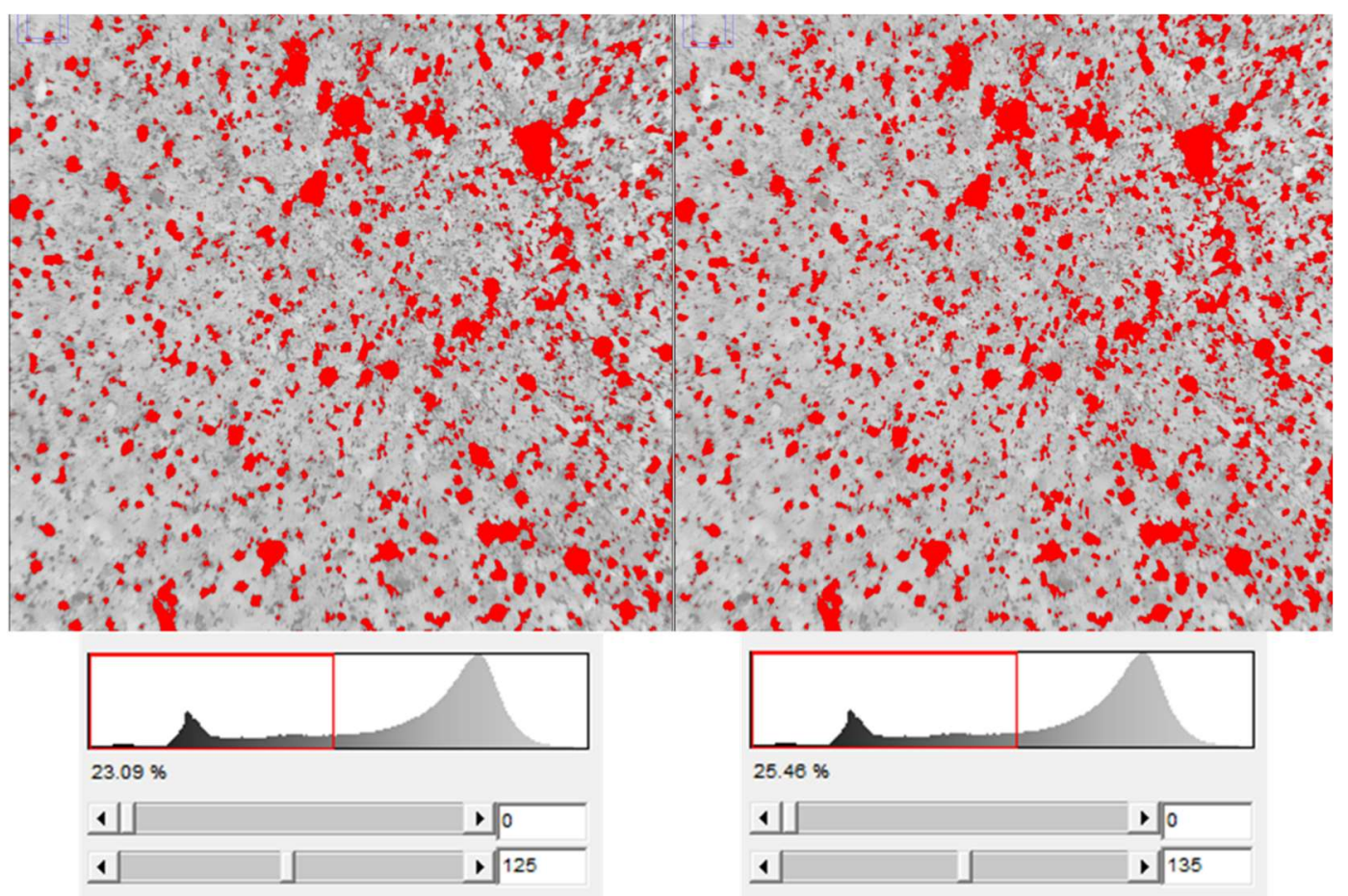

Figura 42 - Gomo: (a) Segmentação com limiar =125; (b) Segmentação com limiar = 135. 

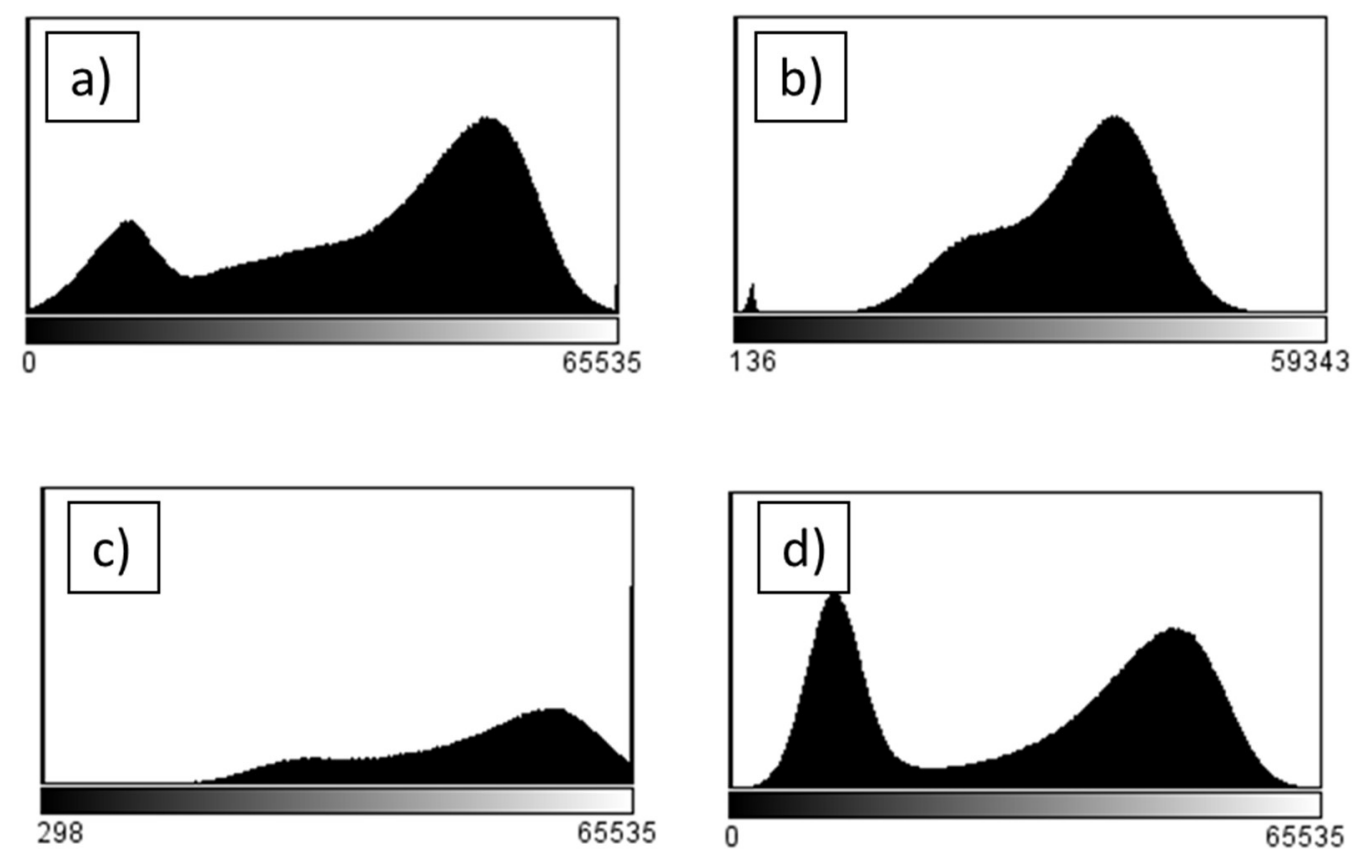

Figura 43 - Histogramas: a) gomo com $4 \mu \mathrm{m}$ de resolução; b) cilindro com $2 \mu \mathrm{m}$ de resolução; c) cilindro com $4 \mu \mathrm{m}$ de resolução e d) pelota inteira com 7,5 $\mu \mathrm{m}$.

\subsection{Estudo da Porosidade em Diferentes Regiões de Análise}

Para comparar a porosidade dos diferentes volumes obtidos, foi feito uma junção do cilindro equivalente com a resolução de $4 \mu \mathrm{m}$ e a pelota inteira com resolução de 7,6 $\mu \mathrm{m}$, como ilustrado nas figuras 44 e 45 a seguir. 


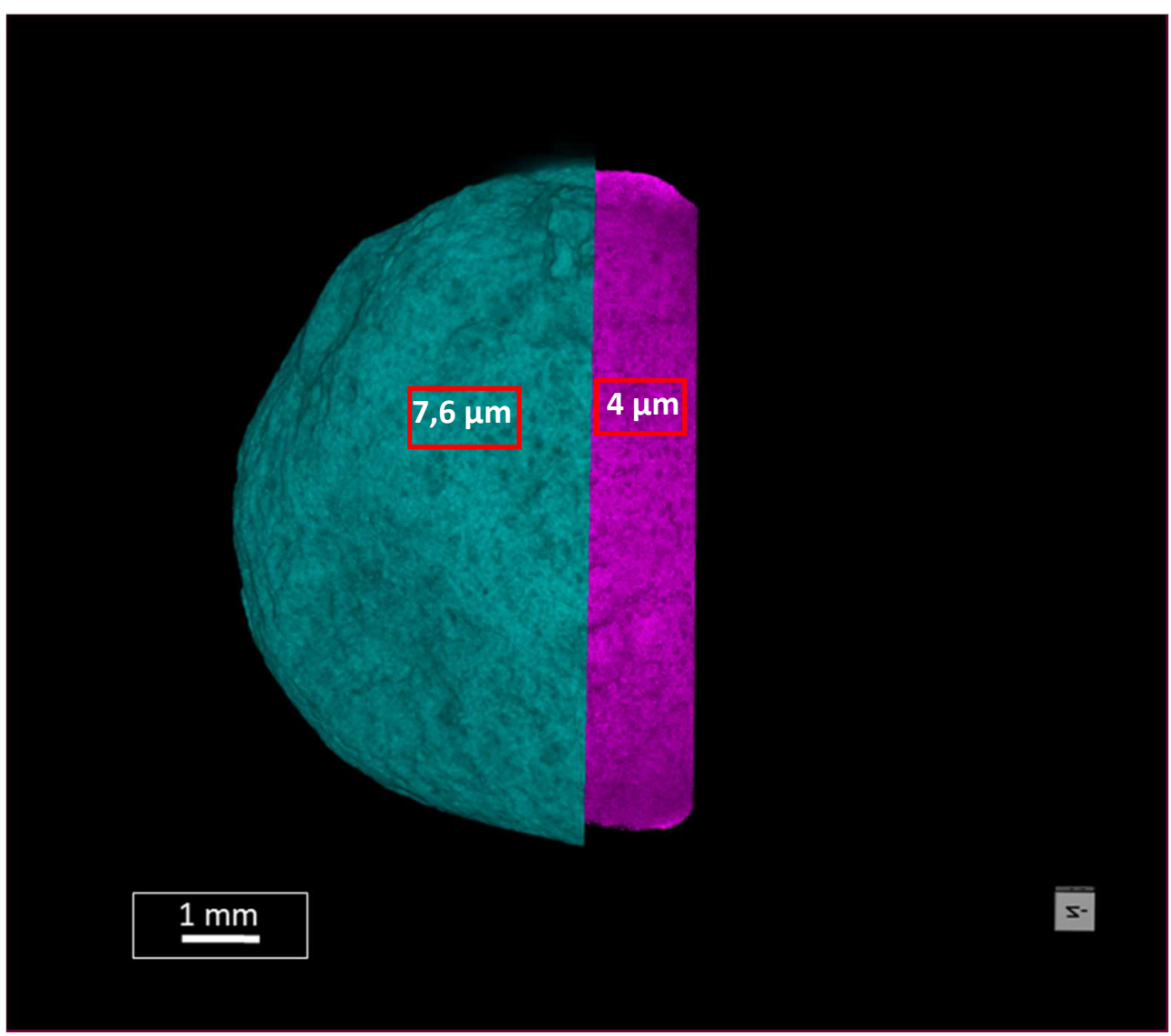

Figura 44 - Volume em 3D do cilindro com $4 \mu \mathrm{m}$ (rosa) de resolução em relação à pelota inteira com resolução de 7,6 $\mu \mathrm{m}$ (azul). 


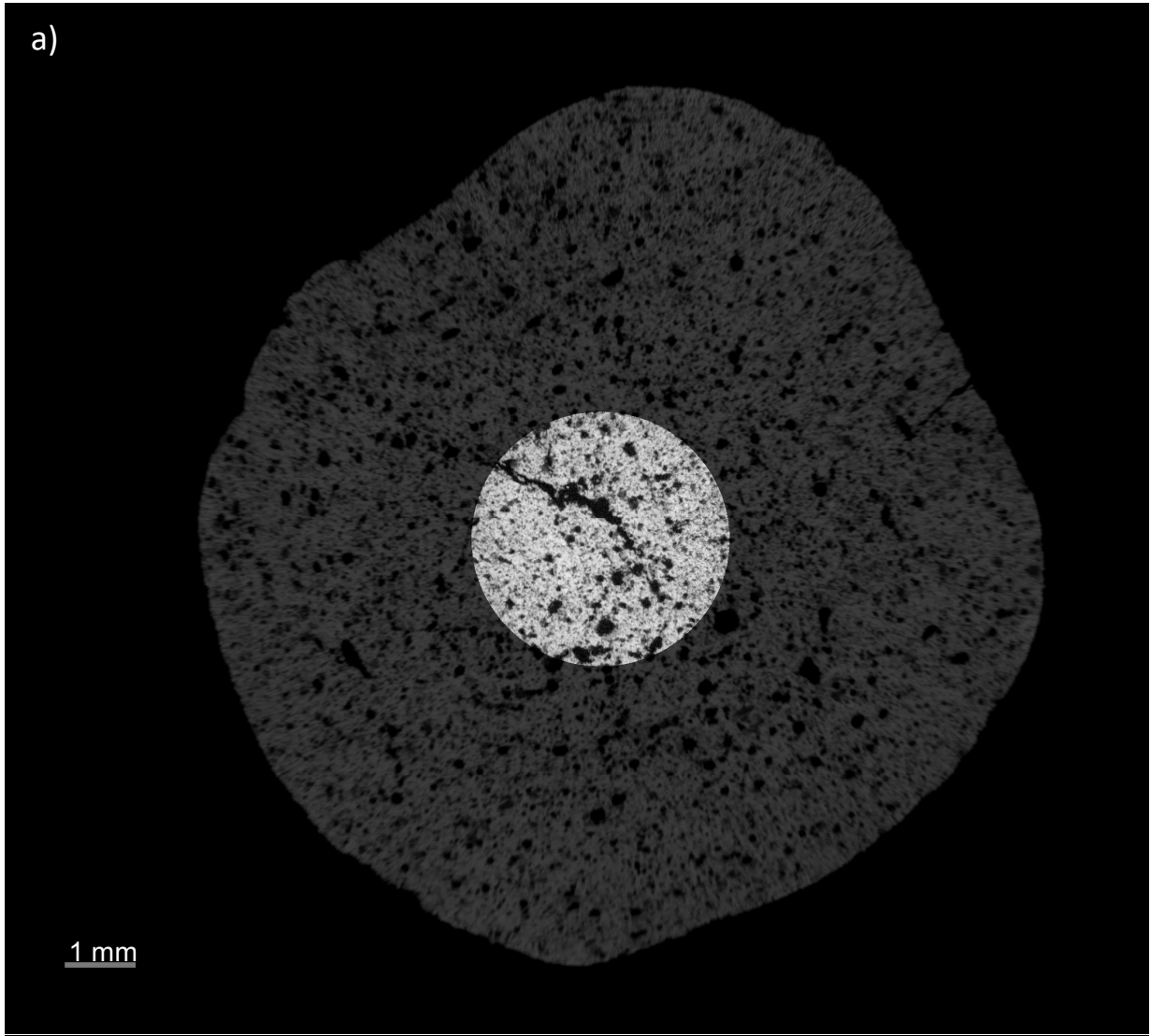

b)

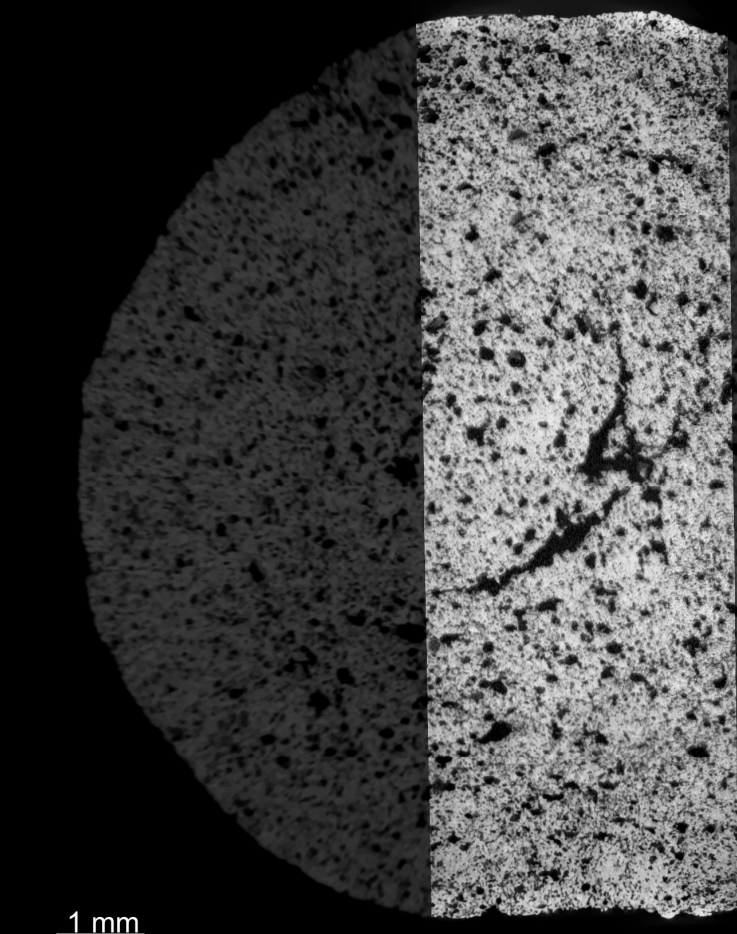

Figura 45 - Cilindro com $4 \mu \mathrm{m}$ de resolução em relação à pelota inteira com resolução de 7,6 $\mu \mathrm{m}$ : a) Fatia 2D plano $X Z$; b) Fatia plano $X Y$. 
A fim de estudar a representatividade desse subvolume com relação à pelota inteira e a influência da resolução em uma mesma região de análise, alinhou-se o centro das imagens no software Dragonfly, em seguida fez-se uma interseção entre a parte sólida segmentada da pelota inteira com a parte sólida preenchida do cilindro (figura 46).

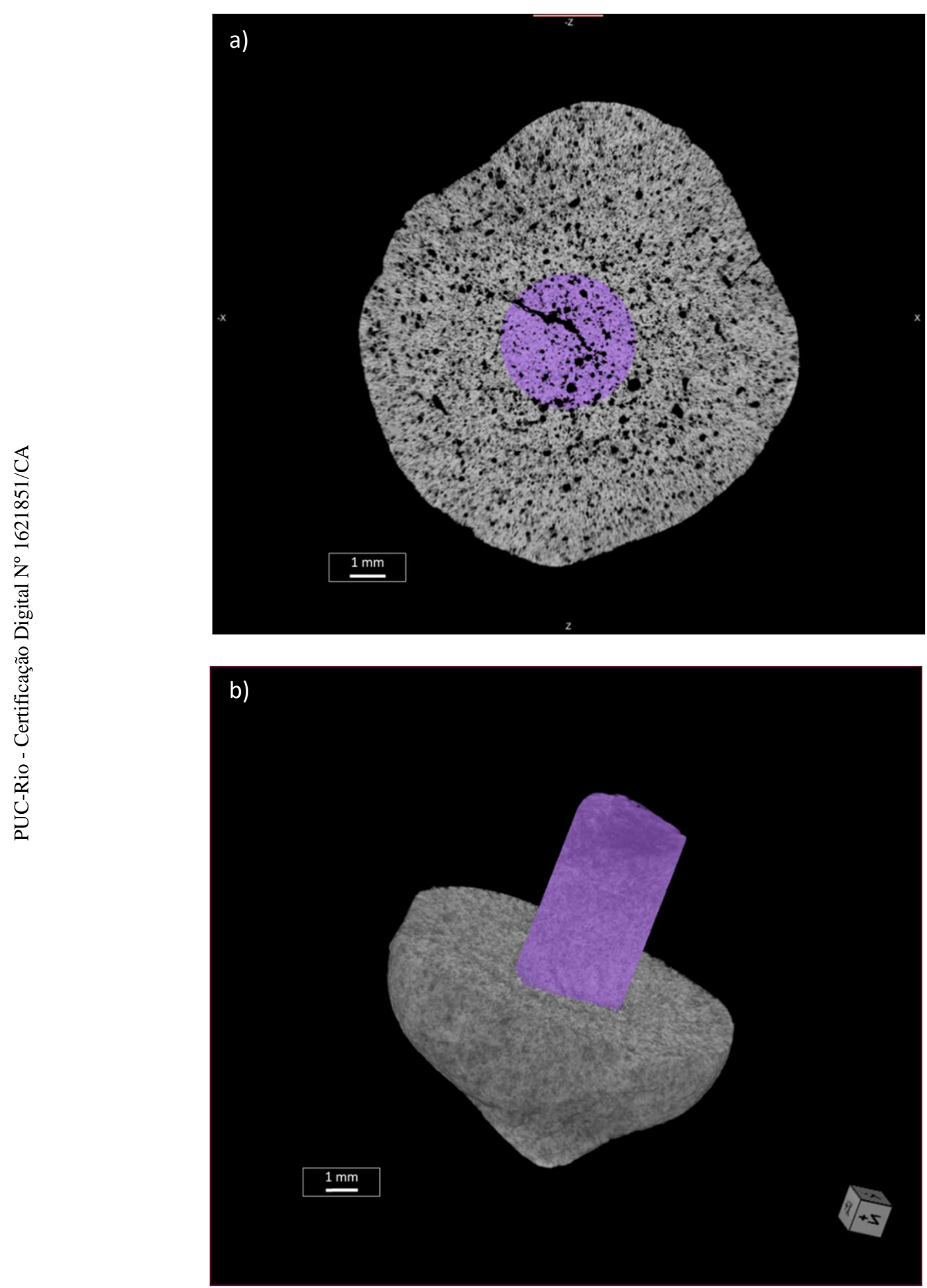

Figura 46 - Sólido de interseção entre a pelota inteira e o cilindro: a) Fatia 2D; b) Volume 3D. 
Com isso, garante-se que os pixels brancos (referente ao sólido) da pelota inteira esteja também no cilindro, assim, tem-se o cilindro resultante equivalente da pelota inteira. Obtendo a fase sólida equivalente, basta fazer o mesmo processo da segmentação detalhada nas seções anteriores, preenchendo e subtraindo para a obtenção dos poros (figura 47). Fixou-se o valor do limiar para cada resolução, e não para as duas pois a diferença na geometria de aquisição faz com que o limiar varie, se fosse utilizado apenas um valor para ambas, haveria perda ou superestimação do volume de porosidade. O percentual de porosidade do cilindro resultante com resolução de $7,6 \mu \mathrm{m}$ é de $14,83 \%$ e do cilindro com resolução de 4 $\mu \mathrm{m}$ é de $23,69 \%$, uma diferença significativa que comprova o impacto da resolução alcançada. 

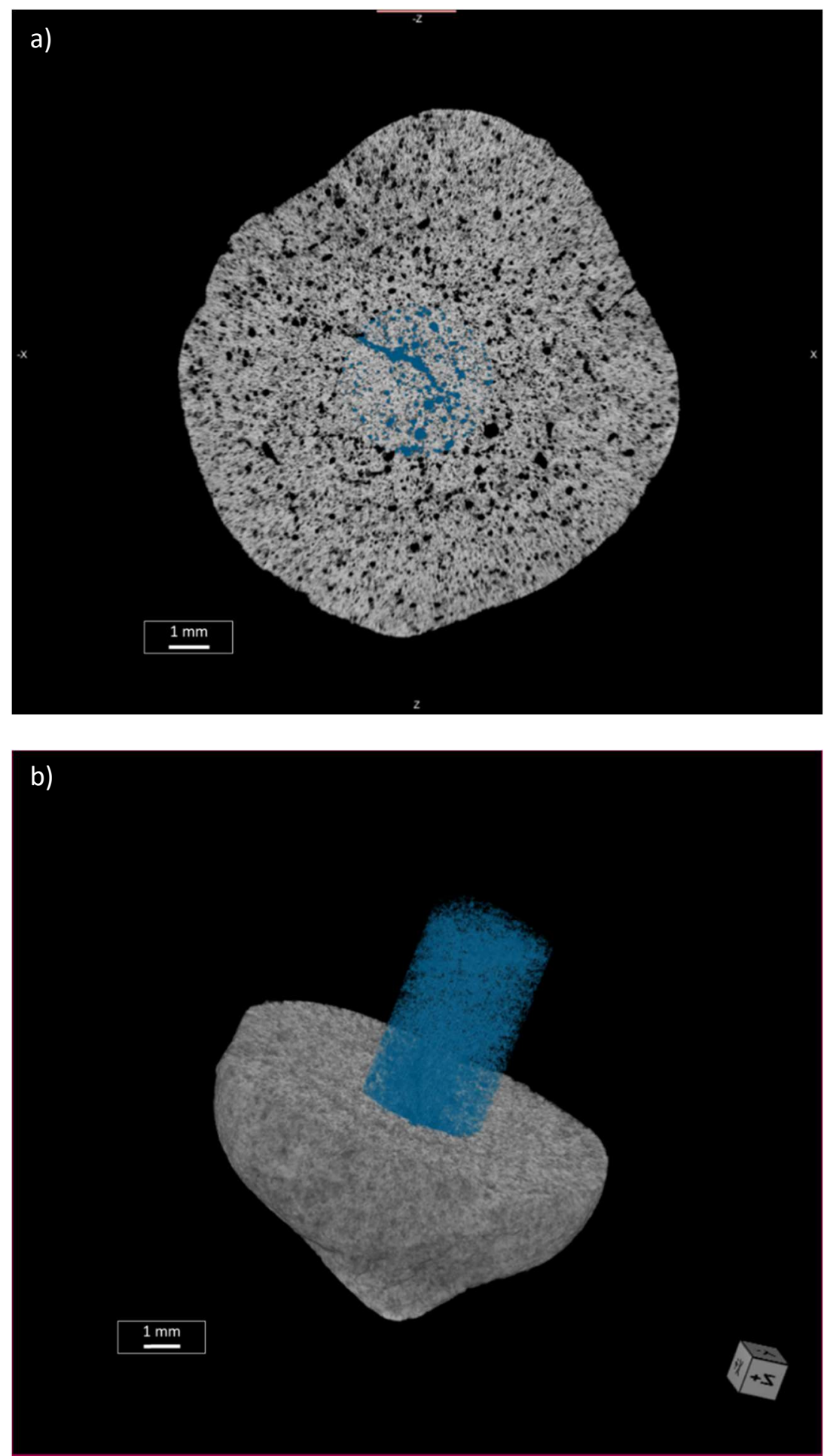

Figura 47 - Poros do cilindro equivalente resultante: a) Fatia 2D; b) Volume 3D.

Essa análise também permitiu entender que os subvolumes não são uma boa representação para o cálculo de porosidade, visto que a percentagem de poros na pelota inteira é de $10.70 \%$ e para o cilindro, mantendo a mesma faixa tonal de corte, obteve-se $14.83 \%$. Foi feito a comparação com todos os subvolumes e os resultados estão na tabela 5 a seguir. 
Tabela 5 - Comparação da porosidade com diferentes volumes e resoluções

\begin{tabular}{|c|c|c|}
\hline Tipo de volume & $\begin{array}{c}\text { Resolução } \\
(\boldsymbol{\mu m})\end{array}$ & $\begin{array}{c}\text { Porosidade } \\
\mathbf{( \% )}\end{array}$ \\
\hline \multirow{2}{*}{$\begin{array}{c}\text { Subvolume } \\
\text { (cilindro) }\end{array}$} & 7,6 & 14,83 \\
\cline { 2 - 3 } & 4 & 23,69 \\
\cline { 2 - 3 } & 2 & 26,75 \\
\hline Inteira & 7,6 & 10,70 \\
\hline
\end{tabular}

Assim, é possível confirmar que o centro da pelota é mais poroso que sua periferia e, por isso, o valor percentual do cilindro é maior que o da pelota inteira, numa mesma resolução. A tabela mostra que o percentual de porosidade em relação à pelota inteira não é exatamente igual ao subvolume na mesma resolução, mas que ainda pode ser considerada como uma pequena variação em termos de propriedade da pelota visto que há uma diferença de aproximadamente $4 \%$ entre um valor e outro. Esta diferença é pequena, dadas as incertezas inerentes aos diversos métodos de análise. Além disso, possui uma grande vantagem operacional, pois analisar apenas um subvolume demanda um menor tempo de aquisição. Como esperado, nota-se a grande variação entre as diferentes resoluções, o que confirma o fato de que existe uma fração substancial de poros pequenos que não são adequadamente revelados nas piores resoluções.

A fim de compreender como a porosidade varia ao longo da mesma pelota, analisou-se a mesma dividindo-a em 3 partes aproximadamente semelhantes: uma parte central e duas extremidades. A figura 48 a seguir mostra a porosidade nas diferentes regiões da pelota inteira com resolução de 7,6 $\mu \mathrm{m}$ e a figura 49 mostra as diferentes regiões ao longo do subvolume de resolução $4 \mu \mathrm{m}$. 


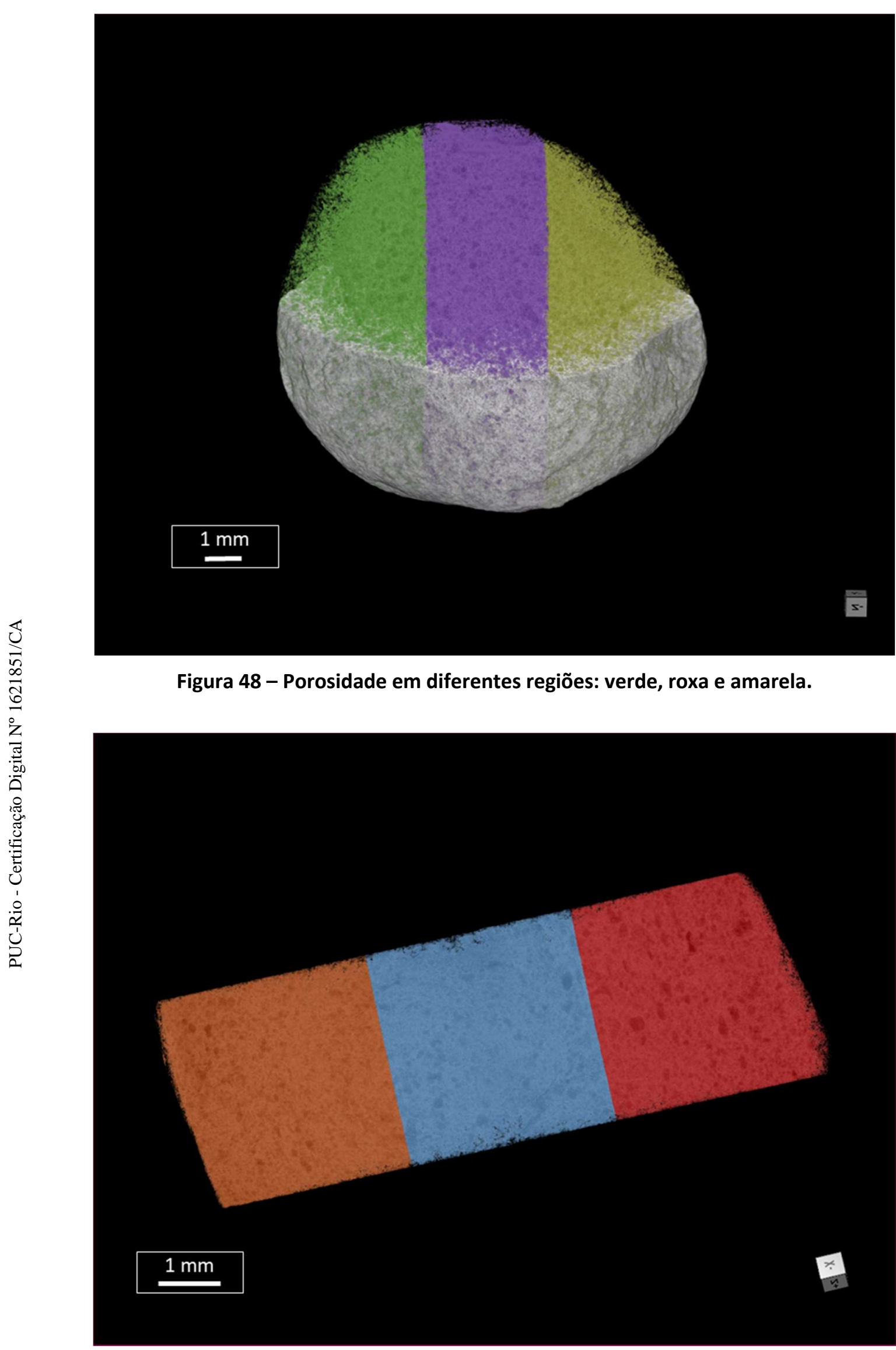

Figura 49 - Porosidade em diferentes regiões: laranja, azul e vermelha. 
O resultado do cálculo de porosidade para um limiar de segmentação fixo pode ser visualizado na tabela abaixo:

Tabela 6 - Percentual da fração de poros em diferentes regiões da pelota

\begin{tabular}{|c|c|c|c|}
\hline Tipo de volume & $\begin{array}{c}\text { Resolução } \\
(\boldsymbol{\mu m})\end{array}$ & Região & $\begin{array}{c}\text { Porosidade } \\
(\%)\end{array}$ \\
\hline \multirow{2}{*}{ Inteira } & \multirow{2}{*}{7,6} & Verde & 9,65 \\
\cline { 3 - 4 } & & Roxa & 11,74 \\
\cline { 3 - 4 } & & Amarela & 9,81 \\
\hline \multirow{2}{*}{$\begin{array}{c}\text { Subvolume } \\
\text { (cilindro) }\end{array}$} & \multirow{2}{*}{4} & Laranja & 26,05 \\
\cline { 3 - 4 } & & Azul & 20,75 \\
\cline { 3 - 4 } & & Vermelha & 26,15 \\
\hline
\end{tabular}

É perceptível que na pelota inteira o centro é mais poroso, como era esperado. Já no cilindro central nota-se maiores valores de porosidade nas extremidades, este fato se deve principalmente pela grande quantidade de poros pequenos que são detectados na resolução de $4 \mu \mathrm{m}$ e contribuem para um maior valor percentual de poros. A figura 50 auxilia na compreensão desta discussão: é possível visualizar a porosidade fina nas duas extremidades do cilindro.

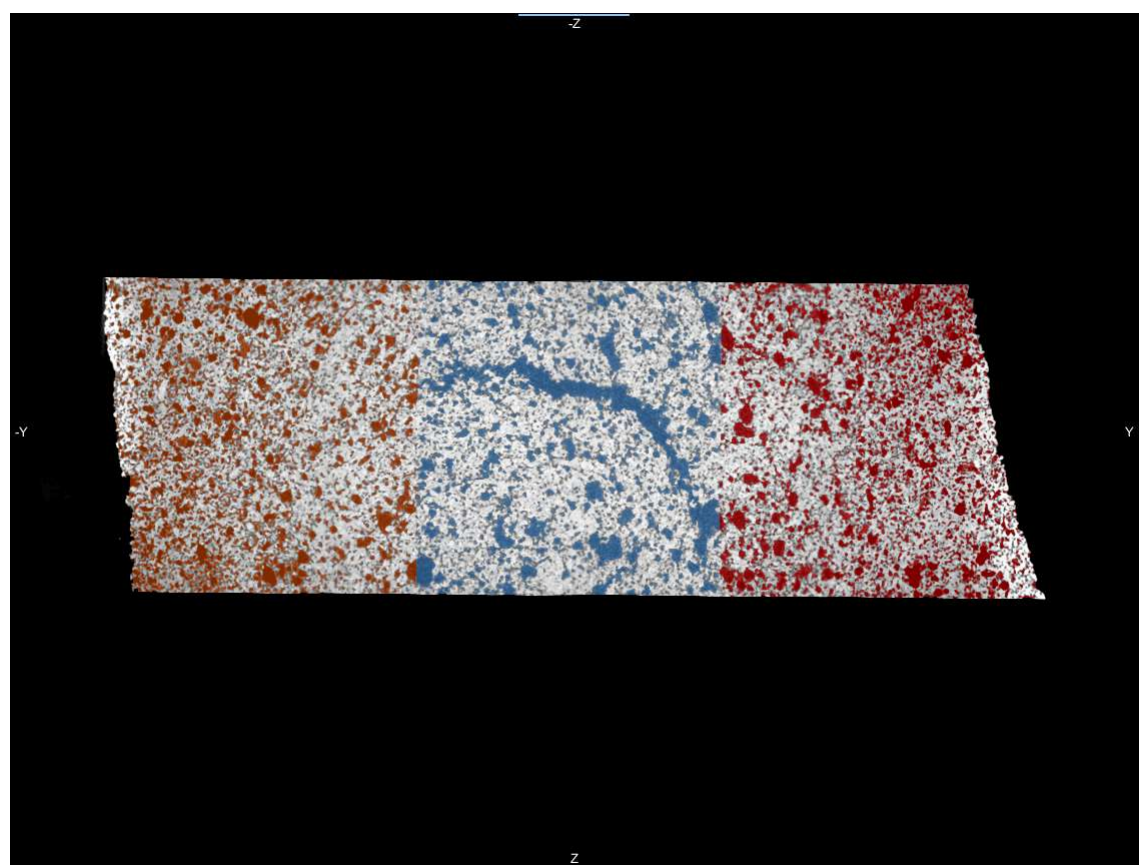

Figura 50 - Visualização em 2D da variação da porosidade ao longo das regiões no cilindro. 


\subsection{Porosidade Aberta e Fechada}

Com o intuito de diferenciar porosidade aberta e fechada foi desenvolvida uma nova metodologia de discriminação de poros baseada no cálculo do Mapa de Distâncias Euclidianas (MDE) para conseguir delimitar a borda da pelota, como explicado na seção 4.3.4.2. O MDE do objeto preenchido proporciona uma referência tonal, na qual cada objeto possui uma tonalidade associada à distância do pixel à borda do objeto e a tonalidade mínima é referente aos poros conectados, visto que esse tipo de poro está em contato com a borda. Portanto, após o cálculo do MDE, há a construção de um gráfico de intensidade mínima onde os menores valores são referentes aos poros conectados. $O$ valor de corte para a distinção dos poros entre abertos e fechados é feita visualmente de maneira manual, o que pode acarretar em erros nas medidas e seria interessante um estudo para que o limiar seja definido de maneira automática em análises futuras. Nos resultados obtidos para a pelota inteira, o percentual de porosidade aberta e fechada em relação ao total de poros ficou em 55,84\% do volume de poros fechados (rosa) e 44,16\% de poros abertos (verde), como pode ser visualizado nas figuras 51, 52 e 53, percebe-se a presença de uma grande trinca em verde que corresponde a poros conectados. 


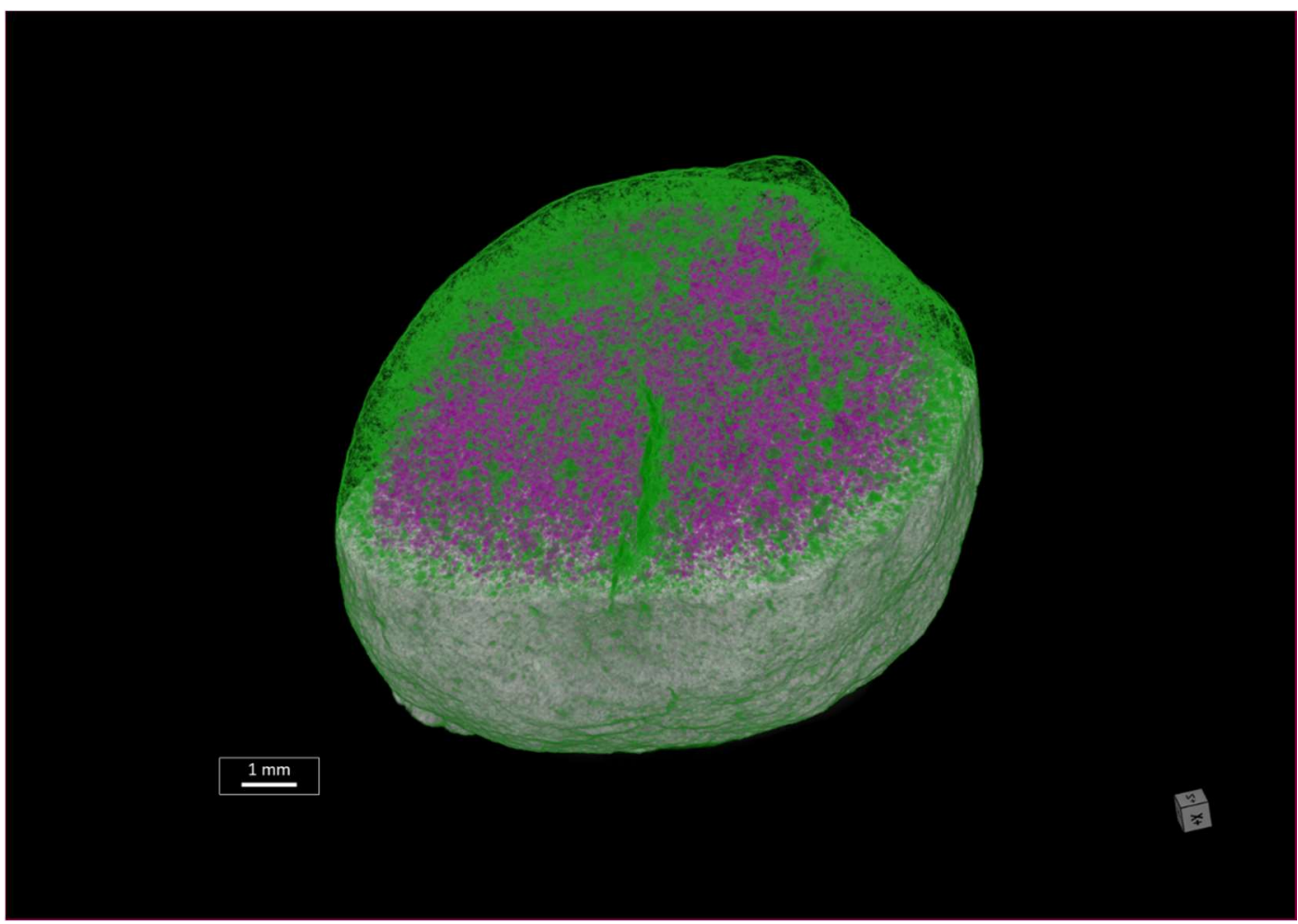

Figura 51 - Porosidade aberta e fechada da pelota inteira, poros abertos em verde e poros fechados em rosa.

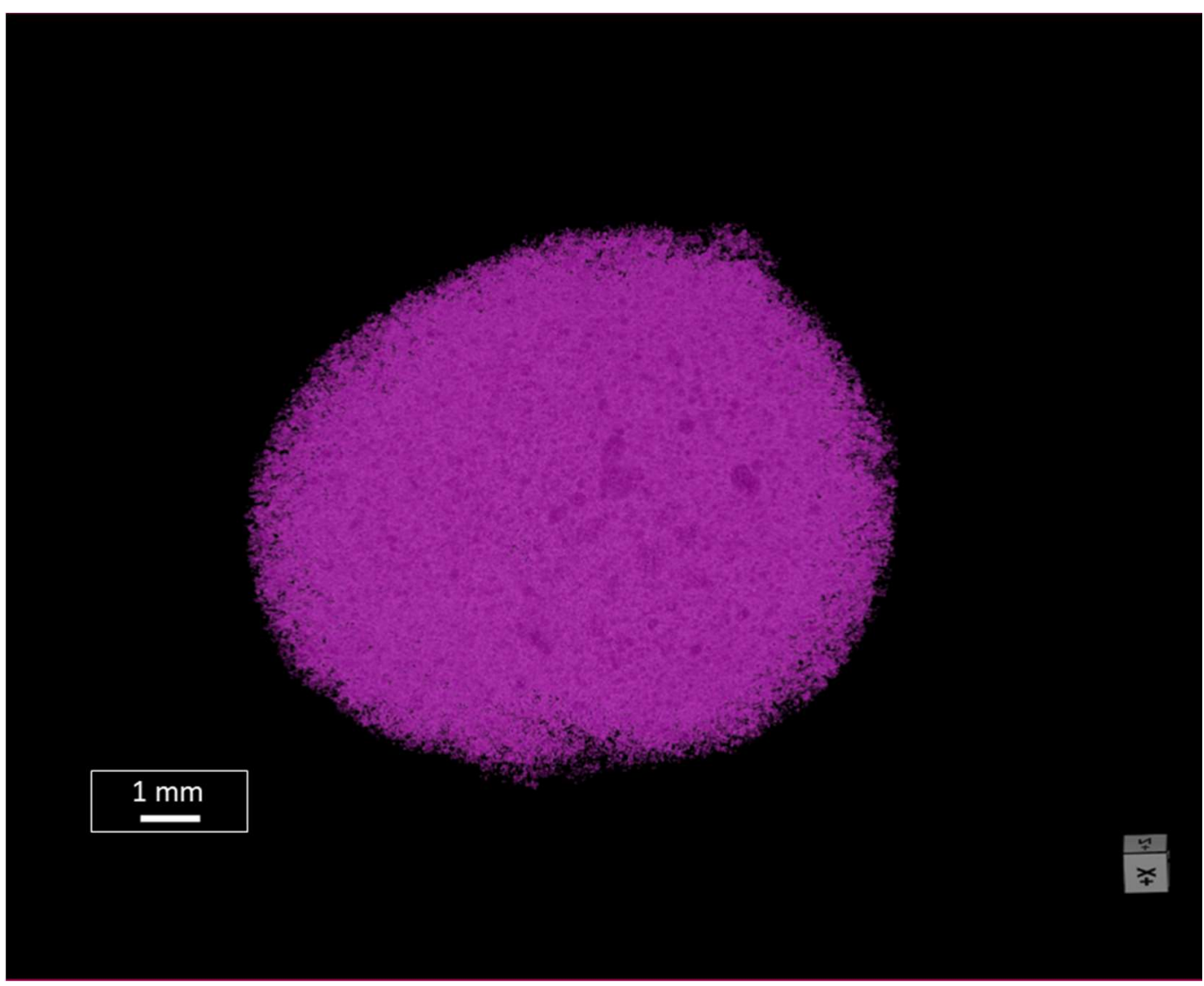

Figura 52 - Poros fechados da pelota inteira. 


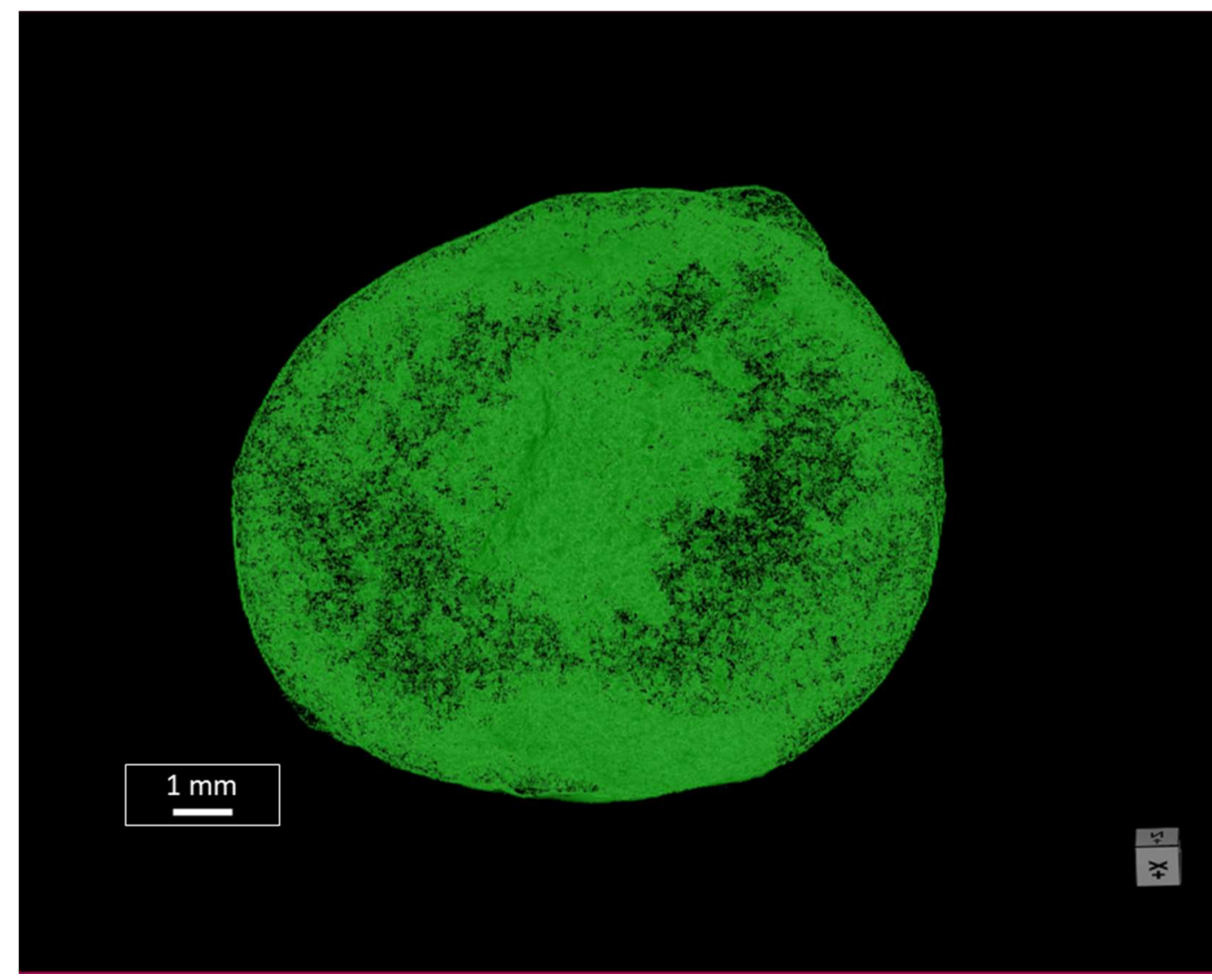

Figura 53 - Poros abertos da pelota inteira.

Para corroborar essa análise de porosidade aberta com auxílio do MDE no software Dragonfly e verificar se houve erro na escolha do limiar de distinção entre poros abertos e fechados, quantificou-se o percentual de porosidade em um outro software, o CTAn. (CTAn) utilizando o mesmo processamento de Augusto (2016), que consiste em: thresholding (segmentação da fase sólida mantendo o mesmo valor de limiar utilizado no Dragonfly), ROI Shrink-wrap (que delimita a borda da pelota) e 3D analysis. A figura 54 mostra a pelota segmentada e a figura 55 ilustra a ROI resultante do Shrink-wrap. 


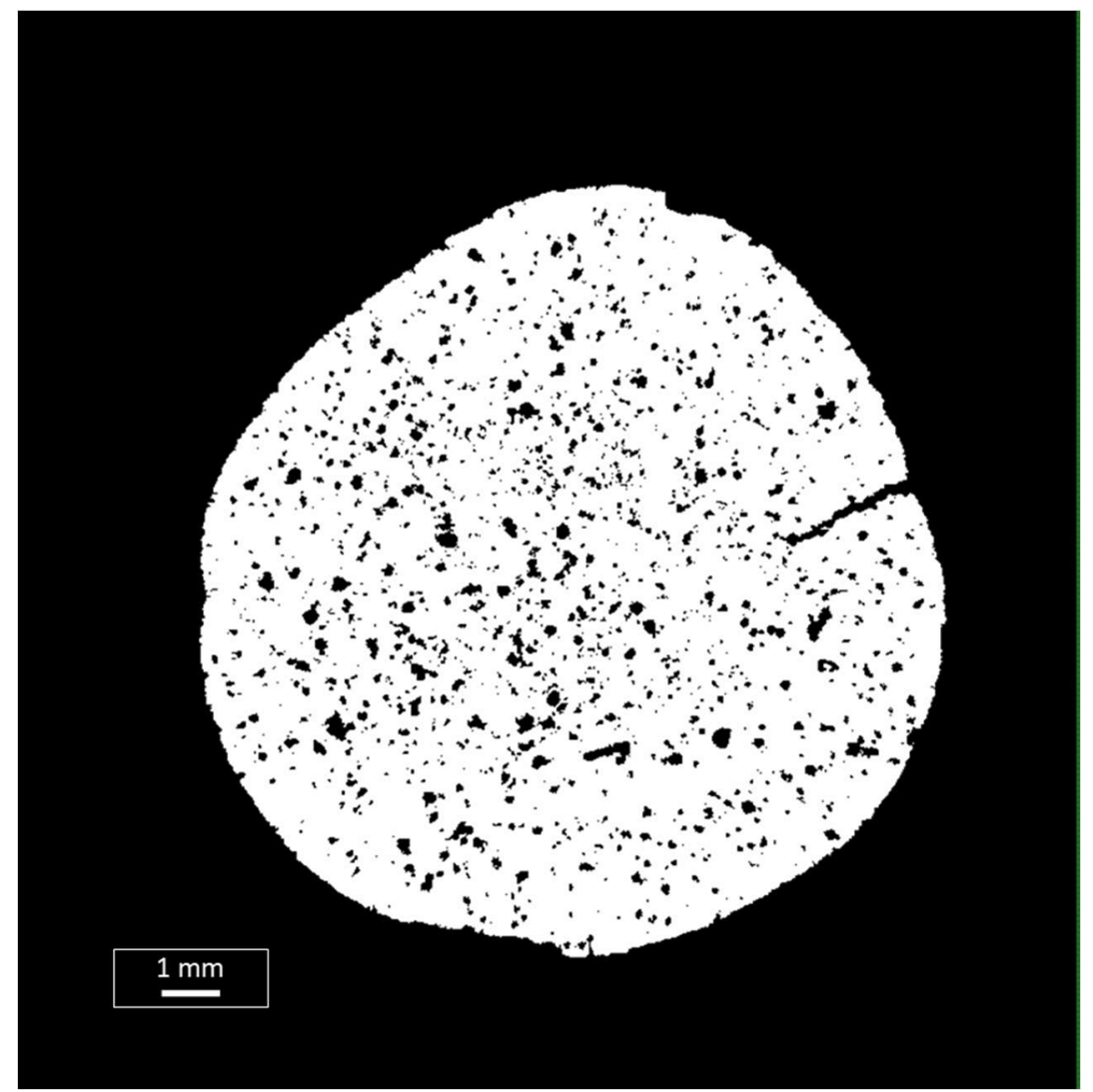

Figura 54 - Seção em 2D com a segmentação da fase sólida.

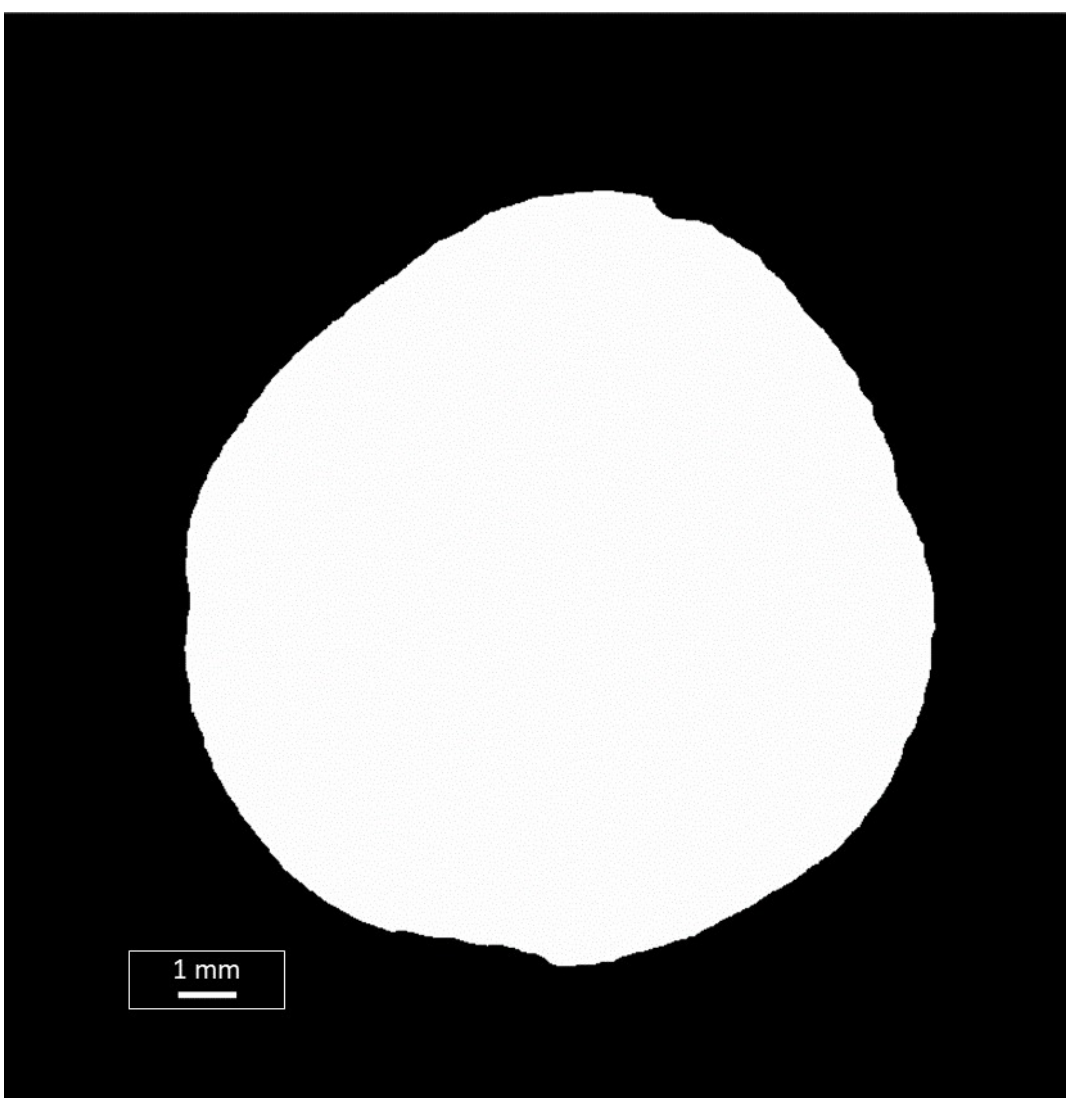

Figura 55 - Seção em 2D após a aplicação do ROI Shrink-wrap. 
O software CTAn é capaz de calcular a porosidade aberta e fechada de acordo com as equações a seguir:

$$
\begin{aligned}
& \% \text { Poros abertos }=\frac{\text { Volume de poros abertos }}{\text { Volume da ROI }} \\
& \% \text { Poros fechados }=\frac{\text { Volume de poros fechados }}{(\text { Volume da ROI-Volum dos poros abertos })}
\end{aligned}
$$

Assim, o valor encontrado no CTAn, para a mesma amostra, foi de 41,63\% de porosidade aberta, enquanto que a metodologia utilizada no Dragonfly resultou em um valor de $44,16 \%$ de volume de poros abertos. Ou seja, com uma diferença absoluta $2,5 \%$ e relativa de $6,1 \%$ é possível dizer que utilização do MDE para análise de porosidade aberta e fechada no Dragonfly é válida. 


\section{6 Conclusões e Trabalhos Futuros}

A presente dissertação propôs otimizar a caracterização tridimensional de pelotas de minério de ferro através do processamento e análise de imagens obtidas por microtomografia computadorizada de raios X. Haja visto que a metodologia foi desenvolvida anteriormente, alguns parâmetros foram melhorados como o tempo de aquisição, a resolução alcançada e a metodologia de distinção de poros abertos e fechados.

Foi testada uma ampla faixa de resoluções, sendo elas: 7,6 $\mu \mathrm{m} ; 4 \mu \mathrm{m} ; 2 \mu \mathrm{m}$; $1 \mu \mathrm{m}$, e diferentes volumes de amostra: a pelota inteira; subvolumes em formato de cilindro abrangendo o diâmetro da pelota original; um gomo de pelota. A variação do volume amostral visou solucionar as limitações da técnica já detectadas anteriormente, e concluiu-se que é possível alcançar melhores resoluções com menores tempos de aquisição partindo de amostras com tamanhos reduzidos (gomo).

Os resultados confirmaram que na resolução de 7,6 $\mu \mathrm{m}$ há perda de informações com relação à porosidade devido aos tamanhos dos poros. Os percentuais de poros nas resoluções de $4 \mu \mathrm{m}$ e $2 \mu \mathrm{m}$ são próximos, porém para alcançar a melhor resolução há um grande aumento no tempo total de análise e, portanto, pode-se dizer que o valor de $4 \mu \mathrm{m}$ oferece um bom compromisso entre tempo e resolução espacial para analisar a distribuição de poros. Verificou-se que há uma diferença dos resultados quanto à região de análise, pois um subvolume cilíndrico não representa perfeitamente a pelota inteira no que tange a caracterização da sua porosidade, porém esta diferença é aceitável porque possibilita um grande ganho no tempo de aquisição das imagens.

Seria interessante conseguir analisar a pelota inteira com a resolução de $4 \mu \mathrm{m}$ para ter os valores reais da distribuição de poros, porém, devido à limitação geométrica do tomógrafo essa análise só é possível utilizando a técnica de tomografia widefield. Este tipo de tomografia não foi possível obter sem problemas 
de foco pela falta de configuração correta do aparelho disponível e fica como sugestão para outros trabalhos.

Com relação ao tempo total de aquisição das imagens, houve uma significativa melhora devido às mudanças nas configurações geométricas da análise em microCT. O principal motivo foi a notável aproximação da amostra em relação à fonte de raios $\mathrm{X}$ e ao detector, que alcançou uma distância de $14 \mathrm{~mm}$ em relação à fonte e $11 \mathrm{~mm}$ ao detector. Em comparação ao tempo de aquisição alcançado anteriormente de $18 \mathrm{~h}$, agora foi obtido um tempo de cerca de 3 horas para analisar a pelota completa e aproximadamente 9 horas para um subvolume de melhor resolução.

O processamento e a análise digital das imagens foi realizado principalmente em dois softwares: Fiji e Dragonfly. O Fiji foi utilizado para auxiliar na segmentação e na aplicação do filtro Non Local Means, pois foi constatado que os resultados após o filtro no Fiji são melhores do que os obtidos utilizando o Dragonfly. Porém é possível reproduzir as etapas de processamento utilizando apenas o Dragonfly, o que aceleraria e simplificaria o processo.

A metodologia utilizada para distinguir porosidade aberta e fechada utilizando o cálculo de MDE no software proporcionou resultados muito satisfatórios. Porém, a escolha do valor de corte para distinção entre poros abertos e fechados é feita de maneira visual no gráfico do MDE. Portanto, para trabalhos futuros sugere-se a automação da escolha desse limiar a fim de evitar possíveis erros manuais, e também o aprofundamento de algumas recentes funcionalidades do mesmo software que podem auxiliar na caracterização de porosidade. Uma delas é a função Active Contour (ORS, 2004c), que pode auxiliar na deteç̧ão de bordas para uma possível medida de porosidade aberta e fechada.

Outra função do programa que pode ser extremamente útil é o Segmentation Trainer (ORS, 2004d), este plug-in permite treinar um classificador e, em seguida, segmentar os pixels de todo o próprio conjunto de dados utilizado na aprendizagem ou outros semelhantes, possibilitando assim uma separação de objetos com diferentes tamanhos e formas, sendo aplicável na análise de trincas das pelotas de minério de ferro por exemplo. 
7

\section{Referências bibliográficas}

ALEKSANDROV, $V$. M. et al. Digital petrophysics and standard laboratory methods for determining terrigenous container rocks capacitive properties. Journal of Industrial Pollution Control, v. 33, n. 1, p. 1048-1051, 2017.

ALVES, H. D. L. Metodologia de Microtomografia Computadorizada com Dupla Energia para Caracterizaçãp Mineralógica de Rochas. Tese de Doutorado - COPPE, Universidade Federal do Rio de Janeiro, Rio de Janeiro, 2015.

ANDERSON, C.M., CARLOS, R. A., IARA, F. M., ET AL. Effects of manual threshold setting on image analysus results of a sandstone sample structural characterization by $x$-ray microtomography. Aplied Radiation and Isotopes, v. 70, p. 937-941, 2012.

ANDREOLA, F. et al. Techniques used to determine porosity. American Ceramic Society Bulletin, v. 79, n. 7, p. 49-52, 2000.

ANOVITZ, L. M.; COLE, D. R. Characterization and Analysis of Porosity and Pore Structures. Reviews in Mineralogy and Geochemistry, v. 80, n. 1, p. 61-164, 2015.

AUGUSTO, K. S.; PACIORNIK, S. Microtomografia Computadorizada de Raios X Aplicada à Caracterização de Porosidade em Pelotas de Minério de Ferro. Tese de Doutorado - Departamento de Ciência de Materiais e Metalurgia, Pontifícia Universidade Católica do Rio de Janeiro, Rio de Janeiro, 2016.

AUGUSTO, K. S.; PACIORNIK, S. Porosity Characterization of Iron Ore Pellets by X-Ray Microtomography. Materials Research, v. 21, n. 2, 2018.

AUGUSTO, K. S.; PACIORNK, S.; GOMES, O. DA F. M. Identificação Automática do Grau de Matruração de Pelotas de Minério de Ferro. Dissertação de Mestrado - Departamento de Ciência de Materiais e Metalurgia, Pontifícia Universidade Católica do Rio de Janeiro, Rio de Janeiro, 2012.

BECKMANN, E. C. CT scanning the early days. The British Journal of Radiology, v. 79, p. 5-8, 2006.

BUADES, A.; COLL, B.; A, J. M. A non-local algorithm for image denoising. In CVPR, v. 2, n, 7, p. 60-65, 2005.

CASTELLANOS, R. M. et al. Characterization of iron ore pellets by multimodal microscopy and image analysis. Metallurgy and materials, $v$. 71, n. 2, p. 209-215, 2018. 
CAVALCANTI, P. P.; TAVARES, L. M. Statistical analysis of fracture characteristics of industrial iron ore pellets. Powder Technology, v. 325, p. 659-668, 2018.

COSTA, R. V. P. DA. Otimização da Resistência à Compressão de Pelotas de Minério de Ferro para Redução Direta pela Aplicação de Projeto Robusto. Tese de Doutorado - REDEMAT, Universidade Federal de Ouro Preto, Ouro Preto, 2008.

CSN. Companhia Siderúrgica Nacional. Disponível em: $<$ http://www.csn.com.br/conteudo_pti.asp?idioma $=0$ \&conta $=45 \&$ tipo $=6106$ 2>. Acesso em: 10 abr. 2018.

CTAn. Disponível em: <http://bruker-microct.com/products/ctan.htm.>. Acesso em: 18 jul. 2018.

FERR, N.; BRASILEIRAS, F. Geologia do Minério de Ferro. BNDES Setorial, v. 39, p. 197-234, 2006.

Fiji/lmageJ, 2009. Disponível em: <https://fiji.sc/>. Acesso em: 5 maio. 2018.

GONZALEZ, W. R. E. W. Digital Image Processing Using MATLAB. Third New Jersey: Prentice Hall, 2004.

HOFFMANN, E. C. Estudo de Parâmetros Físicos Envolvidos com a Qualidade da Imagem em Tomografia Computadorizada de Feixe Cônico. Revista da Graduação, v. 4, n. 1, p. 1-63, 2011.

IGLESIAS, J. C. Á. et al. Automatic characterization of iron ore by digital microscopy and image analysis. Journal of Materials Research and Technology, v. 7, n. 3, p. 376-380, 2018.

KLOBES, P.; MEYER, K.; MUNRO, R. G. Porosity and Specific Surface Area Measurements for Solid Materials. National Institute of Standards and Technology. Setembro, 2016.

LANDIS, E. N.; KEANE, D. T. X-ray microtomography. Materials Characterization, v. 61, n. 12, p. 1305-1316, 2010.

LOPES, A. P. et al. Análise tridimensional de rochas por meio de microtomografia computadorizada de raios $\mathrm{X}$ integrada à petrografia. Geociencias, v. 31, n. 1, p. 129-142, 2012.

MACHADO, M. M.; CASAGRANDE, C. Influence of Larger Scale of the Pellet Feed from Brucutu. $2^{\circ}$ Simpósio Brasileiro de Aglomeração de Minério de Ferro, Belo Horizonte, 2015.

MANTOVANI, I. F. Microtomografia e nanotomografia de raios $X$ aplicada à caracterização multiescalar de sistemas porosos carbonáticos. Tese de Doutorado - Universidade Federal de Santa Catarina, Florianópolis, 2013.

MEYER, K. Pelletizing of Iron Ore. Springer-Verlag. Berlin, Heidelberg, and Verlag Stahleisen $\mathrm{mbH}$, Düsseldorf, 1980.

MILANEZ, B.; SANTOS, R. DOS. A Firma e suas estratégias 
corporativas no pós-boom das commodities. 2016.

MOURÃO, J. M.; NAPOLEÃO, A. . P. E. C. Avaliação de qualidade e exame microestrutural de pelotas CVRD envelhecidas por dois anos e meio - Exame de pelotas "brancas" e "cinzas". SUTEC, 1993.

MOURÃO, J. M. Aspectos Conceituais Relativos à Pelotização de Minérios de Ferro. Conceitual Consultaria Mínero-Siderúrgica, Vitória. Janeiro, 2017.

MURPHY, T. F.; SCHADE, C. T.; ZWIREN, A. Using Automated Image Analysis for Characterization of Additive Manufacturing Powders. Hoeganaes Corporation, Cinnaminson, 2014.

NUNES, P. F. et al. Uso do Algoritmo de Médias Não-Locais para Filtragem do Ruído de Mamogramas Adquiridos com Dose Reduzida. International Journal of Powder Metallurgy, v. 54, n. 1, p. 47 - 59, 2014.

Object Research Systems (ORS), 2004a. Dragonfly. Disponível em: <https://www.theobjects.com/dragonfly/>. Acesso em: 15 abr. 2018.

Object Research Systems (ORS), 2004b. Dragonfly Help. Disponível em: <http://www.theobjects.com/dragonfly/dfhelp/Default.htm>. Acesso em: 15 abr. 2018.

Object Research Systems (ORS), 2004c. Active Contour. Disponível em: <http://www.theobjects.com/dragonfly/dfhelp/Default.htm>. Acesso em: 20 jun. 2018.

Object Research Systems (ORS), 2004d. Segmentation Trainer. Disponível em: <http://www.theobjects.com/dragonfly/dfhelp/Default.htm>. Acesso em: 20 jun. 2018.

PACIORNIK, S. Notas de Aula. Disciplina de Processamento Digital de Imagens. Departamento de Engenharia dos Materiais - PUC-Rio. 2010. Disponível em: <www.deqm.puc-rio.br/cursos/ipdi>. Acesso em: 10 abr. 2018.

PALOMBO, L. et al. Caracterização de Rochas Reservatório por Microtomografia de Raios X. HOLOS, v. 5, p. 65, 2015.

PARK, K. J. B. et al. Considerações temodinâmicas das isotermas. Revista Brasileira de Produtos Agroindustriais. Campina Grande., v. 10, n.1, p. 83-94, 2008.

RETHWISCH, D. G.; CALLISTER JUNIOR, W. D. Ciência e Engenharia de Materiais: Uma Introdução. 8 ed., LTC, 2013.

RIVEST, J. F.; SOILLE, P.; BEUCHER, S. Morphological gradients. Proc. SPIE "Image Science and Technology", 1992.

SANTOS, A. V et al. O Incrível Mundo dos Materiais Porosos. Química e Sociedade, v. 4, n. 1, p. 4-11, 2016.

U.S. GEOLOGICAL SURVEY. Mineral Commodity Summaries, 2018.

ULIANA, D. et al. Microtomografia de alta resolução no setor mineral. 
Holos, v. 3, n. 3, p. 11, 2014.

VALE.

Disponível

em:

$<$ http://www.vale.com/brasil/PT/Paginas/default.aspx>. Acesso em: $10 \mathrm{abr}$. 2018.

VAN AARLE, W. et al. Fast and flexible X-ray tomography using the ASTRA toolbox. Optics Express, v. 24, n. 22, p. 25129-25147, 2016.

VERSA, Z. X. 510. Flexible Working Distance at the Highest Resolution Breakthrough Flexibility for 3D Submicron Imaging.

WAGNER, D. T. et al. Caracterização de pelotas de minério de ferro por microscopia digital e análise de imagens. Tecnologia em Metalurgia e Materiais, v. 5, p. 215-218, 2009.

YOSHIMURA, E. M. Física das Radiações : interação da radiação com a matéria. Revista Brasileira de Física Médica, v. 3, n. 1, p. 57-67, 2009.

ZANDOMENEGHI, D. et al. Quantitative analysis of X-ray microtomography images of geomaterials: Application to volcanic rocks. Geosphere, v. 6, n. 6, p. 793-804, 2010.

ZEISS, C. ZEISS Xradia Versa User's Guide. Carl Zeiss X-ray Microscopy Inc., 2016. 